\title{
Pharmacokinetics and dosing of antibiotics in neonates
}

Citation for published version (APA):

Pullen, J. (2007). Pharmacokinetics and dosing of antibiotics in neonates. [Doctoral Thesis, Maastricht University]. Datawyse / Universitaire Pers Maastricht. https://doi.org/10.26481/dis.20070426jp

Document status and date:

Published: 01/01/2007

DOI:

10.26481/dis.20070426jp

Document Version:

Publisher's PDF, also known as Version of record

\section{Please check the document version of this publication:}

- A submitted manuscript is the version of the article upon submission and before peer-review. There can be important differences between the submitted version and the official published version of record.

People interested in the research are advised to contact the author for the final version of the publication, or visit the DOI to the publisher's website.

- The final author version and the galley proof are versions of the publication after peer review.

- The final published version features the final layout of the paper including the volume, issue and page numbers.

Link to publication

\footnotetext{
General rights rights.

- You may freely distribute the URL identifying the publication in the public portal. please follow below link for the End User Agreement:

www.umlib.nl/taverne-license

Take down policy

If you believe that this document breaches copyright please contact us at:

repository@maastrichtuniversity.nl

providing details and we will investigate your claim.
}

Copyright and moral rights for the publications made accessible in the public portal are retained by the authors and/or other copyright owners and it is a condition of accessing publications that users recognise and abide by the legal requirements associated with these

- Users may download and print one copy of any publication from the public portal for the purpose of private study or research.

- You may not further distribute the material or use it for any profit-making activity or commercial gain

If the publication is distributed under the terms of Article $25 \mathrm{fa}$ of the Dutch Copyright Act, indicated by the "Taverne" license above, 
Pharmacokinetics and Dosing of Antibiotics in Neonates 
The studies in this thesis and publication of this thesis were financially supported by a grant from the 'Profileringsfonds' of the University Hospital of Maastricht.

Publication of this thesis was financially supported by:

VB-GROEP BVBA

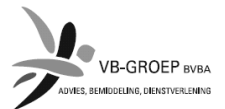

GlaxoSmithKline BV

\section{gsk}

GlaxoSmithKline

Novartis Pharma BV

(1) NOVARTIS

Pharmachemie BV

\section{(b) $P C H$}

Copyright @ 2007 J. Pullen, Maastricht

ISBN 978-90-5278-617-9

Cover design: Robbert Oidtmann

Printing and layout: Datawyse Boekproducties Maastricht 


\title{
Pharmacokinetics and Dosing of Antibiotics in Neonates
}

\author{
PROEFSCHRIFT
}

ter verkrijging van de graad van doctor aan de Universiteit Maastricht, op gezag van de

Rector Magnificus, prof. mr. G.P.M.F. Mols, volgens het besluit van het College van

Decanen, in het openbaar te verdedigen op donderdag 26 april 2007 om 14.00 uur

door

Joyce Pullen

geboren op 31 maart 1982 te Eindhoven

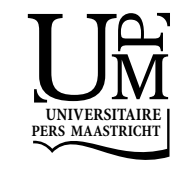




\section{Promotores}

Prof. dr. L.J.I. Zimmermann

Prof. dr. C. Neef

\section{Copromotores}

Dr. L.M.L. Stolk

Dr. P.L.J. Degraeuwe

\section{Beoordelingscommissie}

Prof. dr. J.F.M. Smits (voorzitter)

Prof. dr. J.N. van den Anker (George Washington University School of Medicine and Health Sciences, Washington, DC)

Prof. dr. C.A. Bruggeman

Dr. D.J. Touw (Apotheek Haagse Ziekenhuizen) 
De gezonde mens heeft duizend wensen,

de zieke slechts één.

Ton Luiting, dichter 



\section{Contents}

Chapter 1 General Introduction 9

Chapter 2 Microanalysis of Amoxicillin, Flucloxacillin, and Rifampicin in Neonatal Plasma

Chapter 3 Population Pharmacokinetics and Dosing of Amoxicillin in (Pre)term Neonates

Chapter 4 Amoxicillin Pharmacokinetics in (Preterm) Infants Aged 10 to 52 Days: Effect of Postnatal Age

Chapter 5 Population Pharmacokinetics and Dosing of Flucloxacillin in Preterm and Term Neonates

Chapter 6 Protein Binding of Flucloxacillin in Neonates

Chapter 7 Pharmacokinetics of Intravenous Rifampicin (Rifampin) in Neonates

Chapter 8 Application of Artificial Neural Network Modeling to Predict Gentamicin Clearance in Neonates: Preliminary Study

Chapter 9 General Discussion and Future Perspectives

Summary

Samenvatting

Dankwoord

Curriculum Vitae

List of Publications 

Chapter 1

General Introduction 


\section{The Newborn Infant}

\section{Classification of the Newborn Infant}

Newborn infants can be classified according to birth weight or gestational age. ${ }^{1}$ Gestational age is calculated from the first day of the last normal menstrual period to the date of birth and is expressed in completed weeks. Term neonates are born at or after 37 and before 42 weeks' gestation, preterm neonates are born after less than 37 weeks' gestation, and postterm neonates are born at or after 42 completed weeks of gestation. Low birth weight infants weigh less than $2500 \mathrm{~g}$ at birth. These infants are either (or both) born too early (preterm) or (and) have grown inadequately in the uterus. Very low birth weight infants weigh less than $1500 \mathrm{~g}$ at birth and extremely low birth weight infants weigh less than $1000 \mathrm{~g}$ at birth. ${ }^{1}$

\section{The Apgar Scoring System}

The Apgar scoring system was originally designed by Virginia Apgar, an anaesthesiologist, in 1953. The Apgar score is a useful aid for evaluating the condition of the newborn infant and is recorded routinely at 1,5 , and 10 minutes after birth. The condition of the newborn infant is expressed on a scale of 0 to 10 . Five clinical signs (colour, heart rate, reflex irritability, muscle tone, and respiratory effort) are evaluated and each given a score of 0,1 , or $2 .^{1-3}$ The lower the Apgar score, the more depressed the baby is, hence necessitating more aggressive resuscitating efforts. ${ }^{1,2}$ Generally, an Apgar score of 7 to 10 at 1 minute is considered normal, 4 to 6 is considered moderately depressed, and 0 to 3 is considered severely depressed. ${ }^{1,2}$ The correlation of the 1-minute Apgar score with long-term neurological outcome has been poor. ${ }^{4}$ The 5 -minute Apgar score is more predictive of long-term neurological outcome and mortality. A newborn infant with a 5-minute Apgar score of less than 7 should be considered at risk. ${ }^{5}$

\section{Neonatal Sepsis}

Neonatal sepsis is a clinical syndrome characterized by systemic signs of infection and accompanied by bacteremia in the first month of life. ${ }^{2,3,6}$ Neonatal sepsis has always been one of the most important causes of neonatal mortality. ${ }^{1}$ The incidence of neonatal sepsis is approximately 1 to 10 per 1000 live births. ${ }^{3}$ This incidence is higher for premature infants ${ }^{1}$ and infants weighing less than $1500 \mathrm{~g}^{3}$

\section{Immature Immune System}

Relative immaturity of the immune system is considered to be an important cause of increased risk of infection during the neonatal period. ${ }^{6}$ Immunity includes specific and nonspecific defences. ${ }^{1}$ Specific immunity is mediated through lymphocytes. There are two types of lymphocytes: B cells and T cells. When stimulated, B cells produce immunoglobulin (lg). Neonates have low levels of Igs, particularly IgM and IgA. When stimulated, $T$ cells produce chemical messengers called lymphokines, such as interleukin and interferon, which have a role in amplifying the immune response. Neonatal lymphocytes have a reduced production of lymphokines. Phagocytes are the predominant non-specific immune cells. Phagocytes need opsonins to kill bacteria. In neonates, phagocytic as well as opsonic activity is impaired. Exogenous factors may also predispose the infant to infection. Infants exposed to very early 
antibiotic use may be predisposed to infection. Drugs and hyperbilirubinaemia may reduce immune function and fat emulsions may impair phagocytic function. ${ }^{1}$

\section{Risk Factors}

There are many risk factors associated with neonatal infections. ${ }^{2,3}$ Prematurity and low birth weight are the most important risk factors for neonatal sepsis. Two other important risk factors are prolonged rupture of the membranes and maternal peripartum fever or infection. Infants who experienced fetal distress, obtained by traumatic delivery, or severely depressed at birth and requiring intubation and resuscitation, are at higher risk for infections. Male infants, infants who are the first born of twins, infants of diabetic mothers, infants with a skin or mucosal defect, and infants with galactosemia, immune defects, or asplenia, are also at higher risk. Other factors are invasive procedures, such as invasive monitoring, endotracheal tubes, and indwelling central venous catheters, iron therapy, and improper hand hygiene of care givers and family members. ${ }^{2,3}$

\section{Origins}

Neonatal infections may be acquired in utero (congenital/intrauterine), intrapartum, or postnatally. ${ }^{1}$ Two congenital infections can be distinguished: transplacental and ascending infections. Ascending infections can occur after rupture of the membranes. ${ }^{1}$ The feto-maternal membranes protect the developing fetus against the microbial flora of the maternal genital tract. With rupture of the membranes, bacteria from the maternal genital tract may ascend to reach the amniotic cavity and the fetus. ${ }^{3,6}$ Intrapartum infections occur during passage of the infant through the maternal birth canal. Postnatal infections can be acquired in the nursery (nosocomial). ${ }^{1}$ In the neonatal ward, the newborn may become infected via various pathways involving either human carriers or contaminated materials and equipment. ${ }^{6}$ Human sources in the hospital include personnel, family members, and other infants. The methods of human transmission may include: (1) droplets spread from the respiratory tract of adults or other newborn infants, (2) carriage of the micro-organism on the hands of hospital personnel, (3) suppurative lesions, (4) human milk, and (5) blood products. Contaminated solutions, catheterization of the umbilical vein and artery, and parenteral feeding with lipid emulsions have been associated with neonatal sepsis. ${ }^{6}$

\section{Early-Onset and Late-Onset Infections}

Neonatal infections occur in the first few days of life (early-onset infections) or later on (lateonset infections). ${ }^{3,4,6}$ Early-onset infections are caused by bacteria acquired from the maternal genital tract in utero or during delivery. Group B streptococci, Escherichia coli, and other Gram-negative rods, and Listeria monocytogenes are the predominant organisms in earlyonset infections. ${ }^{4}$ Bacteria responsible for late-onset infections include those acquired from the maternal genital tract as well as bacteria acquired after birth in the nursery from human contacts or from contaminated equipment or materials. Therefore, horizontal transmission plays a significant role in late-onset infections. ${ }^{3,4,6}$ Some of the late-onset infections are caused by the same organisms that are the causative agents of early-onset sepsis. These organisms first colonize the infant at the time of birth and later invade the blood stream. ${ }^{4}$ Staphylococcus aureus and coagulase negative staphylococci are usually associated with late-onset sepsis. ${ }^{6}$ 


\section{Treatment}

The threshold to initiate antibiotic therapy in neonates is low, since sepsis has a high morbidity and mortality in this age group, and empirical antibiotic treatment is started while awaiting the blood culture results and sensitivity tests. ${ }^{2}$ The choice of empirically administered antibiotics depends on the type of infection (early-onset versus late-onset), since other bacterial species may be responsible for late-onset compared with early-onset sepsis. The choice also depends on the current local antibiotic susceptibility of Staphylococcus species and of Gramnegative rods. ${ }^{2}$ In early-onset infections, initial antibiotic therapy must include coverage of Gram-positive cocci, particularly Group B streptococci, and Gram-negative enteric bacilli. ${ }^{6}$ Therefore, it consists of a penicillin, such as amoxicillin, plus an aminoglycoside, such as gentamicin., In late-onset infections, initial antibiotic therapy includes additional coverage of Staphylococcus aureus, Staphylococcus epidermidis, and other coagulase negative staphylococci, which are sometimes hospital acquired. ${ }^{6}$ Initial antibiotic therapy of late-onset infections should include a penicillinase-resistant penicillin derivative, such as flucloxacillin, or vancomycin if a substantial prevalence of methicillin resistance has been documented for staphylococci. ${ }^{6}$ The choice of antibiotic therapy is always reviewed as soon as results of blood cultures and susceptibility tests become available. ${ }^{6}$

\section{Pharmacokinetics in the Newborn Infant}

Pharmacokinetics describes how drugs are absorbed, distributed, metabolized, and excreted by the body. The route along which drugs pass through the body is presented in Figure $1 .{ }^{7}$ Pharmacokinetics of drugs in newborn infants cannot be extrapolated from data obtained in older infants and adults, since physiological processes that influence absorption, distribution, metabolism, and excretion are immature in the newborn infant. ${ }^{6}$ With postnatal development, growth and functional maturation of the physiological processes may alter the pharmacokinetic processes. Therefore, absorption, distribution, metabolism, and excretion are constantly changing during the neonatal period. ${ }^{6,8}$ In the following paragraphs, the pharmacokinetic processes of absorption, distribution, metabolism, and excretion of drugs in the newborn infant are outlined and differences between neonates and adults are discussed. In the last paragraph, the pharmacokinetic parameters used to describe these pharmacokinetic processes are presented.

\section{Absorption}

Absorption refers to the transfer of drugs from the site of administration into the circulation. ${ }^{9}$ There are several routes of drug administration, but intravenous drug administration is recommended for the treatment of sick newborns to ensure effective circulating drug concentrations. ${ }^{9,10}$ 
Enterohepatic circulation

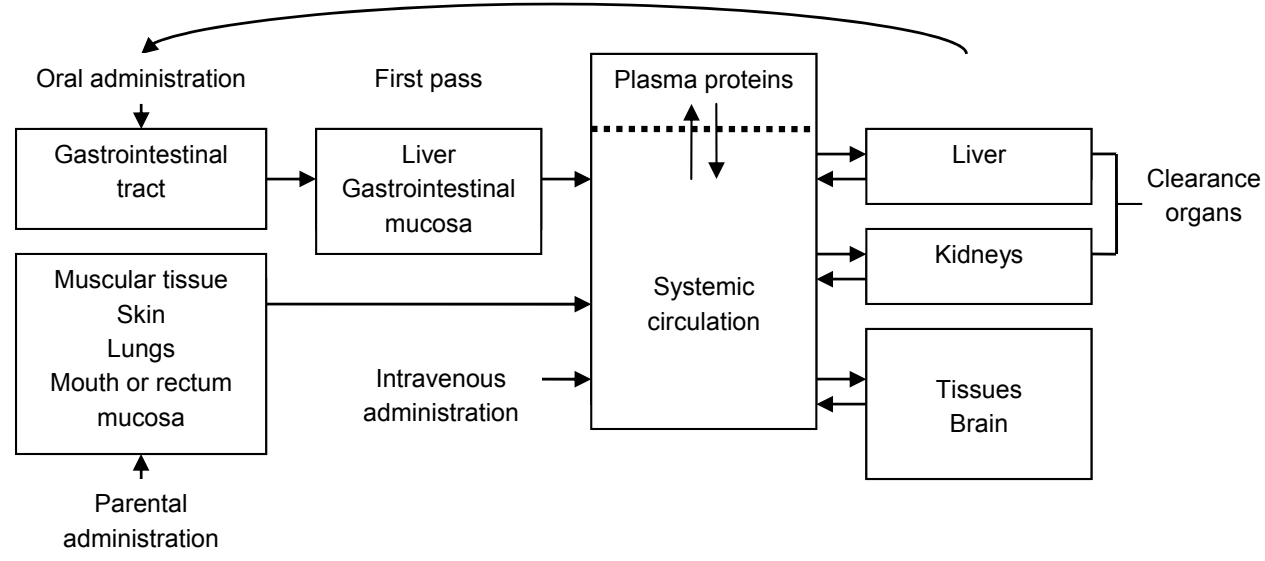

Figure 1. The route along which drugs pass through the body. ${ }^{7}$

\section{Distribution}

After absorption, the drug is distributed from the circulation into various body fluids, organs, and tissues. The distribution of drugs within the body is mostly influenced by body composition and drug binding to plasma proteins. ${ }^{8,11}$ In newborn infants, the high relative proportion of total body water and low proportion of fat results in higher distribution volumes for watersoluble compounds and lower distribution volumes for fat-soluble drugs relative to adults. ${ }^{8,11}$ Changes in body composition correlate with both gestational age and postnatal age. ${ }^{8}$ Total body water, expressed as a percentage of total body weight, is $85 \%$ in preterm neonates and $70 \%$ in term neonates. Preterm neonates have much less fat than term neonates. Total body fat in preterm neonates is about $1 \%$ of total body weight, compared with $15 \%$ in term neonates. ${ }^{12}$ With postnatal development, total body water decreases, while total body fat increases. $^{8}$

The binding of drugs to plasma proteins, especially albumin, is reduced in newborn infants in comparison to adults. Age-related differences in plasma protein binding affinity, plasma protein concentrations, and availability of competing endogenous compounds largely explain the differences in the extent of plasma protein binding between neonates and adults. ${ }^{8}$ Because of the reduced plasma protein binding in neonates, the concentration of free (unbound) drug in plasma is increased. High unbound fractions may result in enhanced distribution and enhanced renal clearance by glomerular filtration and hepatic clearance in the newborn. ${ }^{8}$

\section{Metabolism}

The metabolism of most drugs occurs in the liver. Many drugs require biotransformation to more polar forms before they can be eliminated from the body. Biotransformation involves phase I reactions, which make the drug more polar through oxidation, reduction, or hydroxylation, and phase II conjugation reactions, such as glucuronidation, sulfation, and acetylation. ${ }^{9}$ The drug-metabolizing activities of phase I enzymes (cytochromes P450) as well as 
phase II enzymes (conjugating enzymes) are not yet fully developed during the neonatal period. ${ }^{11,12}$ Their activities increase with gestational and postnatal age. ${ }^{11}$

\section{Excretion}

Excretion involves elimination of drug from the body by several routes, including the biliary tract, lungs, and kidneys. Both unchanged and metabolized forms of drug may be excreted. ${ }^{9}$ Renal function, whether or not normalized to body weight, is reduced at birth compared with that in the adult. ${ }^{9,10}$ Renal function includes glomerular filtration, tubular secretion, and tubular reabsorption. ${ }^{8}$ At birth, glomerular function is more advanced than tubular function, because of the relatively small renal tubules in relation to their corresponding glomeruli. ${ }^{10,11}$ Moreover, glomerular maturation seems to proceed faster than tubular maturation after birth. ${ }^{9,10}$ Postnatal functional maturation of the kidney is associated with enhancements in renal blood flow, as a result of increased cardiac output and reduced renal vascular resistance, with improvements in glomerular filtration efficiency, and with the growth and maturation of renal tubules and tubular processes. ${ }^{8,10}$

\section{First-Order One-Compartment Pharmacokinetic Model}

Pharmacokinetics describes the changes in drug concentration within the body with time. Most drugs are cleared from the body with first-order exponential rates. Exponential clearance indicates that a constant fraction or constant proportion of drug is removed per unit time. This means that the higher the concentration, the greater the amount of drug removed from the body. ${ }^{9}$ The first-order elimination rate constant $\left(\mathrm{K}_{\mathrm{el}}\right)$ refers to the fraction of drug eliminated per unit time and is related to the drug concentration in plasma $(C)$ by the following equation: $C=C_{0} \cdot e^{-k e l \cdot t}$, where $C$ is the concentration at a particular time $t$ and $C_{0}$ is the starting concentration. ${ }^{9,13}$ In the following studies, a one-compartment model was used. The one-compartment model depicts the body as a single, kinetically homogeneous unit. It is assumed that the rate of change of drug concentration in plasma reflects quantitatively the change in drug concentration throughout the body. ${ }^{14}$ Iterative two-stage Bayesian fitting was used for population modeling. Individual concentration-time profiles were analysed and the individual pharmacokinetic parameters were estimated using pharmacokinetic parameters from literature as priors for Bayesian fitting. This process was iterated using the population mean and covariance as Bayesian priors.

\section{Pharmacokinetic Parameters}

To quantify the distribution of drugs within the body, the pharmacokinetic parameter volume of distribution (V), also known as apparent volume of distribution, is used. Volume of distribution relates the amount of drug in the body (central compartment) (A) to the concentration in plasma $(C)(V=A / C) .{ }^{15}$ Total body clearance $(C L)$ quantifies the volume of plasma that can be completely cleared from drug per unit time. ${ }^{15}$ The elimination half-life $\left(t \frac{1}{2}\right)$ of a drug is defined as the amount of time necessary to decrease plasma drug concentration by $50 \% .{ }^{15}$ The elimination half-life depends on the pharmacokinetic parameters volume of distribution and total body clearance $\left(t^{1} 1 / 2=0.693 \cdot \mathrm{V} / \mathrm{CL}\right)$ and is inversely related to the first-order elimination rate constant $\left(t \frac{1}{2}=0.693 / \mathrm{K}_{\mathrm{el}}\right){ }^{15}$ 


\section{Aim and Outline of the Thesis}

Because of the differences in pharmacokinetics between neonates and adults, a simple reduction of the adult dose may not be adequate to determine a safe and effective neonatal dose. For safe and effective neonatal antibiotic therapy, knowledge of the pharmacokinetic characteristics of the antibiotic in the neonate is required. However, the pharmacokinetics of many antibiotics, including amoxicillin, flucloxacillin, and rifampicin, have been studied insufficiently in neonates. The aim of this thesis is to establish the population pharmacokinetic parameters of these three antibiotic drugs in neonates, in order to improve the safety and efficacy of these antibiotics in the neonatal period.

Chapter 2 describes the reversed-phase high-performance liquid chromatographic assays used in the following studies for the determination of amoxicillin, flucloxacillin, and rifampicin in neonatal plasma.

In chapter 3, the population pharmacokinetic parameters of amoxicillin in as much as 150 preterm and term neonates are presented. The prediction of the pharmacokinetic parameters, especially amoxicillin clearance, using demographic, anthropometric, and clinical covariates, is discussed. Recommendations regarding amoxicillin dosing in these neonates are made. Chapter $\mathbf{4}$ focuses on the pharmacokinetics and dosing of amoxicillin in older infants, since amoxicillin is not only used for the treatment of early-onset neonatal sepsis, but also for infectious diseases in older infants.

Chapter 5 presents the population pharmacokinetic parameters of flucloxacillin in 55 preterm and term neonates treated with flucloxacillin for (suspected) late-onset sepsis. Dose suggestions are made to optimize flucloxacillin dosing in neonates. For optimal flucloxacillin dosing, knowledge of the plasma protein binding is essential, since only the free (non-protein-bound) fraction of this highly protein-bound penicillin is pharmacologically active. Therefore, chapter 6 explores the binding of flucloxacillin to plasma proteins in aggregated samples from 56 individual neonates. The influence of several covariates, including plasma albumin concentration, on the plasma protein binding of flucloxacillin is described. Moreover, the consequences of the magnitude and variability of the protein binding for the dosing of flucloxacillin in newborn infants are discussed.

In chapter 7, the first study of rifampicin pharmacokinetics in neonates is introduced. The pharmacokinetic parameters of rifampicin, determined in 21 neonates, are presented. Since rifampicin seems to induce its own metabolism, the pharmacokinetic parameters after two weeks of rifampicin therapy are also presented.

Chapter 8 describes a preliminary study of the application of artificial neural network modeling to predict gentamicin clearance in neonates. Predictive performance was compared with that of multiple linear regression analysis.

Chapter 9 summarizes and discusses the main findings of the preceding studies and gives ideas for future research. 


\section{References}

1. Levene MI, Tudehope DI, Thearle MJ. Essentials of Neonatal Medicine. 3rd ed. Oxford: Blackwell Science; 2000.

2. Harper RG, Yoon JJ. Handbook of Neonatology. 2nd ed. Chicago: Year Book Medical Publishers; 1987.

3. Gomella TL, Cunningham MD, Eyal FG, et al. Neonatology: Management, Procedures, On-Call Problems, Diseases, and Drugs. 5th ed. New York: Lange Medical Books/McGraw-Hill; 2004.

4. Pomerance JJ, Richardson CJ. Neonatology for the Clinician. Norwalk, CT: Appleton \& Lange; 1993.

5. Bharti B, Bharti S. A review of the Apgar score indicated that contextualization was required within the contemporary perinatal and neonatal care framework in different settings. J Clin Epidemiol. 2005;58:121-129.

6. Remington JS, Klein JO, Wilson CB, et al. Infectious Diseases of the Fetus and Newborn Infant. 6th ed. Philadelphia, PA: Elsevier Saunders; 2006.

7. Loenen van AC, editor. Farmacotherapeutisch Kompas. Diemen: College voor zorgverzekeringen; 2006.

8. Alcorn J, McNamara PJ. Pharmacokinetics in the newborn. Adv Drug Deliv Rev. 2003;55:667-686.

9. MacDonald MG, Mullett MD, Seshia MMK. Avery's Neonatology: Pathophysiology \& Management of the Newborn. 6th ed. Philadelphia, PA: Lippincott Williams \& Wilkins; 2005.

10. Brody TM, Larner J, Minneman KP. Human Pharmacology: Molecular to Clinical. 3rd ed. St. Louis: Mo2sby; 1998.

11. Milsap RL, Jusko WJ. Pharmacokinetics in the infant. Environ Health Perspect. 1994;102 (Suppl. 11):107110.

12. Katzung BG. Basic \& Clinical Pharmacology. 8th ed. New York: Lange Medical Books/McGraw-Hill; 2001.

13. Rowland M, Tozer TN. Clinical Pharmacokinetics: Concepts and Applications. Philadelphia: Lea \& Febiger; 1980.

14. Gibaldi M, Perrier D. Pharmacokinetics. 2nd ed. New York: Marcel Dekker; 1982.

15. Anker van den JN. Pharmacokinetics and renal function in preterm infants. Acta Paediatr. 1996;85:13931399. 


\section{Chapter 2}

\section{Microanalysis of Amoxicillin, Flucloxacillin, and Rifampicin in Neonatal Plasma}

Joyce Pullen, Leo M.L. Stolk, Cees Neef, and Luc J.I. Zimmermann

Submitted for Publication 


\begin{abstract}
Simple and rapid reversed-phase high-performance liquid chromatographic assays with ultraviolet detection have been developed and validated for the determination of amoxicillin, flucloxacillin, and rifampicin in neonatal plasma. Plasma samples were either precipitated with perchloric acid (amoxicillin) or methanol (rifampicin) or extracted with methylene chloride (flucloxacillin). Precision coefficients of variation and inaccuracy were less than $15 \%$ for all three assays. Only small sample volumes $(20 \mu \mathrm{L}$ to $40 \mu \mathrm{L})$ were required, making the assays suitable for therapeutic drug monitoring and pharmacokinetic studies in preterm and term neonates. The assays have successfully been applied to analysis of amoxicillin, flucloxacillin, and rifampicin in previously published pharmacokinetic studies in neonates.
\end{abstract}




\section{Introduction}

Routine therapeutic drug monitoring (TDM) of antibiotics like gentamicin and vancomycin in preterm and term neonates is widely accepted. Other antibiotics like amoxicillin, flucloxacillin, and rifampicin are also widely used in neonates. TDM of these antibiotics is not routinely performed, but could be useful in special occasions. ${ }^{1-3}$ In literature, information about analytical assays of these antibiotics in neonates is either very concisely described in pharmacokinetic papers or lacking. ${ }^{1-5}$ Abundant information is available about these assays for adults. However, TDM in neonates is complicated by the very small sample volume available. Phlebotomy has been reported as cause of anemia and transfusion in neonates. ${ }^{6}$ In this paper, we describe simple and rapid microanalytical assays for the determination of amoxicillin, flucloxacillin, and rifampicin in neonatal plasma, based on reversed-phase high-performance liquid chromatography (RP-HPLC).

\section{Assay of Amoxicillin in Neonatal Plasma}

\section{Introduction}

Various HPLC assays with UV detection have been developed to determine amoxicillin in adult human plasma. ${ }^{7,8,9}$ However, these assays are not suitable for determination of amoxicillin in neonatal plasma, because they require a relatively large plasma volume. Therefore, we developed a RP-HPLC assay with UV detection for the determination of amoxicillin in small volume neonatal plasma samples, based on a RP-HPLC-UV method for the analysis of amoxicillin in adult plasma samples described earlier in the literature. ${ }^{7}$ The assay was validated for linearity, precision, accuracy, and stability. Lindegårdh et $\mathrm{al}^{9}$ evaluated long-term stability of amoxicillin in plasma at $8^{\circ} \mathrm{C},-17^{\circ} \mathrm{C}$, and $-80^{\circ} \mathrm{C}$ over one month. Amoxicillin was found unstable in plasma stored both at $8^{\circ} \mathrm{C}$ and $-17^{\circ} \mathrm{C} .{ }^{9}$ Amoxicillin was stable in plasma stored at $-80^{\circ} \mathrm{C}$ for at least one month. ${ }^{9}$ Mascher et $\mathrm{al}^{10}$ also found that amoxicillin in human plasma was stable over a time period of at least 50 days at approximately $-70^{\circ} \mathrm{C}$, but not at $20^{\circ} \mathrm{C}$.

\section{Materials and Methods}

\section{Chemicals}

The following chemicals were used: amoxicillin $\left(\mathrm{C}_{16} \mathrm{H}_{19} \mathrm{~N}_{3} \mathrm{O}_{5} \mathrm{~S}\right)$ (Fluka, Buchs, Switzerland), sotalol hydrochloride $\left(\mathrm{C}_{12} \mathrm{H}_{20} \mathrm{~N}_{2} \mathrm{O}_{3} \mathrm{~S} \mathrm{HCl}\right)$ (Bristol-Myers Squibb, New York, NY), potassium dihydrogen phosphate $\left(\mathrm{KH}_{2} \mathrm{PO}_{4}\right)$, dipotassium hydrogen phosphate $\left(\mathrm{K}_{2} \mathrm{HPO}_{4}\right)$, perchloric acid $\left(\mathrm{HClO}_{4}\right)$, and methanol $\left(\mathrm{CH}_{4} \mathrm{O}\right)$ (Merck, Darmstadt, Germany).

\section{Chromatography}

The RP-HPLC system consisted of an automatic sample injector (model 717, Waters, USA), a pump (model 1050, Hewlett Packard, USA), a column, combined with a guard column, and an UV spectrophotometer detector (model 486, Waters, USA). The same chromatographic equipment was used for the determination of flucloxacillin and rifampicin in neonatal plasma. The mobile phase, consisting of $0.067 \mathrm{~mol} / \mathrm{L} \mathrm{KH}_{2} \mathrm{PO}_{4}$ (adjusted to $\mathrm{pH} 3.5$ with phosphoric acid 25\%), methanol, and water (450:50:100), was pumped through a C8 column (250 x 4.6 $\mathrm{mm}, 5 \mu \mathrm{m})$ (Beckman, USA) after being degassed with helium. With a flow rate of 2.0 
$\mathrm{mL} / \mathrm{min}$, amoxicillin and sotalol hydrochloride (internal standard) were detected at a wavelength of $225 \mathrm{~nm}$.

\section{Preparation of Calibration Standards and Quality Controls}

Two independent stock solutions of amoxicillin $(1000 \mathrm{mg} / \mathrm{L})$ were prepared on the day of analysis by dissolving $23.1 \mathrm{mg}$ amoxicillin in $20 \mathrm{~mL}$ water (factor of weight 1.155 for $\mathrm{H}_{2} \mathrm{O}$ bound to amoxicillin). One was used for the preparation of the calibration standards and the other was used for the preparation of the quality controls $(50 \mathrm{mg} / \mathrm{L})$. The working solution of amoxicillin $(200 \mathrm{mg} / \mathrm{L})$ was prepared by adding $600 \mu \mathrm{L}$ stock solution to $2400 \mu \mathrm{L}$ blank human plasma. Calibration standards were prepared by adding the required amount of working solution to blank human plasma to obtain concentrations of $10,50,100,150$, and $200 \mathrm{mg} / \mathrm{L}$ of amoxicillin. The stock solution of the internal standard sotalol hydrochloride $(1000 \mathrm{mg} / \mathrm{L})$ was prepared by dissolving $22.7 \mathrm{mg}$ sotalol hydrochloride $(\mathrm{HCL})$ in $20 \mathrm{~mL}$ ethanol (factor of weight 1.134 for $\mathrm{HCL})$. The internal standard working solution $(100 \mathrm{mg} / \mathrm{L})$ was prepared by diluting the stock solution 10 times with water. The stock and working solutions of sotalol hydrochloride were stored at $4^{\circ} \mathrm{C}$. The quality controls were stored in separate containers at $70^{\circ} \mathrm{C}$ until analysis.

\section{Sample Preparation}

Aliquots $(40 \mu \mathrm{L})$ of patient plasma, calibrations standards, and quality controls were transferred into Eppendorf tubes and mixed with the internal standard working solution $(40 \mu \mathrm{L})$ and perchloric acid $3 \%(80 \mu \mathrm{L})$ for protein precipitation. Following centrifugation at $10,500 \times g$ for 5 minutes, the clear supernatant $(100 \mu \mathrm{L})$ was transferred into an Eppendorf tube, mixed with $1.2 \mathrm{~mol} / \mathrm{L} \mathrm{K}_{2} \mathrm{HPO}_{4}(40 \mu \mathrm{L})$, and centrifuged again. The clear supernatant $(10 \mu \mathrm{L})$ was injected.

\section{Validation}

The RP-HPLC assay was validated for linearity, precision, accuracy, and stability. To evaluate linearity of the calibration curves, six calibration curves were independently prepared and analyzed. The calibration curves with zero intercept were considered linear when the correlation coefficient $(r)$ was higher than 0.99 as calculated by linear regression. Plasma samples at six concentration levels of amoxicillin $(8,20,40,60,80$, and $160 \mathrm{mg} / \mathrm{L})$ were prepared and analyzed on six separate days to determine precision and accuracy of the RP-HPLC assay. The precision coefficient of variation (CV) determined at each concentration level should not exceed $15 \%$ except for the lower limit of quantification (LLOQ), where it should not exceed $20 \% .{ }^{11}$ Accuracy should be within $15 \%$ of the actual value except at LLOQ, where it should not deviate by more than $20 \% .{ }^{11}$ Long-term stability of amoxicillin in neonatal plasma during storage at $-70^{\circ} \mathrm{C}$ was determined by analyzing three plasma controls of amoxicillin $(25,100$, and $200 \mathrm{mg} / \mathrm{L}$ ) stored $a t-70^{\circ} \mathrm{C}$ in routine assay runs for a period of one month. Desktop stability of amoxicillin in neonatal plasma at room temperature (light/dark) was evaluated by analyzing the three controls maintained at room temperature (light/dark) for three and six hours. Post-preparative stability of amoxicillin in processed neonatal plasma samples during the run was checked by analyzing the three controls at the beginning of the run and at the end of the run after approximately three hours. 


\section{Results}

The calibration curves were linear. The correlation coefficients of the calibration curves were all higher than $0.99(r=0.9985, \mathrm{n}=6)$. The precision $\mathrm{CV}$ and inaccuracy determined at each concentration level of amoxicillin were less than $5 \%$. The precision and accuracy of the amoxicillin RP-HPLC assay are presented in Table 1. The results of the quality control samples $(50 \mathrm{mg} / \mathrm{L})$, included in 48 routine assay runs during 3 months, were $53.7 \pm 2.0 \mathrm{mg} / \mathrm{L}$ (precision CV 3.7\%).

Table 1. Precision and Accuracy $(n=6)$ of the Amoxicillin RP-HPLC Assay

\begin{tabular}{lllll}
\hline $\begin{array}{l}\text { True Concentration } \\
(\mathbf{m g} / \mathbf{L})\end{array}$ & $\begin{array}{l}\text { Measured Concentration } \\
(\mathbf{m g} / \mathbf{L})\end{array}$ & $\begin{array}{l}\text { SD } \\
(\mathbf{m g} / \mathbf{L})\end{array}$ & $\begin{array}{l}\text { Precision CV } \\
\mathbf{( \% )}\end{array}$ & $\begin{array}{l}\text { Accuracy } \\
\mathbf{( \% )}\end{array}$ \\
8 & 8.13 & 0.24 & 3.0 & +1.6 \\
20 & 20.66 & 0.32 & 1.5 & +3.3 \\
40 & 38.25 & 0.44 & 1.2 & -4.4 \\
60 & 61.08 & 0.74 & 1.2 & +1.8 \\
80 & 79.04 & 1.89 & 2.4 & -1.2 \\
160 & 158.50 & 5.71 & 3.6 & -0.9 \\
\hline
\end{tabular}

$\mathrm{CV}$, coefficient of variation; SD, standard deviation.

To determine the error pattern of the RP-HPLC assay, the relationship between the plasma concentration and the standard deviation (SD) with which it was determined, was fitted with a polynomial of second order (Figure 1). ${ }^{12}$ The error pattern of the assay was: $S D=0.1647+$ $0.0009 C+0.0002 C^{2}\left(r^{2}=0.992\right)$. This polynomial equation can be used to calculate the SD corresponding with each plasma concentration. The LLOQ of the assay, the concentration that could just be determined with a precision of $20 \%$, was $0.8 \mathrm{mg} / \mathrm{L}$.

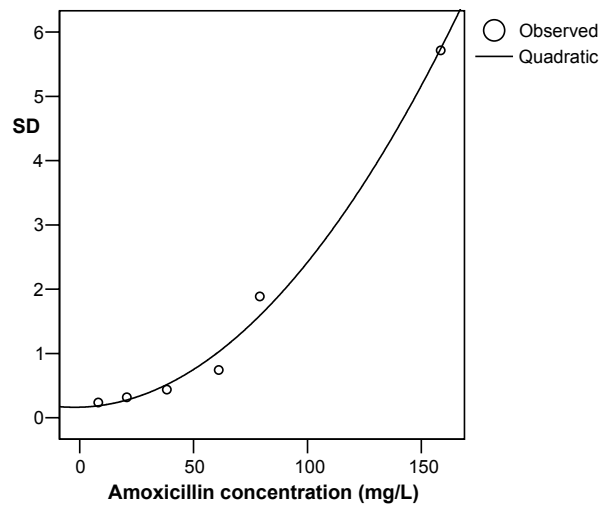

Figure 1. Error pattern of the amoxicillin RP-HPLC assay $(n=6)$. 
Amoxicillin was stable in neonatal plasma during storage at $-70^{\circ} \mathrm{C}$. Mean $( \pm \mathrm{SD})$ amoxicillin plasma concentrations of the three controls $(25,100$, and $200 \mathrm{mg} / \mathrm{L})$, included in 28 routine assay runs during one month, were 24.2 ( \pm 0.9$), 97.7$ ( \pm 4.8$)$, and $195.9( \pm 8.5) \mathrm{mg} / \mathrm{L}$, respectively. The desktop and post-preparative stability results are summarized in Table 2.

Table 2. Desktop and Post-Preparative Stability of Amoxicillin in Neonatal Plasma

\begin{tabular}{|c|c|c|c|c|c|}
\hline \multirow[t]{2}{*}{$\begin{array}{l}\text { Quality Control } \\
\text { (mg/L) }\end{array}$} & \multicolumn{2}{|c|}{$\begin{array}{l}\text { Desktop Stability } \\
\text { (Light) }\end{array}$} & \multicolumn{2}{|c|}{$\begin{array}{l}\text { Desktop Stability } \\
\text { (Dark) }\end{array}$} & \multirow{2}{*}{$\begin{array}{l}\text { Post-Preparative Stability } \\
3 \text { hours }\end{array}$} \\
\hline & 3 hours & 6 hours & 3 hours & 6 hours & \\
\hline 25 & $95.8 \%$ & $85.0 \%$ & $105.8 \%$ & $95.0 \%$ & $98.1 \%$ \\
\hline 100 & $97.7 \%$ & $97.5 \%$ & $98.7 \%$ & $97.5 \%$ & $107.8 \%$ \\
\hline 200 & $101.2 \%$ & $98.9 \%$ & $106.1 \%$ & $97.1 \%$ & $99.8 \%$ \\
\hline
\end{tabular}

\section{Assay of Flucloxacillin in Neonatal Plasma}

\section{Introduction}

Microbiological methods ${ }^{13,14}$ were used for the analysis of flucloxacillin in adult human plasma before more specific HPLC assays ${ }^{15-17}$ became available. Herngren et $\mathrm{al}^{18}$ used a microbiological method, based on agar diffusion and bacterial growth, to determine flucloxacillin concentrations in neonatal plasma in a study of the pharmacokinetics of flucloxacillin in newborn infants. An important reason for them to use a microbiological method instead of a more specific HPLC assay was the small plasma volume available for analysis from newborn infants. ${ }^{19}$ For this microbiological assay, a plasma volume of $10 \mu \mathrm{L}$ to $20 \mu \mathrm{L}$ was sufficient. We developed a RP-HPLC assay for the determination of flucloxacillin using only small plasma volumes $(20 \mu \mathrm{L})$. This assay was based on a RP-HPLC method developed by Thijssen ${ }^{16}$ for flucloxacillin analysis in adults. The assay was validated for linearity, precision, accuracy, stability, and recovery.

\section{Materials and Methods}

\section{Chemicals}

The following chemicals were used: flucloxacillin $\left(\mathrm{C}_{19} \mathrm{H}_{16} \mathrm{CIFN}_{3} \mathrm{NaO}_{5} \mathrm{~S} \cdot \mathrm{H}_{2} \mathrm{O}\right)$ (Synopharm, Barsbüttel, Germany), cloxacillin $\left(\mathrm{C}_{19} \mathrm{H}_{18} \mathrm{ClN}_{3} \mathrm{O}_{5} \mathrm{~S}\right)$ (SmithKline Beecham Pharmaceutical, Middlesex, United Kingdom), acetonitrile $\left(\mathrm{CH}_{3} \mathrm{CN}\right)$, citric acid monohydrate $\left(\mathrm{C}_{6} \mathrm{H}_{8} \mathrm{O}_{7} \cdot \mathrm{H}_{2} \mathrm{O}\right)$, methylene chloride $\left(\mathrm{CH}_{2} \mathrm{Cl}_{2}\right)$, hydrochloric acid $(\mathrm{HCl})$, and sodium perchlorate $\left(\mathrm{NaClO}_{4} \cdot \mathrm{H}_{2} \mathrm{O}\right)$ (Merck, Darmstadt, Germany).

\section{Chromatography}

Flucloxacillin and the internal standard cloxacillin were separated in a C8 column $(250 \times 4.6$ $\mathrm{mm}, 5 \mu \mathrm{m})$ (Beckman, USA) at a flow rate of $2.0 \mathrm{~mL} / \mathrm{min}$. A mixture of $0.02 \mathrm{~mol} / \mathrm{L}$ sodium perchlorate and acetonitrile (750:250) was used as mobile phase. Flucloxacillin and cloxacillin were detected at a wavelength of $220 \mathrm{~nm}$. 


\section{Preparation of Calibration Standards and Quality Controls}

For flucloxacillin, a stock solution (1000 mg/L) was freshly prepared by dissolving $11 \mathrm{mg}$ sodium flucloxacillin in $10 \mathrm{~mL}$ water (factor of weight 1.1 for sodium) and a working solution (100 mg/L) was freshly prepared by adding $200 \mu \mathrm{L}$ stock solution to $1800 \mu \mathrm{L}$ blank human plasma. The working solution was used to prepare the calibration standards by adding the required amount of working solution to blank human plasma to obtain concentrations of 10 , $25,50,75$, and $100 \mathrm{mg} / \mathrm{L}$ of flucloxacillin. An independent stock solution was prepared and used for the preparation of the quality controls $(25 \mathrm{mg} / \mathrm{L})$, which were stored in separate containers at $-70^{\circ} \mathrm{C}$ until analysis. The stock solution of the internal standard cloxacillin (1000 $\mathrm{mg} / \mathrm{L}$ ) was prepared by dissolving $10 \mathrm{mg}$ cloxacillin in $10 \mathrm{~mL}$ water. This stock solution was diluted 25 times with water to obtain the internal standard working solution (40 mg/L). Both cloxacillin stock and working solutions were stored at $4^{\circ} \mathrm{C}$.

\section{Sample Preparation}

In glass tubes, $20 \mu \mathrm{L}$ sample volume was mixed with the internal standard working solution $(20 \mu \mathrm{L}), 0.5 \mathrm{~mol} / \mathrm{L}$ citric acid monohydrate $(40 \mu \mathrm{L})$, and $0.5 \mathrm{~mol} / \mathrm{L} \mathrm{HCL}(10 \mu \mathrm{L})$, extracted with methylene chloride $(1 \mathrm{~mL})$ for 2 minutes, and centrifuged at $1780 \times g$ for 5 minutes. After removal of the top water layer with vacuum, the organic phase was transferred into a glass tube and centrifuged again. After centrifugation, the organic phase was transferred into a glass tube and evaporated to dryness under a flow of nitrogen. The residue was dissolved in the mobile phase $(100 \mu \mathrm{L})$ and injected $(25 \mu \mathrm{L})$.

\section{Validation}

The RP-HPLC assay was validated for linearity, precision, accuracy, stability, and recovery. To evaluate precision and accuracy, plasma samples at six concentration levels of flucloxacillin $(5,10,20,40,60$, and $100 \mathrm{mg} / \mathrm{L})$ were prepared and analyzed on six separate days. Long-term stability of flucloxacillin in neonatal plasma during storage at room temperature (light/dark), $4^{\circ} \mathrm{C},-20^{\circ} \mathrm{C}$, and $-70^{\circ} \mathrm{C}$ was determined by analyzing the quality controls over a period of 30 days at day 3,7 , and $30(n=2)$. The recovery of flucloxacillin was determined by comparing the analytical results for extracted samples at two flucloxacillin concentrations (50 and $100 \mathrm{mg} / \mathrm{L}$ ) with unextracted standards that represent $100 \%$ recovery.

\section{Results}

All calibration curves were linear $(r=0.9964, \mathrm{n}=6)$. The precision CV and inaccuracy at all six concentration levels of flucloxacillin were $<10 \%$ and $<15 \%$, respectively. The precision and accuracy of the flucloxacillin RP-HPLC assay are shown in Table 3 . The results of the quality control samples $(25 \mathrm{mg} / \mathrm{L}$ ), included in 30 routine assay runs during 2 months, were $24.6 \pm 1.2 \mathrm{mg} / \mathrm{L}$ (precision CV 4.7\%).

The quadratic relationship between the measured plasma concentration and the SD is presented in Figure 2. The error pattern of the assay can be described by the following polynomial equation: $\mathrm{SD}=0.5117+0.0108 \mathrm{C}+0.0002 \mathrm{C}^{2}\left(r^{2}=0.907\right)$. The LLOQ of the assay, as calculated from this polynomial equation, was $2.7 \mathrm{mg} / \mathrm{L}$. 
Table 3. Precision and Accuracy $(n=6)$ of the Flucloxacillin RP-HPLC Assay

\begin{tabular}{lllll}
\hline $\begin{array}{l}\text { True Concentration } \\
(\mathbf{m g} / \mathbf{L})\end{array}$ & $\begin{array}{l}\text { Measured Concentration } \\
(\mathbf{m g} / \mathbf{L})\end{array}$ & $\begin{array}{l}\text { SD } \\
(\mathbf{m g} / \mathbf{L})\end{array}$ & $\begin{array}{l}\text { Precision CV } \\
\mathbf{( \% )}\end{array}$ & $\begin{array}{l}\text { Accuracy } \\
\mathbf{( \% )}\end{array}$ \\
5 & 5.61 & 0.38 & 6.8 & +12.2 \\
10 & 10.70 & 0.77 & 7.2 & +7.0 \\
20 & 20.37 & 0.76 & 3.7 & +1.9 \\
40 & 39.82 & 1.87 & 4.7 & -0.5 \\
60 & 58.00 & 1.29 & 2.2 & -3.3 \\
100 & 101.08 & 3.82 & 3.8 & +1.1 \\
\hline
\end{tabular}

$\mathrm{CV}$, coefficient of variation; SD, standard deviation.

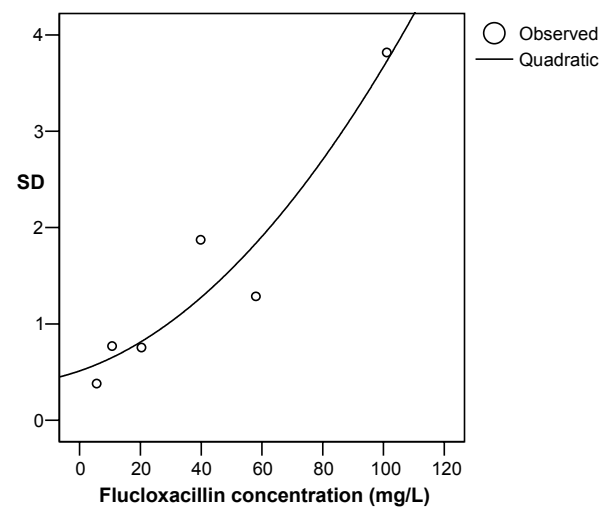

Figure 2. Error pattern of the flucloxacillin RP-HPLC assay $(n=6)$.

The long-term stability of flucloxacillin in neonatal plasma after storage at room temperature (light/dark), $4^{\circ} \mathrm{C},-20^{\circ} \mathrm{C}$, and $-70^{\circ} \mathrm{C}$ for 3,7 , and 30 days is presented in Table 4. Flucloxacillin appeared to be stable in neonatal plasma at $-20^{\circ} \mathrm{C}$ and $-70^{\circ} \mathrm{C}$ for at least one month.

Mean recoveries of flucloxacillin at the two concentrations (50 and $100 \mathrm{mg} / \mathrm{L}$ ) were $101.4 \%$ and $100.6 \%(n=2)$, respectively.

Table 4. Long-Term Stability of Flucloxacillin in Neonatal Plasma $(25 \mathrm{mg} / \mathrm{L})(\mathrm{n}=2)$

\begin{tabular}{llll}
\hline & 3 Days & 7 Days & 30 Days \\
Room temperature (light) & $90.8 \%$ & $80.8 \%$ & $15.5 \%$ \\
Room temperature (dark) & $92.3 \%$ & $95.4 \%$ & $2.7 \%$ \\
$4{ }^{\circ} \mathrm{C}$ & $100.4 \%$ & $104.0 \%$ & $82.6 \%$ \\
$-20^{\circ} \mathrm{C}$ & $101.3 \%$ & $122.3 \%$ & $100.0 \%$ \\
$-70^{\circ} \mathrm{C}$ & $104.0 \%$ & $101.2 \%$ & $105.0 \%$ \\
\hline
\end{tabular}




\section{Simultaneous Assay of Rifampicin and 25-O-Desacetylrifampicin in Neonatal Plasma}

\section{Introduction}

Many HPLC assays have been developed for the simultaneous determination of rifampicin and its main metabolite(s) in human plasma. ${ }^{20-23}$ However, none of these assays was specifically developed for neonates. We developed a RP-HPLC assay suitable for the simultaneous determination of rifampicin and 25-O-desacetylrifampicin in small volumes $(40 \mu \mathrm{L})$ of neonatal plasma. The assay was based on a method for adult patients described by Chandi et al. ${ }^{20}$ The assay was validated for linearity, precision, accuracy, and stability. Rifampicin was found to be stable in human plasma samples frozen at $\leq-70^{\circ} \mathrm{C}$, but unstable at room temperature and $-20^{\circ} \mathrm{C}^{24,25}$

\section{Materials and Methods}

\section{Chemicals}

The following chemicals were used: rifampicin $\left(\mathrm{C}_{43} \mathrm{H}_{58} \mathrm{~N}_{4} \mathrm{O}_{12}\right)$ (Yamanouchi Pharma, Leiderdorp, The Netherlands), 25-O-desacetylrifampicin $\left(\mathrm{C}_{41} \mathrm{H}_{56} \mathrm{~N}_{4} \mathrm{O}_{11}\right)$ (Novartis Pharma, Arnhem, The Netherlands), ammonium sulphate $\left(\left(\mathrm{NH}_{4}\right)_{2} \mathrm{SO}_{4}\right)$, methanol $\left(\mathrm{CH}_{4} \mathrm{O}\right)$, and Titriplex ${ }^{\circledR}$ III $\left(\mathrm{C}_{10} \mathrm{H}_{14} \mathrm{~N}_{2} \mathrm{Na}_{2} \mathrm{O}_{8} \cdot 2 \mathrm{H}_{2} \mathrm{O}\right)$ (Merck, Darmstadt, Germany).

\section{Chromatography}

The mobile phase consisted of $0.005 \mathrm{~mol} / \mathrm{L}$ disodium EDTA $\left(0.93 \mathrm{~g}\right.$ Titriplex ${ }^{\circledR} \mathrm{III}$ in $500 \mathrm{~mL}$ water) and methanol (200:300). This mobile phase was pumped with a flow rate of 1.0 $\mathrm{mL} / \mathrm{min}$ through a C18 symmetry column $(150 \times 4.6 \mathrm{~mm}, 5 \mu \mathrm{m})$ (Waters, USA). The detection was performed at a wavelength of $340 \mathrm{~nm}$.

\section{Preparation of Calibration Standards and Quality Controls}

Stock solutions of rifampicin and 25-O-desacetylrifampicin (1000 mg/L) were prepared on the day of analysis by dissolving $20 \mathrm{mg}$ rifampicin in $15 \mathrm{~mL}$ methanol and $5 \mathrm{~mL}$ water and by dissolving $20 \mathrm{mg} \mathrm{25-O-desacetylrifampicin} \mathrm{in} 6 \mathrm{~mL}$ methanol and $14 \mathrm{~mL}$ water. A solution containing both rifampicin and 25-O-desacetylrifampicin $(100 \mathrm{mg} / \mathrm{L})$ was prepared by adding $100 \mu \mathrm{L}$ stock solution of rifampicin and $100 \mu \mathrm{L}$ stock solution of $25-\mathrm{O}$-desacetylrifampicin to $800 \mu \mathrm{L}$ blank human plasma. This solution was diluted 10 times with blank human plasma to obtain the working solution $(10 \mathrm{mg} / \mathrm{L})$. Calibration standards were prepared by adding the required amount of working solution to blank human plasma to obtain concentrations of 2,4 , 6,8 , and $10 \mathrm{mg} / \mathrm{L}$ of rifampicin and 25 -O-desacetylrifampicin. Independent stock solutions of rifampicin and 25-O-desacetylrifampicin were made and used for the preparation of the quality controls, containing both rifampicin and 25-O-desacetylrifampicin (5 mg/L), which were stored in separate containers at $-70^{\circ} \mathrm{C}$ until analysis.

\section{Sample Preparation}

Small plasma volumes $(40 \mu \mathrm{L})$ of patient samples, calibration standards, and quality controls were transferred into Eppendorf tubes and mixed with ammonium sulphate 5\% (10 $\mu \mathrm{L})$ and methanol $(80 \mu \mathrm{L})$ for protein precipitation. The mixture was centrifuged at $10,500 \times g$ for 5 minutes and the clear supernatant $(30 \mu \mathrm{L})$ was injected. 


\section{Validation}

The RP-HPLC assay was validated for linearity, precision, accuracy, and stability. For rifampicin and 25-O-desacetylrifampicin, precision and accuracy were evaluated by measuring plasma samples at five concentration levels $(2,4,6,8$, and $10 \mathrm{mg} / \mathrm{L})$ on six separate days. Plasma samples at twelve concentrations levels of rifampicin and 25-O-desacetylrifampicin $(0.1,0.2,0.3,0.4,1,2,4,6,8,10,25$, and $50 \mathrm{mg} / \mathrm{L})$ were measured on six separate days to determine the assay error patterns of rifampicin and 25-O-desacetylrifampicin. Rifampicin stability in neonatal plasma at room temperature (dark) was evaluated by analyzing plasma samples, containing $6 \mathrm{mg} / \mathrm{L}$ of rifampicin, stored at room temperature (dark) for 1, 2, 3, and 4 hours. Post-preparative stability of rifampicin in processed neonatal plasma during the run was checked by analyzing plasma samples ( $6 \mathrm{mg} / \mathrm{L}) 1,1.5$, and 2 hours after sample preparation.

\section{Results}

The calibration curves of rifampicin and 25-O-desacetylrifampicin were considered linear $(r=$ $0.995, \mathrm{n}=6$ and $r=0.994, \mathrm{n}=6$, respectively). Precision CV and inaccuracy, measured at the five concentration levels, were $<10 \%$ and $<5 \%$, respectively, for both rifampicin and $25-$ O-desacetylrifampicin (Table 5). The results of the quality control samples (5 mg/L), included in 30 routine assay runs during 2 months, were $4.7 \pm 0.3 \mathrm{mg} / \mathrm{L}$ (precision CV 6.6\%).

Table 5. Precision and Accuracy $(n=6)$ of the RP-HPLC Assay of Rifampicin and 25-O-Desacetylrifampicin

\begin{tabular}{lllllll}
\hline $\begin{array}{l}\text { True Concentration } \\
(\mathbf{m g} / \mathrm{L})\end{array}$ & \multicolumn{2}{l}{$\begin{array}{l}\text { Measured Concentration (SD) } \\
(\mathbf{m g} / \mathbf{L})\end{array}$} & $\begin{array}{l}\text { Precision CV } \\
(\%)\end{array}$ & Accuracy \\
& RIF & DES & RIF & DES & RIF & DES \\
2 & $2.05(0.17)$ & $2.04(0.20)$ & 8.3 & 9.8 & +2.5 & +2.0 \\
4 & $3.95(0.26)$ & $3.98(0.24)$ & 6.6 & 6.0 & -1.3 & -0.5 \\
6 & $6.10(0.21)$ & $6.09(0.25)$ & 3.4 & 4.1 & +1.7 & +1.5 \\
8 & $7.97(0.14)$ & $7.99(0.16)$ & 1.8 & 2.0 & -0.4 & -0.1 \\
10 & $9.98(0.26)$ & $9.96(0.31)$ & 2.6 & 3.1 & -0.2 & -0.4 \\
\hline
\end{tabular}

CV, coefficient of variation; DES, 25-O-desacetylrifampicin; RIF, rifampicin; SD, standard deviation.

The plasma concentrations of rifampicin and 25-O-desacetylrifampicin and the corresponding standard deviations, used for the determination of the assay error patterns, are presented in Table 6. In Figure 3, the standard deviations are plotted against the measured plasma concentrations of rifampicin and 25-O-desacetylrifampicin and fitted with a polynomial of second order. The corresponding error patterns were: $\mathrm{SD}=0.0173+0.0455 \mathrm{C}+0.0002 \mathrm{C}^{2}\left(r^{2}=\right.$ $0.993)$ for rifampicin and $S D=0.0561+0.0323 C+0.0005 C^{2}\left(r^{2}=0.996\right)$ for 25-Odesacetylrifampicin. The LLOQ was determined by analyzing plasma samples at low concentration levels $(0.1,0.2,0.3$, and $0.4 \mathrm{mg} / \mathrm{L})$. The response at the LLOQ was at least 5 times the response compared to blank response and was identifiable, discrete, and reproducible with a precision of $<20 \%$ and accuracy of $80 \%$ to $120 \%$. The LOQ was $0.1 \mathrm{mg} / \mathrm{L}$ for rifam-

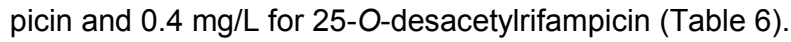


No decrease of rifampicin concentration in neonatal plasma stored at $-70^{\circ} \mathrm{C}$ was observed during the entire period of two months. Rifampicin was stable in neonatal plasma at room temperature (dark) for 1 (103.8\%), 2 (104.5\%), 3 (105.5\%), and 4 hours (102.4\%). After sample preparation, rifampicin was stable for 1 (96.7\%), $1.5(97.4 \%)$, and 2 hours $(96.1 \%)$.

Table 6. Assay Error Patterns of Rifampicin and 25-O-Desacetylrifampicin ( $n=6)$

\begin{tabular}{|c|c|c|c|c|c|c|c|c|}
\hline \multirow[t]{2}{*}{$\begin{array}{l}\text { True Concentration } \\
\text { (mg/L) }\end{array}$} & \multicolumn{2}{|c|}{$\begin{array}{l}\text { Measured Concentration } \\
(\mathrm{mg} / \mathrm{L})\end{array}$} & \multicolumn{2}{|c|}{$\begin{array}{l}\text { SD } \\
(\mathrm{mg} / \mathrm{L})\end{array}$} & \multicolumn{2}{|c|}{$\begin{array}{l}\text { Precision CV } \\
\text { (\%) }\end{array}$} & \multicolumn{2}{|c|}{$\begin{array}{l}\text { Accuracy } \\
(\%)\end{array}$} \\
\hline & RIF & DES & RIF & DES & RIF & DES & RIF & DES \\
\hline 0.1 & 0.10 & 0.12 & 0.01 & 0.02 & 10.8 & 20.8 & +3.7 & +15.0 \\
\hline 0.2 & 0.18 & 0.25 & 0.03 & 0.07 & 17.6 & 27.4 & -8.6 & +23.5 \\
\hline 0.3 & 0.29 & 0.36 & 0.04 & 0.08 & 12.6 & 22.1 & -4.3 & +20.7 \\
\hline 0.4 & 0.39 & 0.45 & 0.03 & 0.07 & 7.5 & 15.0 & -2.2 & +11.9 \\
\hline 1 & 0.99 & 1.05 & 0.08 & 0.10 & 8.4 & 10.0 & -0.6 & +5.0 \\
\hline 2 & 1.99 & 2.07 & 0.11 & 0.12 & 5.6 & 5.9 & -0.6 & +3.6 \\
\hline 4 & 3.83 & 3.93 & 0.32 & 0.31 & 8.2 & 7.8 & -4.2 & -1.8 \\
\hline 6 & 5.85 & 5.95 & 0.31 & 0.27 & 5.2 & 4.6 & -2.4 & -0.8 \\
\hline 8 & 8.00 & 8.02 & 0.29 & 0.29 & 3.7 & 3.6 & -0.0 & +0.3 \\
\hline 10 & 10.2 & 10.0 & 0.36 & 0.32 & 3.5 & 3.2 & +1.6 & +0.3 \\
\hline 25 & 25.8 & 25.4 & 1.40 & 1.24 & 5.4 & 4.9 & +3.3 & +1.4 \\
\hline 50 & 52.8 & 51.9 & 2.87 & 2.99 & 5.4 & 5.8 & +5.7 & +3.8 \\
\hline
\end{tabular}

$\mathrm{CV}$, coefficient of variation; DES, 25-O-desacetylrifampicin; RIF, rifampicin; SD, standard deviation.

A

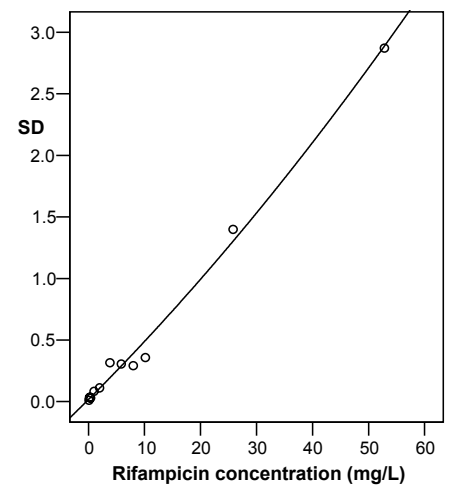

B

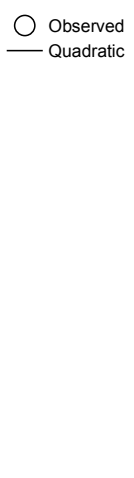

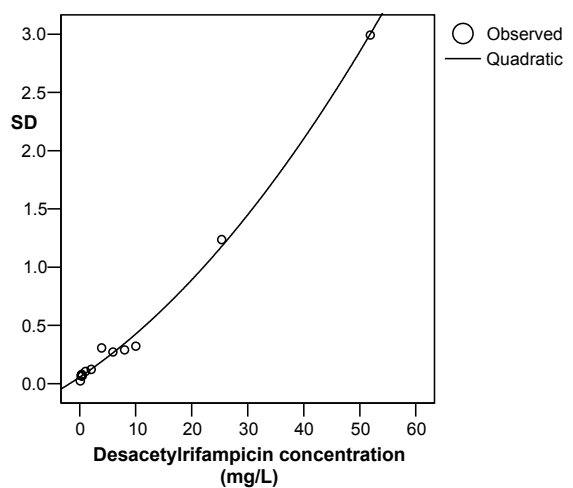

Figure 3. Assay error patterns of rifampicin (A) and 25-O-desacetylrifampicin $(B)(n=6)$. 


\section{Discussion and Conclusions}

Simple and rapid RP-HPLC assays with UV detection for the determination of amoxicillin, flucloxacillin, and rifampicin in small volume neonatal plasma samples with satisfactory precision, accuracy, and sensitivity have been developed. Considering the high precision and accuracy, the plasma volume required for amoxicillin and rifampicin analysis could be reduced from $40 \mu \mathrm{L}$ to $20 \mu \mathrm{L}$ or even $10 \mu \mathrm{L}$. It had been well documented that in vitro $\beta$-lactam antibiotics and aminoglycosides interact with each other resulting in the formation of two biological inactive compounds. ${ }^{26,27}$ Daly et $\mathrm{al}^{28}$ studied the effect of varying concentrations of ampicillin on gentamicin concentration in vitro in pooled plasma obtained from umbilical cord blood representing a medium analogous to neonatal plasma. Although inactivation of gentamicin by ampicillin did occur in this study, the degree of inactivation was small, especially at therapeutic concentrations of ampicillin. In vivo inactivation seems to occur only when high nontherapeutic concentrations of the $\beta$-lactam antibiotic are present in plasma for prolonged periods. Nevertheless, we recommend plasma samples to be stored at $-70^{\circ} \mathrm{C}$ as soon as possible after collection until analysis to avoid possible in vitro inactivation of amoxicillin and flucloxacillin, since the interaction between $\beta$-lactam antibiotics and aminoglycosides is dependent on temperature. ${ }^{26-28}$ Storage at $-70^{\circ} \mathrm{C}$ is also recommended to avoid degradation of the antibiotics. The assays described are suitable for TDM and pharmacokinetic studies in neonates.

\section{References}

1. Pullen J, Stolk LML, Nieman FHM, et al. Population pharmacokinetics and dosing of amoxicillin in (pre)term neonates. Ther Drug Monit. 2006;28:226-231.

2. Pullen J, Rozario de L, Stolk LML, et al. Population pharmacokinetics and dosing of flucloxacillin in preterm and term neonates. Ther Drug Monit. 2006;28:351-358.

3. Pullen J, Stolk LML, Degraeuwe PLJ, et al. Pharmacokinetics of intravenous rifampicin (rifampin) in neonates. Ther Drug Monit. 2006;28:654-661.

4. Huisman-de Boer JJ, Anker van den JN, Vogel M, et al. Amoxicillin pharmacokinetics in preterm infants with gestational ages of less than 32 weeks. Antimicrob Agents Chemother. 1995;39:431-434.

5. Tan TQ, Mason EO, Ou C-N, et al. Use of intravenous rifampin in neonates with persistent staphylococcal bacteremia. Antimicrob Agents Chemother. 1993;37:2401-2406.

6. Lin JC, Strauss RG, Kulhavy JC, et al. Phlebotomy overdraw in the neonatal intensive care nursery. Pediatrics. 2000;106:E19.

7. Bloemhof H, IJmker J, Uges DRA. De bepaling van enige xenobiotica in lichaamsvloeistoffen. Ziekenhuisfarmacie. 1988;4:137.

8. Hoizey G, Lamiable D, Frances C, et al. Simultaneous determination of amoxicillin and clavulanic acid in human plasma by HPLC with UV detection. J Pharm Biomed Anal. 2002;30:661-666.

9. Lindegårdh N, Singtoroj T, Annerberg A, et al. Development and validation of a solid-phase extraction-liquid chromatographic method for determination of amoxicillin in plasma. Ther Drug Monit. 2005;27:503-508.

10. Mascher $\mathrm{HJ}$, Kikuta $\mathrm{C}$. Determination of amoxicillin in human serum and plasma by high-performance liquid chromatography and on-line postcolumn derivatisation. J Chromatogr A. 1998;812:221-226.

11. Shah VP, Midha KK, Dighe S, et al. Analytical methods validation: bioavailability, bioequivalence, and pharmacokinetic studies. J Pharm Sci. 1992;81:309-312.

12. Jelliffe RW. Effect of assumptions concerning assay error patterns upon pharmacokinetic parameter values and model behavior. J Vet Pharmacol Ther. 1994;17:85-119.

13. Jalling $B$, Malmborg AS, Lindman A, et al. Evaluation of a micromethod for determination of antibiotic concentrations in plasma. Eur J Clin Pharmacol. 1972;4:150-157.

14. Sutherland R, Croydon EAP, Rolinson GN. Flucloxacillin, a new isoxazolyl penicillin, compared with oxacillin, cloxacillin, and dicloxacillin. Br Med J. 1970;4:455-460.

15. Charles BG, Foo CC, Gath J. Rapid column liquid chromatographic analysis of flucloxacillin in plasma on a microparticulate pre-column. J Chromatogr B Biomed Appl. 1994;660:186-190. 
16. Thijssen HHW. Analysis of isoxazolyl penicillins and their metabolites in body fluids by high-performance liquid chromatography. J Chromatogr B Biomed Appl. 1980;183:339-345.

17. Hung CT, Lim JK, Zoest AR, et al. Optimization of high-performance liquid chromatographic analysis for isoxazolyl penicillins using factorial design. J Chromatogr. 1988;425:331-341.

18. Herngren L, Ehrnebo M, Broberger U. Pharmacokinetics of free and total flucloxacillin in newborn infants. Eur J Clin Pharmacol. 1987;32:403-409.

19. Herngren L. Flucloxacillin kinetics in newborn infants. Eur J Clin Pharmacol. 1989;36:325.

20. Chandi LS, Sijs van der IH, Guchelaar HJ. Bepaling van rifampicine en desacetylrifampicine. Ziekenhuisfarmacie. 1998;14:71-72.

21. Ishii $\mathrm{M}$, Ogata $\mathrm{H}$. Determination of rifampicin and its main metabolites in human plasma by high-performance liquid chromatography. J Chromatogr. 1988;426:412-416.

22. Oldfield S, Berg JD, Stiles HJ, et al. Measurement of rifampicin and 25-desacetylrifampicin in biological fluids using high-performance liquid chromatography with direct sample injection. J Chromatogr. 1986;377:423-429.

23. Ratti B, Parenti RR, Toselli A, et al. Quantitative assay of rifampicin and its main metabolite 25desacetylrifampicin in human plasma by reversed-phase high-performance liquid chromatography. J Chromatogr. 1981;225:526-531.

24. Le Guellec C, Gaudet ML, Lamanetre S, et al. Stability of rifampin in plasma: consequences for therapeutic monitoring and pharmacokinetic studies. Ther Drug Monit. 1997;19:669-674.

25. Peloquin CA. Rifampin stability. Ther Drug Monit. 1998;20:450-451.

26. Riff LJ, Thomason JL. Comparative aminoglycoside inactivation by beta-lactam antibiotics. Effects of a cephalosporin and six penicillins on five aminoglycosides. J Antibiot (Tokyo). 1982;35:850-857.

27. Tindula RJ, Ambrose PJ, Harralson AF. Aminoglycoside inactivation by penicillins and cephalosporins and its impact on drug-level monitoring. Drug Intell Clin Pharm. 1983;17:906-908.

28. Daly JS, Dodge RA, Glew RH, et al. Effect of time and temperature on inactivation of aminoglycosides by ampicillin at neonatal dosages. J Perinatol. 1997;17:42-45. 



\title{
Chapter 3 \\ Population Pharmacokinetics and Dosing of Amoxicillin in (Pre)term Neonates
}

\author{
Joyce Pullen, Leo M.L. Stolk, Fred H.M. Nieman, Pieter L.J. Degraeuwe, Frank H. van Tiel, \\ and Luc J.I. Zimmermann
}

Ther Drug Monit 2006;28(2):226-231 


\begin{abstract}
Amoxicillin plasma concentrations, pharmacokinetic parameters, and the influence of demographic, anthropometric, and clinical covariates were investigated in 150 neonates. Gestational age (GA) ranged from 25 to 42 weeks and mean postnatal age (PNA) was 0.8 days. Amoxicillin concentrations were measured with reversed-phase HPLC in surplus plasma from routine assays of coadministered gentamicin. Mean total body clearance corrected for body weight $(\mathrm{CL} / \mathrm{W})$ was $0.096 \pm 0.036 \mathrm{Lkg}^{-1} \mathrm{~h}^{-1}$, mean elimination half-life $\left(t^{1} / 2\right)$ was $5.2 \pm 1.9$ $\mathrm{h}$, and mean volume of distribution corrected for body weight (V/W) was $0.65 \pm 0.13 \mathrm{~L} / \mathrm{kg}$. Multiple regression equations were calculated for the prediction of CL/W amoxicillin. CL/W gentamicin, V/W gentamicin, and GA were significant predictors of CL/W amoxicillin. Amoxicillin peak and trough concentrations after the second dose and the time the concentration exceeds the minimum inhibitory concentration $(T>M I C)$, reached with the current dosage regimen, were evaluated. Toxic plasma concentrations were reached in several patients. Therefore, the authors have proposed a lower dosage regimen, based on GA, population pharmacokinetic parameters, bacterial susceptibility ( $T>M I C$ ), and possible toxicity: $15 \mathrm{mg} / \mathrm{kg}$ per 8 hours and $20 \mathrm{mg} / \mathrm{kg}$ per 8 hours for neonates with GA $\leq 34$ and GA > 34 weeks, respectively. Simulation with this new dosage regimen indicated that satisfactory plasma concentrations were reached in all 150 neonates. Therefore, use of therapeutic drug monitoring and pharmacokinetic calculations for dosage adjustment is generally not necessary.
\end{abstract}




\section{Introduction}

Amoxicillin, an aminopenicillin, in combination with gentamicin, an aminoglycoside, is frequently used for the treatment of early-onset neonatal sepsis. ${ }^{1}$ In contrast to gentamicin, therapeutic drug monitoring (TDM) of amoxicillin is not performed on a routine basis, because amoxicillin is considered to have a wide therapeutic window.

Despite the widespread use of amoxicillin in neonates, data on population pharmacokinetics in the literature are limited. The 4 studies available describe only a relatively small number of patients. ${ }^{2-5}$ Charles et $\mathrm{al}^{2}$ and Huisman-de Boer et $\mathrm{al}^{3}$ limited their study population to neonates with gestational age less than 32 weeks. In the study by Autret et $\mathrm{al}^{4}$ only term neonates were included.

The administration of excessive doses of amoxicillin is associated with a variety of adverse effects, such as rashes, urticaria, diarrhea, eosinophilia, elevated liver and muscle enzymes, seizures, and renal dysfunction. ${ }^{6-9}$ Renal impairment and alterations in the blood-brain barrier are the two major risk factors for amoxicillin-induced neurotoxicity in preterm neonates. ${ }^{6}$ The efficacy of penicillins, including amoxicillin, depends on the time the concentration exceeds the minimum inhibitory concentration $(\mathrm{T}>\mathrm{MIC}) .{ }^{10} \mathrm{~A}$ dosage regimen is suitable if it results in effective, nontoxic plasma concentrations.

The objectives of our study were to investigate whether the current dosage regimen of amoxicillin leads to satisfactory plasma concentrations and to devise a better dosage regimen if necessary. To accomplish these goals, our co-objectives were the establishment of the population pharmacokinetic parameters of amoxicillin and the identification of demographic, anthropometric, and clinical covariates that may significantly influence the individual pharmacokinetic parameters.

\section{Materials and Methods}

\section{Patients}

The local Ethical Board approved the study. The population consisted of 150 (pre)term neonates at risk for or with (suspected) early-onset sepsis. The neonates were admitted to the neonatal ward at the University Hospital of Maastricht from July 2002 through February 2005. Inclusion criteria were: coadministration of amoxicillin and gentamicin, postnatal age (PNA) $\leq$ 9 days, availability of at least one plasma sample taken just before the administration of amoxicillin and gentamicin (trough concentrations) and one plasma sample taken one hour after the administration (peak concentrations), and availability of reliable patient data with respect to gestational age (GA), PNA, dosing, and sampling times.

For each patient, the following demographic, anthropometric, and clinical characteristics were recorded: GA, PNA, body weight $(W)$, gender, multiple pregnancy $(P)$, length, head circumference $(\mathrm{HC})$, arterial cord $\mathrm{pH}(\mathrm{ApH}), 5$-minute Apgar score (AP5), divided into two groups $(<7$ and $\geq 7),{ }^{11} 1 /$ plasma creatinine $(1 / \mathrm{Cr}$ ), plasma urea concentration (Ur), blood culture result $(B C)$, C-reactive protein (CRP), total body clearance of gentamicin (CL gentamicin), total body clearance of gentamicin corrected for body weight (CL/W gentamicin), elimination half-life of gentamicin ( $t \frac{1}{2}$ gentamicin), and volume of distribution of gentamicin corrected for body weight (V/W gentamicin). 


\section{Gentamicin and Amoxicillin Administration and Plasma Sampling}

The gentamicin dosage regimen was derived from results of our earlier study ${ }^{12}: 5 \mathrm{mg} / \mathrm{kg}$ per 48 hours, $4.5 \mathrm{mg} / \mathrm{kg}$ per 36 hours, and $4 \mathrm{mg} / \mathrm{kg}$ per 24 hours for neonates with $\mathrm{GA}<30,30 \leq$ $\mathrm{GA} \leq 34$, and GA $>34$ weeks, respectively. Gentamicin was administered intravenously by syringe pump during 30 minutes. Amoxicillin was administered by intravenous slow push according to dosing guidelines in literature ${ }^{13}: 100 \mathrm{mg} / \mathrm{kg}$ per dose for (suspected) meningitis and $50 \mathrm{mg} / \mathrm{kg}$ per dose in other situations. Dosing interval was 12 hours in the first week of life, 8 hours in neonates 1 to 3 weeks old, and 6 hours in neonates $\geq 4$ weeks old. ${ }^{13}$ Eleven neonates were treated with co-amoxiclav (Augmentin ${ }^{\circledR}$ ), 133 neonates with amoxicillin, and 6 neonates with amoxicillin and co-amoxiclav. Amoxicillin and gentamicin were administered shortly after each other. Unless the mother was treated with indomethacin as a tocolytic, all neonates with GA $<32$ weeks or birth weight $<1250 \mathrm{~g}$ were treated prophylactically with indomethacin during the first 3 days of life. ${ }^{14}$

Plasma samples were taken just before and one hour after the administration of amoxicillin and gentamicin. Surplus plasma samples from routine gentamicin assays were stored at $70^{\circ} \mathrm{C}$. Dosing and sampling times were recorded by nursing staff.

\section{Chemicals}

Potassium dihydrogen phosphate $\left(\mathrm{KH}_{2} \mathrm{PO}_{4}\right.$, CAS 7778-77-0), dipotassium hydrogen phosphate $\left(\mathrm{K}_{2} \mathrm{HPO}_{4}\right.$, CAS 7758-11-4), perchloric acid $\left(\mathrm{HClO}_{4}, \mathrm{CAS} 7601-90-3\right)$, and methanol $\left(\mathrm{CH}_{4} \mathrm{O}\right.$, CAS 67-56-1) were obtained from Merck (Darmstadt, Germany). Amoxicillin $\left(\mathrm{C}_{16} \mathrm{H}_{19} \mathrm{~N}_{3} \mathrm{O}_{5} \mathrm{~S}\right.$, CAS 26787-78-0) was provided by Fluka (Buchs, Switzerland), and the internal standard sotalol hydrochloride $\left(\mathrm{C}_{12} \mathrm{H}_{20} \mathrm{~N}_{2} \mathrm{O}_{3} \mathrm{~S} \mathrm{HCl}\right.$, CAS 959-24-0) was obtained from Bristol-Myers Squibb (New York, NY). Ultrapure water was used in all preparations. All chemicals were of analytical grade. Human EDTA plasma for standard and control samples was provided by the Red Cross Blood Bank (Maastricht, The Netherlands).

\section{Amoxicillin HPLC Assay}

Gentamicin plasma concentrations were measured with the COBAS INTEGRA 700 analyzer (Roche, Mannheim, Germany), using the principle of fluorescence polarization. The error pattern of the gentamicin assay was: $S D=0.0129+0.0029 C+0.0034 C^{2}$. The assay error pattern was determined according to a method described in literature. ${ }^{15}$ The lower limit of determination was $0.1 \mathrm{mg} / \mathrm{L}$. Amoxicillin plasma concentrations were determined with reversed-phase HPLC. An automatic sample injector (model 717, Waters, USA), a pump (model 1050, Hewlett Packard, USA), a C8 column, $250 \times 4.6$ mm, $5 \mu \mathrm{m}$ (Beckman, USA), combined with a C8 guard column, and an UV spectrophotometer detector (model 486, Waters, USA) were used. The eluent was composed of $0.067 \mathrm{~mol} / \mathrm{L}$ potassium dihydrogen phosphate ( $\mathrm{pH} 3.5)$, methanol, and distilled water (450:50:100). The separations were performed at room temperature and at a flow rate of $2 \mathrm{~mL} / \mathrm{min}$. The detection occurred at a wavelength of $225 \mathrm{~nm}$. The error pattern of the assay was: SD $=0.1647+0.0009 \mathrm{C}+0.0002$ $\mathrm{C}^{2}$. The lower limit of determination was $1 \mathrm{mg} / \mathrm{L}$.

To $40 \mu \mathrm{L}$ surplus plasma, $40 \mu \mathrm{L}$ of $100 \mathrm{mg} / \mathrm{L}$ sotalol hydrochloride (internal standard) was added. While mixing the solution with the vortex, $80 \mu \mathrm{L}$ of perchloric acid $3 \%$ was added. The solution was centrifuged at $10,500 \times g$ and $100 \mu \mathrm{L}$ of the clear top layer was mixed with 40 $\mu \mathrm{L}$ of $1.2 \mathrm{~mol} / \mathrm{L}$ dipotassium hydrogen phosphate. The solution was centrifuged again at $10,500 \times g$ and $10 \mu \mathrm{L}$ of the clear top layer was injected. The standard samples, containing 
$10,50,100,150$, and $200 \mathrm{mg} / \mathrm{L}$ amoxicillin in plasma, were processed in the same way as the surplus plasma samples. A calibration curve was constructed and amoxicillin concentrations in surplus plasma samples were calculated. Two control samples, each containing 50 $\mathrm{mg} / \mathrm{L}$ of amoxicillin in plasma, were measured in each run. Measurements were performed in duplicate, if sufficient surplus plasma was available.

\section{Data Analysis}

Population pharmacokinetic parameters of amoxicillin and gentamicin were calculated with an iterative two-stage Bayesian fitting procedure (IT2B) (MWPHARM 3.50, Mediware, The Netherlands). The Bayesian fitting procedure uses measured drug concentrations, population-based pharmacokinetic parameters, and the expected variability associated with each measurement to determine individualized pharmacokinetic parameters of a patient. ${ }^{16} \mathrm{We}$ used a one-compartment open model. The initial pharmacokinetic parameters of amoxicillin were derived from other studies: $\mathrm{K}_{\mathrm{el}} 0.1 \pm 0.03 \mathrm{~h}^{-1}$ and V/W $0.67 \pm 0.12 \mathrm{~L} / \mathrm{kg}$ for neonates with $\mathrm{GA}<32$ weeks $^{3}$ and $\mathrm{K}_{\mathrm{el}} 0.16 \pm 0.09 \mathrm{~h}^{-1}$ and V/W $0.62 \pm 0.23 \mathrm{~L} / \mathrm{kg}$ for neonates with GA $\geq 32$ weeks. ${ }^{4}$ The initial pharmacokinetic parameters of gentamicin were derived from the study of Stolk et al. ${ }^{12}$

Statistical analysis was started by checking CL/W and V/W of amoxicillin for normal distribution with the Kolmogorov-Smirnov test. One-way analysis of variance (ANOVA) was used to test whether the factor variables (gender, $\mathrm{P}, \mathrm{AP} 5$, and $\mathrm{BC}$ ) had a significant effect on CL/W and V/W of amoxicillin. Pearson product-moment correlation coefficients $(r)$ between pharmacokinetic parameters of amoxicillin and covariates were calculated. Multiple regression analysis with forward selection and backward elimination techniques was performed, using $\mathrm{CL} / \mathrm{W}$ and V/W of amoxicillin as dependent variables. The significant (factor) variables, detected with one-way ANOVA and correlation analysis, were used as possible predictors. The significant predictors of the dependent variable were used to establish a direct-effects model. First-order interaction effects between the significant predictors were tested for significance by forced entering within a hierarchically constructed regression model. Residual analysis was performed to check the studentized residuals of the dependent variable for normality and outliers. Discrete factors were entered as dummy variables. Listwise deletion of missing cases was used during the entire regression analysis procedure. Statistical analysis was performed by using SPSS ${ }^{\circledR} 12.0$ (Chicago, IL). $P<0.05$ was considered to be statistically significant.

\section{Evaluation of Current and Proposed Dosage Regimen}

The efficacy of penicillins, including amoxicillin, depends on the time the concentration exceeds the minimum inhibitory concentration ( $\mathrm{T}>\mathrm{MIC}) .{ }^{10}$ In neonates, $\mathrm{T}>\mathrm{MIC}$ should at least be $40 \%$ to $50 \%$. ${ }^{10}$ For the different species, identified as causative agents of bacteremia, the breakpoint MIC value of an antibiotic defines the highest MIC value still to be interpreted as indicating susceptibility to that antibiotic. This breakpoint MIC value of amoxicillin is 0.25 $\mathrm{mg} / \mathrm{L}$ for Streptococcus agalactiae and $8 \mathrm{mg} / \mathrm{L}$ for Enterococcus species and species belonging to the Enterobacteriaceae. ${ }^{17}$ Therefore, amoxicillin plasma concentrations will have to exceed $8 \mathrm{mg} / \mathrm{L}$ during $40 \%$ to $50 \%$ of the time. To evaluate the efficacy of the current dosage regimen, we calculated $\mathrm{T}>\mathrm{MIC}$ for each patient, using their individual pharmacokinetic parameters. Shaffer et $\mathrm{al}^{6}$ reported that ampicillin concentrations higher than $140 \mathrm{mg} / \mathrm{L}$ may cause seizures in adults. To evaluate possible toxicity of the current dosage regimen, we 
calculated amoxicillin peak concentrations after the second dose of each patient, using their individual pharmacokinetic parameters.

Amoxicillin plasma concentrations, reached with the proposed dosage regimen, were simulated for all neonates in MWPHARM 3.50 (Mediware, The Netherlands), using the individual pharmacokinetic parameters of amoxicillin.

\section{Results}

\section{Demographic, Anthropometric, and Clinical Characteristics}

Demographic, anthropometric, and clinical characteristics of the study patients are presented in Table 1. The population consisted of $78(52 \%)$ girls and $72(48 \%)$ boys; $123(82 \%)$ neonates were products of singleton pregnancies and $27(18 \%)$ neonates of twin pregnancies. AP5 was $\geq 7$ in 122 of 148 (82.4\%) neonates (2 missing data). Seven of $113(6.2 \%)$ blood cultures (37 missing) were positive. There were 674 amoxicillin and gentamicin plasma concentrations with a mean of $4.5 \pm 1.3$.

Table 1. Demographic, Anthropometric, and Clinical Characteristics of the Study Patients

\begin{tabular}{lllll}
\hline & Unit & $\mathbf{N}$ & Mean (SD) & Range \\
GA & weeks & 150 & $34.6(4.9)$ & $24.9-42.4$ \\
PNA & days & 150 & $0.76(1.57)$ & $0-9$ \\
W & $\mathrm{kg}$ & 150 & $2.29(1.08)$ & $0.57-4.7$ \\
Length & $\mathrm{cm}$ & 104 & $43.7(6.2)$ & $30-56$ \\
$\mathrm{HC}$ & $\mathrm{cm}$ & 108 & $30.8(4.7)$ & $21-55$ \\
$\mathrm{ApH}$ & $\mathrm{pH}$ & 93 & $7.19(0.14)$ & $6.7-7.48$ \\
$\mathrm{AP5}$ & $\mathrm{points}$ & 148 & $9($ median$)$ & $1-10$ \\
$1 / \mathrm{Cr}$ & $\mathrm{L} / \mathrm{\mu mol}$ & 101 & $0.012(0.004)$ & $0.006-0.036$ \\
$\mathrm{Ur}$ & $\mathrm{mmol} / \mathrm{L}$ & 100 & $5.05(2.62)$ & $0.8-13.5$ \\
$\mathrm{CRP}$ & $\mathrm{mg} / \mathrm{L}$ & 141 & $14.7(23.2)$ & $1-117$ \\
$\mathrm{CL}$ gentamicin & $\mathrm{L} / \mathrm{h}$ & 150 & $0.11(0.065)$ & $0.02-0.28$ \\
$\mathrm{CL} / \mathrm{W}$ gentamicin & $\mathrm{Lkg}{ }^{-1} \mathrm{~h}^{-1}$ & 150 & $0.043(0.012)$ & $0.023-0.082$ \\
$t^{1} / 2$ gentamicin & $\mathrm{h}$ & 150 & $10(3.2)$ & $5-19.7$ \\
$\mathrm{~V} / \mathrm{W}$ gentamicin & $\mathrm{L} / \mathrm{kg}$ & 150 & $0.59(0.13)$ & $0.37-1.09$ \\
\hline
\end{tabular}

AP5, 5-minute Apgar score; $\mathrm{ApH}$, arterial cord pH; CL, total body clearance; $\mathrm{Cr}$, plasma creatinine level; CRP, Creactive protein; GA, gestational age; HC, head circumference; PNA, postnatal age; SD, standard deviation; $t^{1} / 2$, elimination half-life; Ur, plasma urea concentration; V, volume of distribution; W, body weight.

\section{Population Pharmacokinetic Parameters}

Mean total body clearance of amoxicillin corrected for body weight (CL/W) was $0.096 \pm 0.036$ $\mathrm{Lkg}^{-1} \mathrm{~h}^{-1}$, mean amoxicillin elimination half-life $\left(t^{1} / 2\right)$ was $5.2 \pm 1.9 \mathrm{~h}$, and mean volume of distribution of amoxicillin corrected for body weight $(\mathrm{V} / \mathrm{W})$ was $0.65 \pm 0.13 \mathrm{~L} / \mathrm{kg}$. Population pharmacokinetic parameters of gentamicin were: CL/W $0.043 \pm 0.012 \mathrm{Lkg}^{-1} \mathrm{~h}^{-1}, t^{1} / 210 \pm 3.2 \mathrm{~h}$, and V/W $0.59 \pm 0.13 \mathrm{~L} / \mathrm{kg}$. 


\section{Statistical Analysis: Prediction of CL/W Amoxicillin}

The factor variables (gender, P, AP5, and BC) had no significant effect on CL/W amoxicillin. Significant Pearson correlations between the elimination parameters of amoxicillin (CL/W, $\mathrm{CL}$, and $t^{1 / 2}$ ) and the demographic, anthropometric, and clinical variables are presented in Table 2. Correlation between CL/W amoxicillin and GA is shown in Figure 1. Multiple regression analysis was performed by using CL/W amoxicillin (normally distributed) as dependent variable and GA, CL/W gentamicin, V/W gentamicin, and PNA as possible predictors. The variables $1 / \mathrm{Cr}$ and Ur were not used as possible predictors, because they had many missing data (49 and 50, respectively). The regression equation to predict CL/W amoxicillin was: CL/W amoxicillin $\left(\mathrm{Lkg}^{-1} \mathrm{~h}^{-1}\right)=0.014+1.825 \mathrm{CL} / \mathrm{W}$ gentamicin $\left(\mathrm{Lkg}^{-1} \mathrm{~h}^{-1}\right)-0.083 \mathrm{~V} / \mathrm{W}$ gentamicin $(\mathrm{L} / \mathrm{kg})+0.001 \mathrm{GA}$ (weeks) $\left(r^{2}=0.615, \mathrm{n}=150\right)$. The standardized beta coefficients, which represent the relative contribution of CL/W gentamicin, V/W gentamicin, and GA in the prediction of CL/W amoxicillin, were $0.580,-0.297$, and 0.201 , respectively. Because data on pharmacokinetics of gentamicin are usually not available at the start of the therapy, regression analysis also was performed without the pharmacokinetic parameters of gentamicin. The regression equation was: CL/W amoxicillin $\left(\mathrm{Lkg}^{-1} \mathrm{~h}^{-1}\right)=-0.067+0.005 \mathrm{GA}$ (weeks) + 0.005 PNA (days) $\left(r^{2}=0.479, \mathrm{n}=150\right)$. The standardized beta coefficients of GA and PNA were 0.623 and 0.223 , respectively. The standardized studentized residuals of all models seemed to be normally distributed.

\section{Statistical Analysis: Prediction of V/W Amoxicillin}

V/W amoxicillin differed significantly between singleton and twin pregnancies, $\mathrm{F}_{(1,148)} 7.14$ ( $P$ $=0.008)$ and between neonates with AP5 $<7$ and AP5 $\geq 7, \mathrm{~F}_{(1,146)} 6.41(P=0.012)$. Therefore, the factor variables $P$ and AP5 were admitted as possible predictors of V/W amoxicillin to subsequent multiple regression analysis. Significant Pearson correlations were found between V/W amoxicillin and the variables CL/W gentamicin $(r=0.216, P=0.008)$ and V/W gentamicin $(r=0.183, P=0.025)$. However, these correlations are very low and, therefore, not relevant for use in clinical practice. The correlation between $\mathrm{V}$ amoxicillin and $\mathrm{W}$ was very strong $(r=0.92)$, leading to the assumption that $\mathrm{V}$ is mainly predicted by $\mathrm{W}$.

\section{Evaluation of Current and Proposed Dosage Regimen}

Amoxicillin peak and trough concentrations after the second dose and T>MIC of each patient are presented in Table 3. With the current dosage regimen, T>MIC was much greater than $50 \%$ in all neonates. Peak concentrations were greater than $140 \mathrm{mg} / \mathrm{L}$ in 28 neonates. These results indicate that the current dosage regimen may result in toxic plasma concentrations. We recommend a reduction of the dose and dosing interval. Because of the high correlation between CL/W amoxicillin and GA and for practical reasons, neonates will be subdivided into the same 3 dosage GA subgroups as already used for gentamicin dosing. We recommend $15 \mathrm{mg} / \mathrm{kg}$ per 8 hours for neonates with $\mathrm{GA}<30$ and $30 \leq \mathrm{GA} \leq 34$ weeks and $20 \mathrm{mg} / \mathrm{kg}$ per 8 hours for neonates with $\mathrm{GA}>34$ weeks. With this new dosage regimen, simulated peak concentrations were $<140 \mathrm{mg} / \mathrm{L}$ in all neonates: $41.9 \pm 8.4 \mathrm{mg} / \mathrm{L}$ (mean $\pm \mathrm{SD}$ ) with a range of 23 to $72.4 \mathrm{mg} / \mathrm{L}$. Simulated T>MIC was greater than $50 \%$ in all neonates: $96.5 \% \pm 8.7 \%$ (mean \pm SD) with a range of $51.5 \%$ to $100 \%$. 
Table 2. Significant Correlations of Demographic, Anthropometric, and Clinical Variables with CL/W, CL, and $t^{1} / 2$ of Amoxicillin

\begin{tabular}{llll}
\hline & CL/W Amoxicillin & CL Amoxicillin & $\boldsymbol{t}^{1} / 2$ Amoxicillin \\
GA & $0.656^{* *}$ & $0.857^{* *}$ & $-0.655^{* *}$ \\
$\mathrm{CL} / \mathrm{W}, \mathrm{CL}$, and $t^{1 / 2}$ of gentamicin & $0.651^{* *}$ & $0.906^{* *}$ & $0.777^{* *}$ \\
$\mathrm{~W}$ & $0.611^{* *}$ & $0.889^{* *}$ & $-0.599^{* *}$ \\
$1 / \mathrm{Cr}$ & $0.521^{* *}$ & $0.352^{* *}$ & $-0.394^{* *}$ \\
Ur & $-0.42^{* *}$ & $-0.277^{* *}$ & $0.446^{* *}$ \\
V/W gentamicin & $-0.356^{* *}$ & $-0.503^{* *}$ & $0.51^{* *}$ \\
PNA & $0.314^{* *}$ & $0.208^{*}$ & $-0.19^{*}$ \\
\hline
\end{tabular}

$\mathrm{CL}$, total body clearance; $\mathrm{Cr}$, plasma creatinine level; GA, gestational age; PNA, postnatal age; $t^{1} / 2$, elimination half-life; Ur, plasma urea concentration; $\mathrm{V}$, volume of distribution; $\mathrm{W}$, body weight; *correlation is significant at the 0.05 level (2-tailed); ${ }^{* *}$ correlation is significant at the 0.01 level (2-tailed).

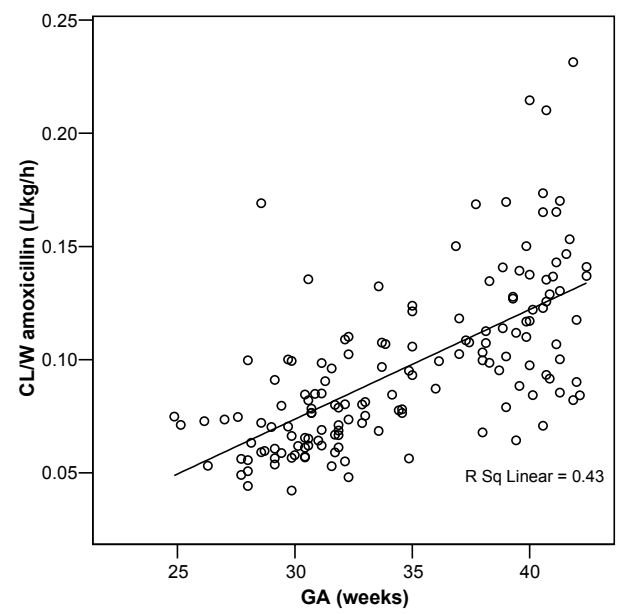

Figure 1. Correlation between total body clearance of amoxicillin corrected for body weight (CL/W amoxicillin) and gestational age (GA).

Table 3. Amoxicillin Peak and Trough Concentrations after the Second Dose and T>MIC

\begin{tabular}{lllllll}
\hline $\begin{array}{l}\text { Dose } \\
\mathbf{( m g} / \mathbf{k g})\end{array}$ & $\begin{array}{l}\text { Interval } \\
\mathbf{( h )}\end{array}$ & $\mathbf{N}^{*}$ & $\begin{array}{l}\text { Trough Concentration } \\
\mathbf{( S D})(\mathbf{m g} / \mathbf{L})\end{array}$ & $\begin{array}{l}\text { Peak Concentration } \\
\mathbf{( S D})(\mathbf{m g} / \mathbf{L})\end{array}$ & $\begin{array}{l}\mathbf{N} \text { Peak }> \\
\mathbf{1 4 0} \mathbf{~ m g / L}\end{array}$ & $\begin{array}{l}\text { T>MIC } \\
\text { (SD) (\%) }\end{array}$ \\
50 & 6 & 1 & 15.9 & 53 & 0 & 100 \\
50 & 8 & 2 & $15.3(1.5)$ & $92.3(12.6)$ & 0 & $100(0)$ \\
75 & 12 & 112 & $21.4(13.1)$ & $101(19.3)$ & 3 & $97.9(6.8)$ \\
100 & 12 & 6 & $24.2(25.4)$ & $147.7(28.2)$ & 5 & $95(12.2)$ \\
100 & 6 & 1 & 85.1 & 216.4 & 1 & 100 \\
100 & 12 & 1 & 115.8 & 323.8 & 1 & 100 \\
\hline
\end{tabular}

T>MIC, the time the concentration exceeds the minimum inhibitory concentration; SD, standard deviation; ${ }^{*}$ nine of 150 patients did not receive a dose of $25,50,75$, or $100 \mathrm{mg} / \mathrm{kg}$. 


\section{Discussion}

\section{Population Pharmacokinetic Parameters}

$\mathrm{CL} / \mathrm{W}$ amoxicillin was approximately two times higher than CL/W gentamicin. This suggests the presence of other elimination pathways in addition to glomerular filtration, such as tubular secretion and/or metabolism, because gentamicin is completely cleared by glomerular filtration. ${ }^{18}$ However, literature indicates that tubular secretion is very inefficient ${ }^{19}$ and glomerular filtration is the major pathway for amoxicillin elimination ${ }^{3}$ in (pre)term neonates.

The population pharmacokinetic parameters of amoxicillin found in the present study are similar to the results of Autret et al, ${ }^{4} \mathrm{CL} / \mathrm{W} 0.10 \mathrm{Lkg}^{-1} \mathrm{~h}^{-1}$ and V/W $0.62 \mathrm{~L} / \mathrm{kg}$. Huisman-de Boer et $\mathrm{al}^{3}$ found a comparable V/W $(0.67 \mathrm{~L} / \mathrm{kg})$, but a lower CL/W $\left(0.07 \mathrm{Lkg}^{-1} \mathrm{~h}^{-1}\right)$, which may be partially explained by the lower GA of the neonates. Peskine et $\mathrm{al}^{5}$ found a much higher $\mathrm{CL} / \mathrm{W}$ amoxicillin $\left(0.21 \mathrm{Lkg}^{-1} \mathrm{~h}^{-1}\right)$ and V/W amoxicillin $(1.38 \mathrm{~L} / \mathrm{kg})$. These differences may be attributable to the relatively small study population and the use of the method of disk diffusion in nutrient agar instead of a more specific HPLC method.

\section{Prediction of CL/W Amoxicillin}

According to literature, plasma creatinine in the first week of life does not reflect glomerular filtration rate (GFR) of the neonate. ${ }^{20}$ Immediately after birth, plasma creatinine levels of the neonate represent maternal levels. Shortly thereafter, the tubular reabsorption of creatinine seems to be responsible for continuous high plasma creatinine levels in the neonate. ${ }^{20}$ Therefore, we also included data of concomitant gentamicin monitoring for our prediction model. Gentamicin clearance as a predictor of GFR has been suggested earlier. ${ }^{18}$ However, $\mathrm{CL} / \mathrm{W}$ gentamicin as well as $1 / \mathrm{Cr}$ correlated significantly with $\mathrm{CL} / \mathrm{W}$ amoxicillin. Our finding that CL/W gentamicin is a good predictor of CL/W amoxicillin might be useful in clinical practice as an alternative for $1 / \mathrm{Cr}$. The study by Huisman-de Boer et $\mathrm{al}^{3}$ indicated that inulin clearance, another marker of GFR, was highly correlated with amoxicillin clearance. Another important predictor of CL/W amoxicillin was GA. Amoxicillin clearance increases with gestational age, which probably reflects the development of renal function (both filtration and secretion). Other investigators found a positive correlation of $\mathrm{CL}$ amoxicillin with $\mathrm{GA}$ and/or $\mathrm{W}^{2,3,5}$

\section{Dosage Regimen}

Simulation with the proposed dosage regimen indicated that satisfactory plasma concentrations were reached for all 150 neonates. Therefore, we think therapeutic drug monitoring is generally not necessary. We recommend a reduction of the amoxicillin dose and dosing interval. Reduction of the amoxicillin dose in neonates has been recommended previously by other investigators. Charles et $\mathrm{al}^{2}$ recommended $20 \mathrm{mg} / \mathrm{kg}$ per 12 hours or $50 \mathrm{mg} / \mathrm{kg}$ per day instead of $50 \mathrm{mg} / \mathrm{kg}$ per 12 hours for neonates with GA $\leq 32$ weeks in the first week of life. Huisman-de Boer et al $^{3}$ recommended $25 \mathrm{mg} / \mathrm{kg}$ per 12 hours for neonates with $\mathrm{GA}<32$ weeks in the first week of life. Dose reduction reduces the risk of amoxicillin toxicity, but also lowers the costs and prevents unnecessary use of the antibiotic, which promotes bacterial overgrowth and resistance.

The proposed dosage regimen will result in amoxicillin plasma concentrations sufficiently high for the treatment of infections that are easily reached by antibiotics, such as bacteremia, urinary tract infection, and intravascular catheter-related infection. However, in patients who 
are suspected of infections that are not easily reached by antibiotics, such as meningitis, we recommend doses higher than our proposed dosage regimen. Some experts recommend $100 \mathrm{mg} / \mathrm{kg}$ per dose for treating meningitis. ${ }^{21}$ However, our results indicate that a dose of 100 $\mathrm{mg} / \mathrm{kg}$ will probably result in plasma concentrations $>140 \mathrm{mg} / \mathrm{L}$, which may cause seizures. Moreover, literature indicates that inflammation of the meninges results in increased cerebrospinal fluid amoxicillin concentrations caused by the increased permeability of the bloodbrain barrier and a decrease in drug clearance, jeopardizing the infant to amoxicillin neurotoxicity. ${ }^{6}$ We suggest a maximum amoxicillin dose of $40 \mathrm{mg} / \mathrm{kg}$ per 12 hours for neonates with $\mathrm{GA}<30$ weeks and $45 \mathrm{mg} / \mathrm{kg}$ per 12 hours for neonates with $30 \leq \mathrm{GA} \leq 34$ and $\mathrm{GA}>34$ weeks, still resulting in plasma concentrations $<140 \mathrm{mg} / \mathrm{L}$ in all 150 neonates. However, the exact dosage regimen for treating meningitis still needs to be investigated.

\section{Conclusions}

We recommend $15 \mathrm{mg} / \mathrm{kg}$ per 8 hours for neonates with $\mathrm{GA} \leq 34$ weeks and $20 \mathrm{mg} / \mathrm{kg}$ per 8 hours for neonates with GA > 34 weeks. Simulation with this dosage regimen indicated that satisfactory plasma concentrations were reached for all 150 neonates. Therefore, use of therapeutic drug monitoring of amoxicillin and pharmacokinetic calculations for dosage adjustment is generally not necessary.

\section{References}

1. Fanos V, Dall'Agnola A. Antibiotics in neonatal infections: a review. Drugs. 1999;58:405-427.

2. Charles BG, Preechagoon Y, Lee TC, et al. Population pharmacokinetics of intravenous amoxicillin in very low birth weight infants. J Pharm Sci. 1997;86:1288-1292.

3. Huisman-de Boer JJ, Anker van den JN, Vogel M, et al. Amoxicillin pharmacokinetics in preterm infants with gestational ages of less than 32 weeks. Antimicrob Agents Chemother. 1995;39:431-434.

4. Autret E, Laugier J, Marimbu J, et al. Comparaison des concentrations plasmatiques d'amoxicilline par voie orale et intraveineuse dans les colonisations bactériennes néonatales. Arch Fr Pediatr. 1988;45:679-682.

5. Peskine F, Despaux E, Rodiere M, et al. Étude pharmacocinétique et clinique de l'amoxicilline intra-veineuse chez le nouveau-né. Pathol Biol (Paris). 1982;30:476-480.

6. Shaffer CL, Davey AM, Ransom JL, et al. Ampicillin-induced neurotoxicity in very-low-birth-weight neonates. Ann Pharmacother. 1998;32:482-484.

7. Saez-Llorens X, McCracken GH. Clinical pharmacology of antibacterial agents. In: Remington JS, Klein JO, eds. Infectious Diseases of the Fetus and Newborn Infant. 4th ed. Philadelphia: Saunders; 1995:1287-1336.

8. Baltimore RS. Neonatal sepsis: epidemiology and management. Paediatr Drugs. 2003;5:723-740.

9. Jones DP, Gaber L, Nilsson GR, et al. Acute renal failure following amoxicillin overdose. Clin Pediatr (Phila). 1993;32:735-739.

10. Hoog de M, Mouton JW, Anker van den JN. New dosing strategies for antibacterial agents in the neonate. Semin Fetal Neonatal Med. 2005;10:185-194.

11. Wertz AW, Heeren MM. Delivery room resuscitation. In: Pomerance JJ, Richardson CJ, eds. Neonatology for the Clinician. Norwalk, CT: Appleton \& Lange; 1993:93-121.

12. Stolk LML, Degraeuwe PLJ, Nieman FHM, et al. Population pharmacokinetics and relationship between demographic and clinical variables and pharmacokinetics of gentamicin in neonates. Ther Drug Monit. 2002;24:527-531.

13. Hey E, Hall C. Neonatal Formulary. 4th ed. London: Blackwell BMJ Books; 2003.

14. Fowlie PW, Davis PG. Prophylactic indomethacin for preterm infants: a systematic review and metaanalysis. Arch Dis Child Fetal Neonatal Ed. 2003;88:F464-F466.

15. Dodge WF, Jelliffe RW, Zwischenberger JB, et al. Population pharmacokinetic models: effect of explicit versus assumed constant serum concentration assay error patterns upon parameter values of gentamicin in infants on and off extracorporeal membrane oxygenation. Ther Drug Monit. 1994;16:552-559.

16. Proost JH, Meijer DKF. MWIPHARM, an integrated software package for drug dosage regimen calculation and therapeutic drug monitoring. Comput Biol Med. 1992;22:155-163. 
17. National Committee for Clinical Laboratory Standards. Performance Standards for Antimicrobial Susceptibility Testing; Twelfth Informational Standard M100-S12. Wayne, PA: NCCLS; 2002.

18. Koren G, James A, Perlman M. A simple method for the estimation of glomerular filtration rate by gentamicin pharmacokinetics during routine drug monitoring in the newborn. Clin Pharmacol Ther. 1985;38:680-685.

19. Morselli PL. Clinical pharmacology of the perinatal period and early infancy. Clin Pharmacokinet. 1989;17 (Suppl. 1):13-28.

20. Guignard JP, Drukker A. Why do newborn infants have a high plasma creatinine? Pediatrics. 1999;103:E49.

21. Kaplan JM, McCracken GH, Horton LJ, et al. Pharmacologic studies in neonates given large dosages of ampicillin. J Pediatr. 1974;84:571-577. 
CHAPTER 3 


\section{Addendum to Chapter 3}

\section{Gentamicin Clearance versus Plasma Creatinine Level as Predictor of Amoxicillin Clearance}

The use of plasma creatinine level as a traditional measure of glomerular filtration rate (GFR) has been reported to be inaccurate in the first week(s) of life. Immediately after birth, the high plasma creatinine levels of the neonate represent maternal levels. Shortly thereafter, the tubular reabsorption of creatinine seems to be responsible for continuous high plasma creatinine levels in the neonate. ${ }^{1}$ Gentamicin clearance has been suggested as an alternative method for measuring GFR. ${ }^{2}$ Gentamicin is eliminated almost entirely by the kidney and its rate of elimination parallels the GFR. ${ }^{2}$ Plasma creatinine level and gentamicin clearance both correlated significantly with amoxicillin clearance in 150 neonates aged $\leq 9$ days as shown in Chapter 3. Most often, amoxicillin treatment for early-onset neonatal sepsis is initiated immediately on the first or second day after birth (postnatal age $\leq 1$ day). However, in these first two days the correlation between amoxicillin clearance and plasma creatinine level proved to be much lower than the correlation between amoxicillin clearance and gentamicin clearance (Table 1). This strongly suggests that gentamicin clearance should be preferable to plasma creatinine level as a predictor of amoxicillin clearance and/or GFR during this period. Since plasma concentrations of gentamicin are routinely measured in clinical practice, the use of gentamicin clearance as a predictor of amoxicillin clearance and/or GFR does not involve additional interventions or expenses. ${ }^{2}$

Table 1. Correlation of Amoxicillin Clearance with Plasma Creatinine Level and Gentamicin Clearance in Neonates

\begin{tabular}{lll}
\hline & Plasma Creatinine Level $(\mathbf{1} / \mathbf{C r})$ & Gentamicin Clearance \\
& Correlation with Amoxicillin & Correlation with Amoxicillin \\
& Clearance $(r)$ & Clearance $(r)$ \\
PNA $\leq 1$ day $(n=82)$ & $0.233^{*}$ & $0.642^{* *}$ \\
PNA $>1$ day $(n=19)$ & $0.602^{* *}$ & $0.628^{* *}$ \\
Total (PNA $\leq 9$ days $)(n=101)$ & $0.521^{* *}$ & $0.720^{* *}$
\end{tabular}

$\mathrm{Cr}$, plasma creatinine level; PNA, postnatal age; $r$, correlation coefficient; *correlation is significant at the 0.05 level (2-tailed); ${ }^{* *}$ correlation is significant at the 0.01 level (2-tailed).

\section{References}

1. Guignard JP, Drukker A. Why do newborn infants have a high plasma creatinine? Pediatrics. 1999;103:E49.

2. Koren G, James A, Perlman M. A simple method for the estimation of glomerular filtration rate by gentamicin pharmacokinetics during routine drug monitoring in the newborn. Clin Pharmacol Ther. 1985;38:680-685. 
CHAPTER 3 


\section{Addendum to Chapter 3}

Letter to the Editor (Ther Drug Monit 2006;28(6):816-817)

\section{To the Editor}

I would like to commend Pullen et al ${ }^{1}$ on their investigation of the use of amoxicillin in 150 neonates using population pharmacokinetic methods. This is the first report in such a large number of newborn infants. There are, however, several issues mentioned in the paper that need further clarification. The authors state in their paragraph 'Evaluation of current and proposed dosage regimen' that in neonates T>MIC needs to be at least $40 \%$ to $50 \%$, and they refer to the paper by de Hoog et al. $^{2}$ By doing so they have missed two issues reported in that paper that are important for our readers. First, it needs to be clear that the efficacy of amoxicillin, one of the $\beta$-lactam antibiotics, is dependent on the time the free, non-proteinbound concentration remains above the MIC of the microorganism. Therefore, in daily practice, several times the MIC is taken as the cutoff point to correct for this free drug exposure requirement. Second, T>MIC of $40 \%$ to $50 \%$ is probably insufficient for neonates, because this vulnerable group of patients might be regarded as immunocompromised and therefore, a T>MIC of $70 \%$ is more desirable. I would love to see the simulations of Pullen et al taking these two issues into account.

I would love to challenge the authors on another issue. I am always very worried that by having many different dosing regimens $(15 \mathrm{mg} / \mathrm{kg}$ for young infants [GA $<34$ weeks] and 20 $\mathrm{mg} / \mathrm{kg}$ for older ones [GA $>34$ weeks]) we increase the chance of creating medication errors. Looking at the excellent data presented by Pullen et al it looks like the younger kids just need more time to clear amoxicillin. Did the authors consider giving all neonates the same amount per dose (i.e., $20 \mathrm{mg} / \mathrm{kg}$ ), while adjusting the dosing interval?

In the past, studies have been performed that have shown the impact of antenatal exposure to indomethacin and betamethasone on the renal clearing capacity of the neonate. ${ }^{3}$ I therefore wonder if the authors have information on antenatal exposure to these medicines and if they have investigated their potential impact.

The mean postnatal age of the studied neonates was 0.8 days and recognizing the rapid postnatal changes in renal maturation I would like to hear from the authors as to whether they are confident that their dosing regimens will result in appropriate killing of the bacteria after the first week of postnatal life. ${ }^{4}$

Finally, I would like to ask the authors to conduct a prospective validation of their simulated dosing regimens to be sure that their simulation works in real life and to report their findings of that prospective study again in this Journal.

Prof. dr. J.N. van den Anker

\section{References}

1. Pullen J, Stolk LML, Nieman FHM, et al. Population pharmacokinetics and dosing of amoxicillin in (pre)term neonates. Ther Drug Monit. 2006;28:226-231.

2. Hoog de M, Mouton JW, Anker van den JN. New dosing strategies for antibacterial agents in the neonate. Semin Fetal Neonatal Med. 2005;10:185-194.

3. Anker van den JN, Schoemaker RC, Hop WC, et al. Ceftazidime pharmacokinetics in preterm infants: effects of renal function and gestational age. Clin Pharmacol Ther. 1995;58:650-659.

4. Anker van den JN, Hop WC, Schoemaker RC, et al. Ceftazidime pharmacokinetics in preterm infants: effect of postnatal age and postnatal exposure to indomethacin. Br J Clin Pharmacol. 1995;40:439-443. 


\section{Response to van den Anker}

We would like to reply to the comments made by professor John N. van den Anker. He states that we have missed two issues reported in the paper by de Hoog, Mouton, and van den Anker. ${ }^{1}$ First, he states that the efficacy of amoxicillin, one of the $\beta$-lactam antibiotics, is dependent on the time the free, non-protein-bound concentration remains above the MIC of the microorganism. Indeed, we have taken the protein binding of amoxicillin into account. We determined amoxicillin protein binding by ultrafiltration in 10 neonates. Protein binding was low, about $10 \%$. Ehrnebo et al reported similar results for ampicillin protein binding in neonates. ${ }^{2}$ With our proposed dosage regimen the total as well as the free, non-protein-bound concentration will exceed the MIC at least $40 \%$ of the time. The second remark is that T>MIC of $40 \%$ to $50 \%$ is probably insufficient for neonates, because this vulnerable group of patients might be regarded as immunocompromised and therefore a $\mathrm{T}>\mathrm{MIC}$ of $70 \%$ is more desirable. However, in the paper by de Hoog et al, it is stated that, 'although the therapeutic goal for penicillins in general is related to a $\mathrm{T}>\mathrm{MIC}$ of $30 \%$ to $40 \%$, neonates have to be considered as immunocompromised and should at least be in the order of $40 \%$ to $50 \%$. ${ }^{1}$ We are curious to know on which evidence van den Anker based the 70\% T>MIC target.

We agree with van den Anker that many different dosage regimens may increase the chance of creating medication errors. We do not agree with his suggestion to give all neonates a fixed dose and adjust the dosing interval, because medication errors may be the result of an erroneous change of both the dose and the dosing interval. Therefore, we simulated plasma concentrations reached with a fixed $20 \mathrm{mg} / \mathrm{kg}$ dose and a fixed 8-hour dosing interval for all neonates. With this dosage regimen, simulated peak concentrations were $<140 \mathrm{mg} / \mathrm{L}$ in all neonates: $48.8 \pm 11.0 \mathrm{mg} / \mathrm{L}$ (mean $\pm \mathrm{SD}$ ) with a range of 25.6 to $80.9 \mathrm{mg} / \mathrm{L}$. Simulated T>MIC was greater than $50 \%$ in all neonates: $97.0 \% \pm 8.1 \%$ (mean \pm SD) with a range of $51.5 \%$ to $100 \%$. Therefore, this dosage regimen could be a suitable alternative.

We fully agree with van den Anker that our dosage regimens need prospective validation.

We did not investigate the potential impact of antenatal exposure to indomethacin and betamethasone on the renal clearing capacity of our neonates. Administration of corticosteroids, like betamethasone, is standard procedure in our hospital in case of imminent preterm delivery (<33 to 34 weeks gestational age). Indomethacin is rarely used. Our information on antenatal exposure to these medicines is incomplete. However, we demonstrated that our proposed dosage regimens resulted in satisfactory plasma concentrations in all 150 neonates. Therefore, we presume that antenatal exposure to these medicines has limited impact on amoxicillin dosing for our neonates.

In our study we observed a positive correlation between amoxicillin clearance and postnatal age. Therefore, we are currently investigating the pharmacokinetics and dosing of amoxicillin in neonates older than one week. So far we have found a higher amoxicillin clearance after the first week. Therefore, the proposed dose of $20 \mathrm{mg} / \mathrm{kg}$ per 8 hours for neonates in the first week of life might result in ineffective plasma concentration in neonates older than one week. We hope to report our results soon in this Journal.

\section{References}

1. Hoog de M, Mouton JW, Anker van den JN. New dosing strategies for antibacterial agents in the neonate. Semin Fetal Neonatal Med. 2005;10:185-194.

2. Ehrnebo M, Agurell S, Jalling B, et al. Age differences in drug binding by plasma proteins: studies on human foetuses, neonates and adults. Eur J Clin Pharmacol. 1971;3:189-193. 


\section{Chapter 4}

Amoxicillin Pharmacokinetics in (Preterm) Infants

Aged 10 to 52 Days: Effect of Postnatal Age

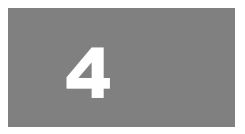

Joyce Pullen, Marja Driessen, Leo M.L. Stolk, Pieter L.J. Degraeuwe, Frank H. van Tiel,

Cees Neef, and Luc J.I. Zimmermann

Ther Drug Monit (in press) 


\section{Abstract}

The pharmacokinetic parameters of amoxicillin were determined in 32 newborn infants aged 10 to 52 days (mean postnatal age $24.7 \pm 12.4$ days) in order to improve amoxicillin dosing in this age group. Amoxicillin plasma concentrations were determined using reversed-phase HPLC in surplus plasma samples from routine gentamicin assays. Amoxicillin pharmacokinetic parameters were (mean $\pm S D$ ): first-order elimination constant $\left(K_{\mathrm{el}}\right)=0.27 \pm 0.10 \mathrm{~h}^{-1}$, volume of distribution corrected for body weight $(\mathrm{V} / \mathrm{W})=0.66 \pm 0.27 \mathrm{~L} / \mathrm{kg}$, total body clearance corrected for body weight $(C L / W)=0.18 \pm 0.10 \mathrm{Lkg}^{-1} \mathrm{~h}^{-1}$, and elimination half-life $\left(t^{1} / 2\right)=$ $3.0 \pm 1.3 \mathrm{~h}$. Amoxicillin body clearance was approximately two-fold greater in our patients compared to published values in younger neonates (mean postnatal age $0.76 \pm 1.57$ days). Simulation studies using the observed amoxicillin pharmacokinetic data suggest an amoxicillin dose of $40 \mathrm{mg} / \mathrm{kg}$ administered every 8 hours in infants $>9$ days PNA, independent of GA and PCA, to achieve satisfactory target plasma amoxicillin concentrations $<140 \mathrm{mg} / \mathrm{L}$ and $\mathrm{T}>\mathrm{MIC}$ at least $40 \%$. Prospective evaluation of this suggested new dosage regimen is necessary before implementation in the care of ill neonates. 


\section{Introduction}

Amoxicillin is an aminopenicillin frequently used for the treatment of early-onset neonatal sepsis. ${ }^{1}$ In an earlier study, we investigated amoxicillin pharmacokinetics, amoxicillin dosing, and the influence of covariates on the individual pharmacokinetic parameters in 150 (pre)term neonates aged $\leq 9$ days (mean postnatal age $0.76 \pm 1.57$ days). ${ }^{2}$ Amoxicillin pharmacokinetics in neonates have also been investigated in 4 smaller studies. ${ }^{3-6}$ In these studies, the pharmacokinetic parameters were established in the first week of neonatal life, underscoring the need for such data in older infants.

Postnatal development of renal function in (pre)term infants has been well documented. ${ }^{7-11}$ The progressive postnatal increase in glomerular filtration rate (GFR) results mainly from an increase in glomerular perfusion pressure. ${ }^{12}$ Because of this postnatal increase in GFR, it is expected that postnatal age (PNA) will exert a major effect on the pharmacokinetics of drugs which are mainly eliminated by glomerular filtration. In our previous study, we found a high correlation between amoxicillin clearance and plasma creatinine and gentamicin body clearance, demonstrating the important role of glomerular filtration in the clearance of amoxicillin in neonates. ${ }^{2}$ In previous studies, the effect of postnatal age on the pharmacokinetics of gentamicin, ${ }^{13}$ ceftazidime,$^{14}$ and piperacillin ${ }^{15}$ in neonates has been investigated. However, we were unable to identify any published data describing the pharmacokinetics of amoxicillin in neonates aged $>9$ days and the effect of postnatal age on amoxicillin pharmacokinetic characteristics (MEDLINE search terms: amoxicillin, amoxycillin, pharmacokinetic(s), pharmacology, postnatal (age), infant(s), newborn(s), neonate(s), and neonatal). Thus, the main objective of the present study was to define an amoxicillin dosage regimen appropriate for (pre)term infants aged $>9$ days.

\section{Materials and Methods}

\section{Patients, Drug Administration, and Plasma Sampling}

The present study was approved by the local Medical Ethical Committee. Thirty-two newborn infants aged $>9$ days, admitted to the neonatal intensive care unit at the University Hospital of Maastricht from June 2002 to March 2006, were identified for inclusion in this study. All infants were treated with amoxicillin in combination with gentamicin for (suspected) infection. Amoxicillin was administered by intravenous slow push according to published dosing guidelines: $100 \mathrm{mg} / \mathrm{kg}$ per dose for (suspected) meningitis and $50 \mathrm{mg} / \mathrm{kg}$ per dose in other situations. ${ }^{16}$ Dosing interval was 12 hours in the first week of life, 8 hours in neonates 1 to 3 weeks old, and 6 hours in neonates $\geq 4$ weeks old. ${ }^{16}$ Gentamicin $(4 \mathrm{mg} / \mathrm{kg})$ was administered intravenously by syringe pump during 30 minutes every 24 hours. Amoxicillin and gentamicin were administered shortly after each other. Most infants (53\%) were treated with a combination of amoxicillin, gentamicin, and metronidazol for (suspected) NEC. Other indications for amoxicillin use were Gram-positive cocci in liquor (group B Streptococcus meningitis), increased C-reactive protein (CRP), and (suspected) urinary tract infection.

Therapeutic drug monitoring of gentamicin was performed on a routine basis. Plasma samples were obtained just before and one hour after the start of the infusion of gentamicin. Surplus plasma samples from routine gentamicin assays were collected and stored at $-70^{\circ} \mathrm{C}$ until amoxicillin analysis. We collected $5.2 \pm 2.1$ plasma samples per infant during $3.5 \pm 1.4$ days (mean $\pm \mathrm{SD})$. 


\section{Amoxicillin Assay}

The determination of amoxicillin in plasma was performed using reversed-phase highperformance liquid chromatography (RP-HPLC) with UV detection as described previously. ${ }^{2}$ With this RP-HPLC assay, total (free + protein-bound) plasma concentrations of amoxicillin are determined. In five infants, aged 10 to 73 days, we determined the extent of amoxicillin binding to plasma proteins. ${ }^{17}$ To determine the free amoxicillin concentration in these 5 infants, we collected and combined several plasma samples of each infant to obtain a sufficiently large sample for analysis $(150 \mu \mathrm{L}$ to $1000 \mu \mathrm{L})$. Free amoxicillin was separated from protein-bound amoxicillin using ultrafiltration by a Centrifree ${ }^{\circledR}$ micropartition device (Millipore Corporation, Bedford, MA, USA). Fibrin was removed by centrifuging the sample at $4000 \mathrm{rpm}$ for 25 minutes at room temperature before loading into the reservoir. For optimum solvent flow, a $33^{\circ}$ fixed-angle centrifuge rotor was used.

\section{Data Analysis}

Amoxicillin pharmacokinetic parameters were estimated from the analysis of the measured amoxicillin plasma concentrations using a one-compartment open model with iterative twostage Bayesian fitting (MWIPHARM 3.60, Mediware, The Netherlands), incorporating previously determined pharmacokinetic parameters ${ }^{2}$ as initial parameters. In our previous study, we found a high correlation between amoxicillin clearance and gentamicin clearance. Since plasma creatinine may reflect GFR poorly in the first week(s) of life ${ }^{18}$, gentamicin clearance was also included as a measure of GFR. ${ }^{19}$ Therefore, gentamicin pharmacokinetic parameters were also calculated, using parameters published by Stolk et al. ${ }^{20}$ The influence of covariates on the individual pharmacokinetic parameters was studied by calculating the Pearson correlation coefficients $(r)$ with SPSS ${ }^{\circledR} 12.0$ (Chicago, IL). The covariates were: gestational age (GA), PNA, postconceptional age (PCA), body weight (W), gender, multiple pregnancy $(P), 1$-minute Apgar score (AP1), 5-minute Apgar score (AP5), 1/plasma creatinine $(1 / C r)$, plasma urea concentration (Ur), CRP, blood culture result $(B C)$, and the pharmacokinetic parameters of gentamicin. One-way analysis of variance (ANOVA) was used to test whether the factor variables (gender, $\mathrm{P}$, and $\mathrm{BC}$ ) had a significant effect on the pharmacokinetic parameters of amoxicillin.

\section{Dosage Regimen}

The projected bacteriologic efficacy and safety of the amoxicillin dosage regimen used in our 32 infants was assessed. Projected bacteriologic efficacy was determined using standard antimicrobial pharmacokinetic-pharmacodynamic modeling ${ }^{21}$ and safety was projected by calculating the amoxicillin peak plasma concentrations after the second dose, which should not exceed $140 \mathrm{mg} / \mathrm{L} .{ }^{22,23}$ For bacteriologic efficacy the amount of time $(\mathrm{T})$ the free amoxicillin plasma concentration must remain above the minimum inhibitory concentration (T>MIC) of important neonatal pathogens (e.g., target MIC $=0.25 \mathrm{mg} / \mathrm{L}$ for Streptococcus agalactiae and $8 \mathrm{mg} / \mathrm{L}$ for Enterococcus species and species belonging to the Enterobacteriacea ${ }^{24}$ ) should be at least $40-50 \%$ of the dosing interval for neonates. ${ }^{25}$ Considering that amoxicillin plasma protein binding in adults is rather low $(<20 \%)^{26}$ and ampicillin protein binding in neonates averages $9.9 \% \pm 1.5 \%$ (range $8.3 \%$ to $11.5 \%, \mathrm{n}=4)^{27}$ and our own data (see Results) suggest $11.7 \%$, we elected to assume amoxicillin protein binding for our simulation studies to be $10 \%$. Our target, optimal dosage regimen, would result in free amoxicillin plasma concentrations that remain above the MIC for a minimum of at least $40 \%$ of the time and total plasma concentrations had to be below $140 \mathrm{mg} / \mathrm{L}$. 


\section{Results}

The clinical characteristics of the infants included in the present study ( 8 girls and 24 boys; 7 infants were twins) and for comparative purposes the data obtained in neonates aged $\leq 9$ days from our previous study ${ }^{2}$ are presented in Table 1. The characteristics of both populations were very much alike, except for CRP and the expected differences in PNA, PCA, and $1 / \mathrm{Cr}$. The lower mean plasma creatinine concentration (45.0 versus $90.7 \mu \mathrm{mol} / \mathrm{L})$ probably reflects a higher GFR and the higher mean CRP (128.0 versus $14.7 \mathrm{mg} / \mathrm{L})$ may indicate a higher incidence of bacterial infection (see Table 1). Seven of 24 blood cultures (29\%) were positive; coagulase negative staphylococci (CoNS) $n=4$, Escherichia coli $n=2$, and Streptococcus mitis $\mathrm{n}=1$.

Table 1. Characteristics of the Infants in the Present Study and in Our Previous Study ${ }^{2}$

\begin{tabular}{|c|c|c|c|c|c|c|c|}
\hline & & Pre & & & Prev & & \\
\hline & Unit & $\mathbf{N}$ & Mean (SD) & Range & $\mathbf{N}$ & Mean (SD) & Range \\
\hline GA & weeks & 32 & $33.7(4.6)$ & $26.3-41.4$ & 150 & $34.6(4.9)$ & $24.9-42.4$ \\
\hline PNA & days & 32 & $24.7(12.4)$ & $10-52$ & 150 & $0.76(1.57)$ & $0-9$ \\
\hline PCA & weeks & 32 & $37.2(4.9)$ & $28-46.1$ & 150 & 34.7 (4.9) & $24.9-42.6$ \\
\hline W & $\mathrm{kg}$ & 32 & $2.27(1.02)$ & $0.78-4.25$ & 150 & $2.29(1.08)$ & $0.57-4.7$ \\
\hline AP5 & points & 30 & 8 (median) & $4-10$ & 148 & 9 (median) & $1-10$ \\
\hline $1 / \mathrm{Cr}$ & $\mathrm{L} / \mu \mathrm{mol}$ & 30 & $0.025(0.009)$ & $0.011-0.050$ & 101 & $0.012(0.004)$ & $0.006-0.036$ \\
\hline Ur & $\mathrm{mmol} / \mathrm{L}$ & 30 & $3.70(2.06)$ & $0.6-11.5$ & 100 & $5.05(2.62)$ & $0.8-13.5$ \\
\hline CRP & $\mathrm{mg} / \mathrm{L}$ & 31 & $128.0(100.2)$ & $3.6-343.0$ & 141 & $14.7(23.2)$ & $1-117$ \\
\hline
\end{tabular}

AP5, 5-minute Apgar score; Cr, plasma creatinine level; CRP, C-reactive protein; GA, gestational age; PCA, postconceptional age; PNA, postnatal age; SD, standard deviation; Ur, plasma urea concentration; W, body weight.

Amoxicillin pharmacokinetic parameters were (mean $\pm \mathrm{SD}$ ): first-order elimination constant $\left(\mathrm{K}_{\mathrm{el}}\right)=0.27 \pm 0.10 \mathrm{~h}^{-1}$, volume of distribution corrected for body weight $(\mathrm{V} / \mathrm{W})=0.66 \pm 0.27$ $\mathrm{L} / \mathrm{kg}$, total body clearance corrected for body weight $(\mathrm{CL} / \mathrm{W})=0.18 \pm 0.10 \mathrm{Lkg}^{-1} \mathrm{~h}^{-1}$, and elimination half-life $\left(t^{1} / 2\right)=3.0 \pm 1.3 \mathrm{~h}$. Gentamicin pharmacokinetic parameters were (mean \pm $\mathrm{SD}): \mathrm{K}_{\mathrm{el}}=0.11 \pm 0.02 \mathrm{~h}^{-1}, \mathrm{~V} / \mathrm{W}=0.59 \pm 0.13 \mathrm{~L} / \mathrm{kg}, \mathrm{CL} / \mathrm{W}=0.06 \pm 0.02 \mathrm{Lkg}^{-1} \mathrm{~h}^{-1}$, and $t^{1} / 2=6.8$ $\pm 1.9 \mathrm{~h}$. The mean ( $\pm \mathrm{SD}$ ) amoxicillin protein binding in the 5 infants aged 10 to 73 was $11.7 \% \pm 2.7 \%$ (range $8.0 \%$ to $14.1 \%$ ).

The highest Pearson correlation coefficient was found between amoxicillin clearance and PCA $(r=0.718, P<0.001)$, which showed a logarithmic rise with PCA $(r=0.717)$. The correlation between amoxicillin clearance and PCA, on linear and semi-logarithmic scales, is shown in Figure 1. Amoxicillin clearance was also significantly related to GA $(r=0.655, P<$ $0.001), 1 / \mathrm{Cr}(r=0.552, P=0.002)$, and gentamicin clearance $(r=0.490, P=0.004)$. However, no significant relationship was observed between amoxicillin clearance and PNA $(r=$ $0.318, P=0.076)$. V/W amoxicillin was significantly correlated with GA $(r=0.455, P=0.009)$, PCA $(r=0.463, P=0.008)$, and CL/W gentamicin $(r=0.444, P=0.011)$. We could not find a relationship between infection and amoxicillin pharmacokinetics. Further, no relationship or differences were observed between amoxicillin pharmacokinetics and infants suffering from an infectious disease (defined by a positive blood culture) and infants having negative blood 
cultures. Moreover, no relationship between CRP and amoxicillin pharmacokinetic parameters was observed.

The amoxicillin T>MIC ( $8 \mathrm{mg} / \mathrm{L}$ ) was $>40 \%$ in all 32 infants: $\mathrm{T}>\mathrm{MIC}=85.4 \% \pm 18.3 \%$ (mean \pm SD), range $41 \%$ to $100 \%$. The average ( \pm SD) peak amoxicillin plasma concentration was 80.1 ( \pm 37.9$) \mathrm{mg} / \mathrm{L}$ with a range of 20.1 to $167.8 \mathrm{mg} / \mathrm{L}$ and the average ( \pm SD) trough amoxicillin plasma concentration was $10.2( \pm 8.4) \mathrm{mg} / \mathrm{L}$ (range 0.6 to $34.8 \mathrm{mg} / \mathrm{L}$ ). In 3 of the 32 infants amoxicillin peak plasma concentrations were higher than $140 \mathrm{mg} / \mathrm{L}(140.6,158.3$, and $167.8 \mathrm{mg} / \mathrm{L})$. Simulation studies using the determined amoxicillin pharmacokinetic parameters to determine the dose to achieve a target $\mathrm{T}>\mathrm{MIC}$ of at least $40 \%$ of the dosing interval and peak amoxicillin concentrations $<140 \mathrm{mg} / \mathrm{L}$ suggest a new dosage regimen of $40 \mathrm{mg}$ amoxicillin per kg every 8 hours, independent of GA, PNA, and PCA, for infants aged $>9$ days. Based upon these simulations this dosage regimen yielded satisfactory amoxicillin plasma concentrations in all infants with the T>MIC greater than $40 \%$ in all 32 infants (mean $\mathrm{T}>\mathrm{MIC}=87.3 \% \pm 19.1 \%$, range $43 \%$ to $100 \%$ ) and greater than $50 \%$ in 31 of the 32 infants. Furthermore, the peak amoxicillin plasma concentrations were below $140 \mathrm{mg} / \mathrm{L}$ in all $32 \mathrm{in}-$ fants: $70.0 \pm 27.4 \mathrm{mg} / \mathrm{L}$ (range 29.7 to $134.5 \mathrm{mg} / \mathrm{L}$ ); average trough plasma concentration was $10.8( \pm 7.6) \mathrm{mg} / \mathrm{L}$ with a range of 1.0 to $32.6 \mathrm{mg} / \mathrm{L}$.
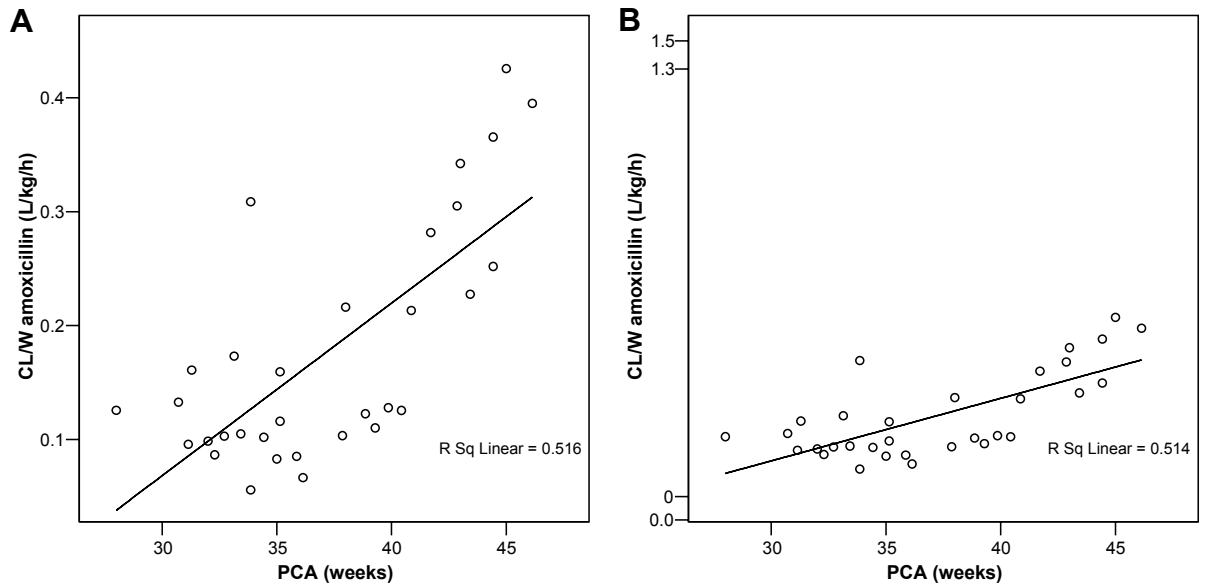

Figure 1. Correlation between total body clearance of amoxicillin corrected for body weight (CL/W amoxicillin) and postconceptional age (PCA) on linear scale (A) and semi-logarithmic scale (B).

\section{Discussion}

The amoxicillin body clearance in infants aged > 9 days (mean PNA $24.7 \pm 12.4$ days) determined in the present study $\left(0.18 \mathrm{Lkg}^{-1} \mathrm{~h}^{-1}\right)$ is approximately two-fold greater that the amoxicillin body clearance observed in younger neonates $\left(0.10 \mathrm{Lkg}^{-1} \mathrm{~h}^{-1}\right)$ aged $\leq 9$ days (mean PNA $0.76 \pm 1.57$ days). In addition, the amoxicillin $t^{1} / 2$ was much shorter $(3.0 \mathrm{~h}$ versus $5.2 \mathrm{~h}$ ), whereas the V/W was approximately the same $(0.66 \mathrm{~L} / \mathrm{kg}$ versus $0.65 \mathrm{~L} / \mathrm{kg})$ in the older and younger infants, respectively. ${ }^{2}$ These results confirm our expectations about the effect of postnatal age on amoxicillin pharmacokinetics. Glomerular filtration and tubular secretion are 
less mature during the first week of life. ${ }^{28}$ Therefore, amoxicillin clearance is considerably reduced in the newborn infant compared with that in older infants.

Amoxicillin clearance showed a logarithmic rise with PCA (Figure 1). For infants aged $>9$ days, amoxicillin clearance hardly seems to increase until the infant reaches a PCA of 34 weeks. After that, there is a rapid linear increase in amoxicillin clearance with PCA $(r=$ 0.863). This finding is consistent with results in the literature. ${ }^{11,29}$ Coulthard reported a logarithmic rise of absolute GFR with PCA, which was independent of postnatal age, based on his own study in 39 infants (GA 27 to 40 weeks and PNA 2 to 63 days) and based on 14 other studies. ${ }^{11}$ Arant reported a slight increase in GFR prior to the time an infant reaches a PCA of 34 weeks and a more rapid increase thereafter. A PCA of 34 weeks seems to be the point in renal development from which the absolute GFR increases gradually to mature values. $^{29}$ So, GFR and thus amoxicillin clearance, are dependent upon the infant's PCA, which differs between our first study (34.7 weeks) and the present study (37.2 weeks). This may help to explain the difference in amoxicillin clearance observed between the two studies.

Amoxicillin clearance was also highly related to GA $(r=0.655)$. In our previous study, we found the same relationship between amoxicillin clearance and GA $(r=0.656)$, which probably reflects the development of renal function. ${ }^{2}$ In the present study too, we found a relationship between amoxicillin clearance and the predictors of GFR, plasma creatinine concentration $(1 / \mathrm{Cr})(r=0.552$ versus $r=0.521)$ and gentamicin clearance $(r=0.490$ versus $r=0.651)$, indicating the important role of glomerular filtration in the clearance of amoxicillin in (pre)term infants. $^{2}$

The amoxicillin body clearance observed in our 32 infants was, on average, three times higher than the observed gentamicin clearance. This observation indicates the additive role of tubular secretion in amoxicillin clearance, because gentamicin is completely cleared by glomerular filtration. ${ }^{19}$ In younger infants, amoxicillin body clearance exceeded the gentamicin clearance by about two-fold ${ }^{2}$ reflecting the dependence upon age for the maturation of the proximal renal tubular weak acid transport system.

Dose simulation assessments incorporating the amoxicillin pharmacokinetic data determined in the present study to achieve specific targets, i.e., T>MIC of at least $40 \%$ (MIC $=8 \mathrm{mg} / \mathrm{L}$ ) and peak amoxicillin concentrations $<140 \mathrm{mg} / \mathrm{L}$, suggest an amoxicillin dose of $40 \mathrm{mg} / \mathrm{kg}$ administered every 8 hours in neonates $>9$ days of age independent of GA and PCA. It should be noted that this dosage regimen will result in plasma concentrations sufficiently high only for the treatment of infections which are easily reached by beta-lactam antibiotics, such as bacteremia, urinary tract infection, and intravascular catheter-related infection, but not for meningitis. Lastly, when performing simulation assessments with expected free amoxicillin concentrations, as we did in this study, it might be possible that higher T>MIC values (e.g., T>MIC 60\%) are necessary for optimal treatment of neonates, who suffer from agedependent deficiencies in immunological functions. However, prospective validation of this new dosage regimen is necessary.

\section{Conclusions}

Postnatal alterations in amoxicillin pharmacokinetics, particularly an increase in amoxicillin body clearance, require adjustment of the dosage regimen after the first week of life. We suggest an amoxicillin dose of $40 \mathrm{mg} / \mathrm{kg}$ every 8 hours for infants aged $>9$ days. The validity of this projected dose regimen must be evaluated before routine implementation in the care of older neonates. 


\section{References}

1. Fanos V, Dall'Agnola A. Antibiotics in neonatal infections: a review. Drugs. 1999;58:405-427.

2. Pullen J, Stolk LML, Nieman FHM, et al. Population pharmacokinetics and dosing of amoxicillin in (pre)term neonates. Ther Drug Monit. 2006;28:226-231.

3. Huisman-de Boer JJ, Anker van den JN, Vogel M, et al. Amoxicillin pharmacokinetics in preterm infants with gestational ages of less than 32 weeks. Antimicrob Agents Chemother. 1995;39:431-434.

4. Peskine F, Despaux E, Rodiere M, et al. Étude pharmacocinétique et clinique de l'amoxicilline intra-veineuse chez le nouveau-né. Pathol Biol (Paris). 1982;30:476-480.

5. Charles BG, Preechagoon Y, Lee TC, et al. Population pharmacokinetics of intravenous amoxicillin in very low birth weight infants. J Pharm Sci. 1997;86:1288-1292.

6. Autret E, Laugier J, Marimbu J, et al. Comparaison des concentrations plasmatiques d'amoxicilline par voie orale et intraveineuse dans les colonisations bactériennes néonatales. Arch Fr Pediatr. 1988;45:679-682.

7. Aperia A, Borberger O, Elinder G, et al. Postnatal development of renal function in pre-term and full-term infants. Acta Paediatr Scand. 1981;70:183-187.

8. Heijden van der AJ, Grose WF, Ambagtsheer JJ, et al. Glomerular filtration rate in the preterm infant: the relation to gestational and postnatal age. Eur J Pediatr. 1988;148:24-28.

9. Fawer CL, Torrado A, Guignard JP. Maturation of renal function in full-term and premature neonates. Helv Paediatr Acta. 1979;34:11-21.

10. Arant BS. Developmental patterns of renal functional maturation compared in the human neonate. J Pediatr. 1978;92:705-712.

11. Coulthard MG. Maturation of glomerular filtration in preterm and mature babies. Early Hum Dev. 1985;11:281-292.

12. Jose PA, Fildes RD, Gomez RA, et al. Neonatal renal function and physiology. Curr Opin Pediatr. 1994;6:172-177.

13. Knight JA, Davis EM, Manouilov K, et al. The effect of postnatal age on gentamicin pharmacokinetics in neonates. Pharmacotherapy. 2003;23:992-996.

14. Anker van den JN, Hop WC, Schoemaker RC, et al. Ceftazidime pharmacokinetics in preterm infants: effect of postnatal age and postnatal exposure to indomethacin. Br J Clin Pharmacol. 1995;40:439-443.

15. Kacet N, Roussel-Delvallez M, Gremillet C, et al. Pharmacokinetic study of piperacillin in newborns relating to gestational and postnatal age. Pediatr Infect Dis J. 1992;11:365-369.

16. Hey E, Hall C. Neonatal Formulary. 4th ed. London: Blackwell BMJ Books; 2003.

17. Notarianni LJ. Plasma protein binding of drugs in pregnancy and in neonates. Clin Pharmacokinet. 1990;18:20-36.

18. Guignard JP, Drukker A. Why do newborn infants have a high plasma creatinine? Pediatrics. 1999;103:E49.

19. Koren G, James A, Perlman M. A simple method for the estimation of glomerular filtration rate by gentamicin pharmacokinetics during routine drug monitoring in the newborn. Clin Pharmacol Ther. 1985;38:680-685.

20. Stolk LML, Degraeuwe PLJ, Nieman FHM, et al. Population pharmacokinetics and relationship between demographic and clinical variables and pharmacokinetics of gentamicin in neonates. Ther Drug Monit. 2002;24:527-531.

21. Andes D, Anon J, Jacobs MR, et al. Application of pharmacokinetics and pharmacodynamics to antimicrobial therapy of respiratory tract infections. Clin Lab Med. 2004;24:477-502.

22. Shaffer CL, Davey AM, Ransom JL, et al. Ampicillin-induced neurotoxicity in very-low-birth-weight neonates. Ann Pharmacother. 1998;32:482-484.

23. Hodgman T, Dasta JF, Armstrong DK, et al. Ampicillin-associated seizures. South Med J. 1984;77:13231325.

24. National Committee for Clinical Laboratory Standards. Performance Standards for Antimicrobial Susceptibility Testing; Twelfth Informational Standard M100-S12. Wayne, PA: NCCLS; 2002.

25. Hoog de M, Mouton JW, Anker van den JN. New dosing strategies for antibacterial agents in the neonate. Semin Fetal Neonatal Med. 2005;10:185-194.

26. Working Party of the British Society for Antimicrobial Chemotherapy. A guide to sensitivity testing. J Antimicrob Chemother. 1991;27 (Suppl. D):1-50.

27. Ehrnebo M, Agurell S, Jalling B, et al. Age differences in drug binding by plasma proteins: studies on human foetuses, neonates and adults. Europ J Clin Pharmacol. 1971;3:189-193.

28. Heimann G. Drug disposition during the perinatal period. Int J Biol Res Pregnancy. 1981;2:1-14.

29. Arant BS. Postnatal development of renal function during the first year of life. Pediatr Nephrol. 1987;1:308313. 


\section{Chapter 5}

\section{Population Pharmacokinetics and Dosing of Flucloxacillin in Preterm and Term Neonates}

Joyce Pullen, Lindsay de Rozario, Leo M.L. Stolk, Pieter L.J. Degraeuwe, Frank H. van Tiel, and Luc J.I. Zimmermann

Ther Drug Monit 2006;28(3):351-358 


\begin{abstract}
In total 235 flucloxacillin total (free + protein-bound) plasma concentrations were determined in 55 neonates (gestational age 26 to 42 weeks, postnatal age 0 to 44 days) with reversedphase HPLC in surplus plasma samples from routine gentamicin assays. Population pharmacokinetic parameters were calculated according to a one-compartment open model with iterative two-stage Bayesian fitting (MWPHARM 3.50, Mediware, The Netherlands). Mean clearance corrected for weight was $0.18 \pm 0.10 \mathrm{Lkg}^{-1} \mathrm{~h}^{-1}$ and volume of distribution corrected for weight was $0.54 \pm 0.17 \mathrm{~L} / \mathrm{kg}$. Pearson correlations between the individual pharmacokinetic parameters and covariates, like gestational age, plasma creatinine, and gentamicin clearance, were low and therefore not relevant for use in clinical practice. Total plasma concentrations above $200 \mathrm{mg} / \mathrm{L}$ were considered toxic and T>MIC (time above minimum inhibitory free plasma concentration) of more than $40 \%$ was considered effective. Protein binding was assumed to be $86.3 \%$ in all neonates, based on literature. The current dosage regimen, 25 or $50 \mathrm{mg} / \mathrm{kg}$ every 8 or 12 hours, did not result in effective plasma concentrations for the treatment of Staphylococcus aureus in $17(31 \%)$ of the 55 neonates. Therefore, the authors suggest an initial dose of $25 \mathrm{mg} / \mathrm{kg} / 4 \mathrm{~h}$ for all neonates, irrespective of their age, based on the breakpoint MIC value of flucloxacillin for Staphylococcus aureus $(2.0 \mathrm{mg} / \mathrm{L})$. After isolation of the causative agent of infection, flucloxacillin administration ought to be reconsidered based on the expected susceptibility pattern of the isolate. When oxacillin sensitive coagulase negative staphylococci are isolated, the initial dose should be reduced to $10 \mathrm{mg} / \mathrm{kg} / 6 \mathrm{~h}$, based on the breakpoint MIC value of $0.25 \mathrm{mg} / \mathrm{L}$. Simulation with these new dosage regimens indicated that satisfactory plasma concentrations were reached in 52 of the 55 neonates. However, the regimens need prospective verification. Moreover, the exact role of neonatal protein binding needs to be further investigated.
\end{abstract}




\section{Introduction}

Late-onset neonatal sepsis is relatively common in hospitalized neonates, especially in those who are extremely premature. Preterm infants frequently need invasive interventions, such as prolonged ventilation and vascular access, which may increase the risk of infection. ${ }^{1}$ Most late-onset infections are caused by Gram-positive organisms. Coagulase negative staphylococci (CoNS) account for half of all late-onset infections. ${ }^{1}$ It is not clear which antibiotic regimen is most suitable for initial treatment of suspected late-onset sepsis. ${ }^{2}$ Flucloxacillin, a narrow spectrum penicillin, in combination with gentamicin, an aminoglycoside, is the drug of choice in the vast majority in Dutch hospitals. ${ }^{3,4}$ In contrast to gentamicin, therapeutic drug monitoring (TDM) of flucloxacillin is not performed on a routine basis.

Data concerning population pharmacokinetics of flucloxacillin in adults are limited to a few studies. ${ }^{5-8}$ Considering the large differences in body composition and metabolic functions between neonates and adults, pharmacokinetic data from studies in adults cannot be applied to newborn infants. In a small study flucloxacillin pharmacokinetics in nine newborn infants of various gestational (mean 36.6 weeks) and chronological (mean 7.2 days) ages were investigated. ${ }^{9}$ Flucloxacillin pharmacokinetics were also investigated in another study with eleven neonates aged between 3 and 60 days undergoing cardiopulmonary bypass surgery. ${ }^{10}$ The elimination half-life was considerably longer, the total body clearance was much lower, and the apparent volumes of distribution in the central and peripheral compartments were much larger than in healthy adults.

The present study was designed to investigate the efficacy of the current dosage regimen of flucloxacillin and to develop a better dosage regimen if necessary. Therefore, flucloxacillin plasma concentrations of a large population of 55 neonates were determined with a specific HPLC method, the population pharmacokinetic parameters of flucloxacillin were calculated, and demographic, anthropometric, and clinical covariates, that may influence the individual pharmacokinetic parameters of flucloxacillin, were investigated for significance.

\section{Materials and Methods}

\section{Patients}

The study was approved by the local Ethical Board. Fifty-five (pre)term neonates, admitted to the neonatal ward at the University Hospital of Maastricht from May 2002 through March 2005, participated in the study. Inclusion criteria were: coadministration of flucloxacillin and gentamicin, postnatal age (PNA) $\leq 2$ months, availability of reliable patient data with respect to gestational age (GA), PNA, dosing and sampling times, and availability of at least one plasma sample taken shortly before the administration of gentamicin and flucloxacillin (trough concentration) and one plasma sample taken one hour after the administration (peak concentration).

For each patient, the following demographic, anthropometric, and clinical characteristics were recorded: GA, PNA, postconceptional age (PCA), birth weight (BW), body weight (W), gender, multiple pregnancy (P), arterial cord pH (ApH), 1-min Apgar score (AP1), 5-min Apgar score (AP5), divided into two groups $(<7$ and $\geq 7$ ), 1/plasma creatinine $(1 / \mathrm{Cr})$, plasma urea concentration (Ur), blood culture result (BC), and C-reactive protein (CRP). Because literature ${ }^{11}$ indicates that plasma creatinine in the first week of life does not reflect glomerular filtration rate (GFR) of the neonate, data on gentamicin clearance were also collected. Gen- 
tamicin clearance as an estimate of GFR in neonates has been suggested previously. ${ }^{12}$ The following pharmacokinetic parameters of gentamicin were calculated: total body clearance corrected for body weight (CL/W gentamicin), elimination half-life ( $t^{1} / 2$ gentamicin), and volume of distribution corrected for body weight (V/W gentamicin).

\section{Drug Administration and Plasma Sampling}

Gentamicin dosage regimen was $5.0 \mathrm{mg} / \mathrm{kg} / 48 \mathrm{~h}, 4.5 \mathrm{mg} / \mathrm{kg} / 36 \mathrm{~h}$, and $4.0 \mathrm{mg} / \mathrm{kg} / 24 \mathrm{~h}$ for neonates in the first week of life with $\mathrm{GA}<30,30 \leq \mathrm{GA} \leq 34$, and GA $>34$ weeks, respectively. ${ }^{13}$ Neonates older than one week received $4 \mathrm{mg} / \mathrm{kg} / 24$ h. ${ }^{14}$ Gentamicin was administered intravenously by syringe pump over $30 \mathrm{~min}$. The flucloxacillin dosage regimen, 25 to 50 $\mathrm{mg} / \mathrm{kg}$ every 8 or 12 hours, depending on GA and PNA, was based on dosing guidelines in literature. ${ }^{4,15}$ Flucloxacillin was administered by intravenous slow push $(0.1 \mathrm{~h})$. Usually, flucloxacillin and gentamicin were administered shortly after each other.

Plasma samples were taken just before and one hour after the infusion of gentamicin. Dosing and sampling times were recorded by nursing staff. Surplus plasma samples from routine gentamicin assays were stored at $-70^{\circ} \mathrm{C}$.

\section{Chemicals}

Acetonitrile $\left(\mathrm{CH}_{3} \mathrm{CN}\right.$, CAS 75-05-8), citric acid monohydrate $\left(\mathrm{C}_{6} \mathrm{H}_{8} \mathrm{O}_{7} \cdot \mathrm{H}_{2} \mathrm{O}\right.$, CAS 5949-29-1), methylene chloride $\left(\mathrm{CH}_{2} \mathrm{Cl}_{2}\right.$, CAS 75-09-2), hydrochloric acid $(\mathrm{HCl}, \mathrm{CAS} 7647-01-0)$, and sodium perchlorate $\left(\mathrm{NaClO}_{4} \cdot \mathrm{H}_{2} \mathrm{O}\right.$, CAS 7601-89-0) were obtained from Merck (Darmstadt, Germany). Flucloxacillin $\left(\mathrm{C}_{19} \mathrm{H}_{16} \mathrm{CIFN}_{3} \mathrm{NaO}_{5} \mathrm{~S} \cdot \mathrm{H}_{2} \mathrm{O}\right.$, CAS 1847-24-1) was provided by Synopharm (Barsbüttel, Germany) and the internal standard cloxacillin $\left(\mathrm{C}_{19} \mathrm{H}_{18} \mathrm{CIN}_{3} \mathrm{O}_{5} \mathrm{~S}\right.$, CAS 6172-3) was obtained from SmithKline Beecham Pharmaceutical (Middlesex, United Kingdom). Ultrapure water was used in all preparations. All chemicals were of analytical grade. Human EDTA plasma for standard and control samples was provided by the Red Cross Blood Bank (Maastricht, The Netherlands).

\section{Analytical Techniques}

Gentamicin plasma concentrations were measured with the COBAS INTEGRA 700 analyzer (Roche, Mannheim, Germany), using the principle of fluorescence polarization. The error pattern of the gentamicin assay was: $S D=0.0129+0.0029 C+0.0034 C^{2}$. The assay error pattern was determined according to a method described in literature. ${ }^{16}$ The lower limit of determination was $0.1 \mathrm{mg} / \mathrm{L}$. Total (free + protein-bound) flucloxacillin concentrations were determined with reversed-phase HPLC in surplus plasma from routine gentamicin assays. The HPLC assay method was based on a method described by Thijssen. ${ }^{17}$ An automatic sample injector (model 717, Waters, USA), a pump (model 1050, Hewlett Packard, USA), a C8 column, $250 \times 4.6 \mathrm{~mm}, 5 \mu \mathrm{m}$ (Beckman, USA), combined with a C8 guard column, and an UV spectrophotometer detector (model 486, Waters, USA) were used. The eluent was composed of $0.02 \mathrm{~mol} / \mathrm{L}$ sodium perchlorate in water and acetonitrile (750:250). The separations were carried out at room temperature and at a flow rate of $2.0 \mathrm{~mL} / \mathrm{min}$. The detection occurred at a wavelength of $220 \mathrm{~nm}$. The error pattern of the assay was: $\mathrm{SD}=0.5117+0.0108$ $\mathrm{C}+0.0002 \mathrm{C}^{2}$. The lower limit of determination was $3 \mathrm{mg} / \mathrm{L}$.

To $20 \mu \mathrm{L}$ surplus plasma, consecutively $20 \mu \mathrm{L} 40 \mathrm{mg} / \mathrm{L}$ cloxacillin internal standard solution, $40 \mu \mathrm{L} 0.5 \mathrm{~mol} / \mathrm{L}$ citric acid monohydrate, $10 \mu \mathrm{L} 0.5 \mathrm{~mol} / \mathrm{L} \mathrm{HCl}$, and $1 \mathrm{~mL}$ methylene chloride were added. The solution was extracted for 2 minutes and centrifuged at $1780 \times g$ for 5 min- 
utes. The top water layer was removed with vacuum and the organic layer containing flucloxacillin was centrifuged at $1780 \times g$ for 5 minutes. The organic layer was evaporated with nitrogen at room temperature. After evaporation, $100 \mu \mathrm{L}$ eluent was added and the solution was mixed for $60 \mathrm{~s}$. This solution $(25 \mu \mathrm{L})$ was injected into the HPLC. Standard solutions, containing $10,25,50,75$, and $100 \mathrm{mg} / \mathrm{L}$ flucloxacillin, were freshly prepared on the day of analysis. The standard plasma samples were processed in the same way as the surplus plasma samples. A calibration curve was constructed and total flucloxacillin concentrations in surplus plasma samples were calculated. Plasma samples containing more than $100 \mathrm{mg} / \mathrm{L}$ flucloxacillin were diluted two times with blank plasma. Control plasma samples, containing $25 \mathrm{mg} / \mathrm{L}$ flucloxacillin, were prepared and stored in separate containers at $-70^{\circ} \mathrm{C}$ until analysis. Two control plasma samples were measured in each run.

\section{Validation}

The HPLC assay method was validated on linearity, precision, accuracy, and extraction recovery. The correlation coefficient of the calibration curves $(n=6)$ was $>0.99$. Inter-day precision and accuracy, measured at 10, 25, 50, 75, and $100 \mathrm{mg} / \mathrm{L}(\mathrm{n}=6)$, were $<10 \%$ and < $5 \%$, respectively. Extraction recovery, measured at 50 and $100 \mathrm{mg} / \mathrm{L}$, was $100 \%$.

Flucloxacillin stability in plasma samples during storage at $-70^{\circ} \mathrm{C}$ was determined by analyzing the control plasma samples stored at $-70^{\circ} \mathrm{C}$ over a period of 30 days at day 3,7 , and 30 . We did not observe decrease of flucloxacillin concentration. In each run, six standard plasma samples, two control plasma samples, and six surplus plasma samples, if possible in duplicate, were included. The duration of each run was about three hours. Flucloxacillin is reported to be stable at $4^{\circ} \mathrm{C}$ and at room temperature for up to 24 hours. ${ }^{18}$

\section{Data Analysis}

Population pharmacokinetic parameters of flucloxacillin and gentamicin were calculated according to a one-compartment open model with an iterative two-stage Bayesian fitting procedure (IT2B) (MWIPHARM 3.50, Mediware, The Netherlands). Individual pharmacokinetic parameters were calculated by maximum a posteriori Bayesian fitting (MWIPHARM 3.50). The Bayesian fitting procedure uses measured drug concentrations, population-based pharmacokinetic parameters, and the expected variability associated with each measurement to determine individualized pharmacokinetic parameters of a patient. ${ }^{19}$ The initial pharmacokinetic parameters of flucloxacillin were derived from Herngren et $\mathrm{al}^{9}: \mathrm{K}_{\mathrm{el}} 0.15 \pm 0.05 \mathrm{~h}^{-1}$ and V/W $0.28 \pm 0.05 \mathrm{~L} / \mathrm{kg}$. The initial pharmacokinetic parameters of gentamicin were derived from the study of Stolk et al. ${ }^{13}$ The population pharmacokinetic model was validated with Monte Carlo analysis. ${ }^{20,21}$ With the MWIPHARM program, 100 sets of 55 simulated patients were generated, based on our own original 55 patients. The individual and population pharmacokinetic parameters of these 5500 simulated patients were calculated with iterative twostage Bayesian fitting. The calculated individual pharmacokinetic parameters were compared with the "real" (generated) individual pharmacokinetic parameters and the bias (mean error) and the root mean square error (RMSE) were determined. The smaller the bias and the RMSE, the better the performance of the model. Also, the calculated population pharmacokinetic parameters of the 5500 simulated patients were compared with the original population pharmacokinetic parameters.

Statistical analysis was started by checking CL/W and V/W of flucloxacillin for normal distribution with the Kolmogorov-Smirnov test. One-way analysis of variance was used to test if 
the factor variables (gender, $\mathrm{P}, \mathrm{AP} 5$, and $\mathrm{BC}$ ) had a significant effect on CL/W and V/W of flucloxacillin. Pearson product-moment correlation coefficients $(r)$ between pharmacokinetic parameters of flucloxacillin and covariates were calculated. Multiple regression analysis with forward selection and backward elimination techniques was done with CL/W and V/W of flucloxacillin as dependent variables. The significant variables, detected with correlation analysis, were used as possible predictors. The significant predictors of the dependent variable were used to establish a direct-effects model. First-order interaction effects between the significant predictors were tested for significance by forced entering within a hierarchically constructed regression model. Residual analysis was performed to check the studentized residuals of the dependent variable for normality and outliers. Discrete factors were entered as dummy variables. Listwise deletion of missing cases was used during the entire regression analysis procedure. Statistical analysis was performed using SPSS ${ }^{\circledR} 12.0$ (Chicago, IL). A P value of $<0.05$ was considered to be statistically significant.

\section{Evaluation of Current and Proposed Dosage Regimen}

The efficacy of penicillins, including flucloxacillin, depends on the time the free (not proteinbound) plasma concentration exceeds the minimum inhibitory concentration ( $>$ MIC) ${ }^{22}$ In neonates, T>MIC should be at least $40 \%{ }^{22}$ The breakpoint MIC value of an antibiotic defines the highest MIC value still to be interpreted as indicating susceptibility to that antibiotic. In neonates, flucloxacillin is frequently used for the treatment of infections caused by CoNS, including Staphylococcus epidermidis, and less frequently by Staphylococcus aureus. For these two bacterial species, the breakpoint MIC values of flucloxacillin are 0.25 and 2.0 $\mathrm{mg} / \mathrm{L}$, respectively. ${ }^{23}$ Therefore, when treating staphylococcal infections, plasma concentrations of free flucloxacillin should exceed 0.25 or $2.0 \mathrm{mg} / \mathrm{L}$, depending on the species determination of the blood isolate, during at least $40 \%$ of the time. To evaluate the efficacy of the current dosage regimen, we calculated $\mathrm{T}>\mathrm{MIC}_{2.0}$ and $\mathrm{T}>\mathrm{MIC}_{0.25}$ for all patients, using their individual pharmacokinetic parameters. The expected level of free flucloxacillin activity was calculated, assuming that our neonates had levels of protein binding of $86.3 \%$, according to Herngren et al. ${ }^{9}$

High intravenous doses of isoxazolyl penicillins have been considered to increase the risk of kernicterus in neonates due to displacement of bilirubin at plasma levels above $200 \mathrm{mg} / \mathrm{L} ., 24$ According to Rolinson et al, ${ }^{25}$ saturation of albumin with penicillins in adults occurs at plasma concentrations of approximately $200 \mathrm{mg} / \mathrm{L}$, when a substantial proportion of available sites on the albumin molecules become occupied by antibiotic molecules. This situation may result in displacement of bilirubin. Therefore, total flucloxacillin plasma concentrations should not exceed the possibly toxic limit of $200 \mathrm{mg} / \mathrm{L}$. To evaluate possible toxicity of the current dosage regimen, we calculated flucloxacillin peak concentrations after the second dose of all patients, using their individual pharmacokinetic parameters.

Flucloxacillin plasma concentrations, reached with the proposed dosage regimen, were simulated in MWIPHARM 3.50 for all neonates, using their individual pharmacokinetic parameters. 


\section{Results}

\section{Patients}

Demographic, anthropometric, and clinical characteristics of the population are presented in Table 1. The population consisted of $21(38.2 \%)$ girls and $34(61.8 \%)$ boys. Forty-four $(80 \%)$ neonates were products of singleton pregnancies and $11(20 \%)$ neonates of twin pregnancies. Eighteen (33.3\%) out of 54 blood cultures (1 missing) were positive. Only Staphylococcus species were isolated: CoNS (88.9\%), including S. epidermidis (25\%), and S. aureus $(11.1 \%)$.

Table 1. Demographic, Anthropometric, and Clinical Characteristics of the Study Patients

\begin{tabular}{lllll}
\hline & Unit & $\mathbf{N}$ & Mean (SD) & Range \\
GA & weeks & 55 & $31.2(4.1)$ & $26.0-42.0$ \\
PNA & days & 55 & $11.1(9.3)$ & $0-44$ \\
PCA & weeks & 55 & $32.7(4.2)$ & $27.1-42.9$ \\
BW & $\mathrm{kg}$ & 55 & $1.39(8.60)$ & $0.37-4.06$ \\
$\mathrm{~W}$ & $\mathrm{~kg}$ & 55 & $1.49(0.82)$ & $0.43-4.11$ \\
$\mathrm{ApH}$ & $\mathrm{pH}$ & 36 & $7.19(0.15)$ & $6.74-7.46$ \\
$\mathrm{AP} 1$ & $\mathrm{points}$ & 55 & 7 (median) & $0-10$ \\
$\mathrm{AP5}$ & points & 55 & $9($ median $)$ & $0-10$ \\
$\mathrm{Cr}$ & $\mu \mathrm{mol} / \mathrm{L}$ & 43 & $64.5(23.9)$ & $21-115$ \\
$\mathrm{Ur}$ & $\mathrm{mmol} / \mathrm{L}$ & 40 & $4.01(2.45)$ & $0.10-10.00$ \\
$\mathrm{CRP}$ & $\mathrm{mg} / \mathrm{L}$ & 55 & $40.0(49.0)$ & $1.0-234.0$ \\
$\mathrm{CL} / \mathrm{W}$ gentamicin & $\mathrm{Lkg}{ }^{-1} \mathrm{~h}^{-1}$ & 55 & $0.057(0.016)$ & $0.029-0.096$ \\
$t / 2$ gentamicin & $\mathrm{h}$ & 55 & $9.1(3.5)$ & $5.0-19.8$ \\
V/W gentamicin & $\mathrm{L} / \mathrm{kg}$ & 55 & $0.69(0.16)$ & $0.43-1.18$ \\
\hline
\end{tabular}

AP1, 1-min Apgar score; AP5, 5-min Apgar score; ApH, arterial cord pH; BW, birth weight; CL, total body clearance; $\mathrm{Cr}$, plasma creatinine level; CRP, C-reactive protein; GA, gestational age; PCA, postconceptional age; PNA, postnatal age; SD, standard deviation; $t^{1} \frac{1}{2}$, elimination half-life; Ur, plasma urea concentration; $V$, volume of distribution; W, body weight.

\section{Population Pharmacokinetic Parameters}

In total 235 flucloxacillin plasma concentrations (mean $4.3 \pm 1.4$ per patient) and 267 gentamicin plasma concentrations ( $4.9 \pm 1.4$ per patient) were measured. An example of a modelled concentration-time profile of a patient with iterative two-stage Bayesian fitting is shown in Figure 1. A plot of the actual measured concentrations versus the estimated concentrations with iterative two-stage Bayesian fitting is presented in Figure 2.

Mean total body clearance of flucloxacillin corrected for body weight (CL/W) was $0.18 \pm 0.10$ $\mathrm{Lkg}^{-1} \mathrm{~h}^{-1}$, mean flucloxacillin elimination half-life $\left(t^{1} / 2\right)$ was $2.6 \pm 1.6 \mathrm{~h}$, and mean volume of distribution of flucloxacillin corrected for body weight $(\mathrm{V} / \mathrm{W})$ was $0.54 \pm 0.17 \mathrm{~L} / \mathrm{kg}$. Mean population pharmacokinetic parameters of gentamicin were: CL/W $0.057 \pm 0.016 \mathrm{Lkg}^{-1} \mathrm{~h}^{-1}, t^{1} / 2$ $9.1 \pm 3.5 \mathrm{~h}$, and V/W $0.69 \pm 0.16 \mathrm{~L} / \mathrm{kg}$.

The population pharmacokinetic parameters of flucloxacillin estimated with Monte Carlo analysis $\left(\mathrm{K}_{\mathrm{el}} 0.3417 \pm 0.1559 \mathrm{~h}^{-1}\right.$ and V/W $\left.0.5486 \pm 0.1735 \mathrm{~L} / \mathrm{kg}\right)$ were almost identical to the 
population pharmacokinetic parameters of our original population $\left(\mathrm{K}_{\mathrm{el}} 0.3486 \pm 0.1662 \mathrm{~h}^{-1}\right.$ and V/W $0.5392 \pm 0.1698 \mathrm{~L} / \mathrm{kg}$ ). The bias and the RMSE of the Monte Carlo analysis were low, respectively, $-2.2 \%$ and $3.1 \%$ for $\mathrm{K}_{\text {el }}$ flucloxacillin and $0.9 \%$ and $1.5 \%$ for $\mathrm{V} / \mathrm{W}$ flucloxacillin.

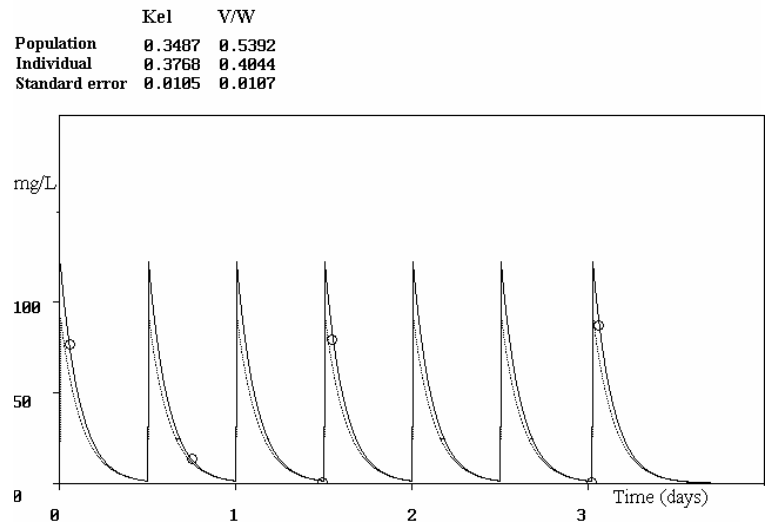

Figure 1. Example of a modelled concentration-time profile of a patient with iterative two-stage Bayesian fitting (MWIPHARM 3.50, Mediware, The Netherlands).

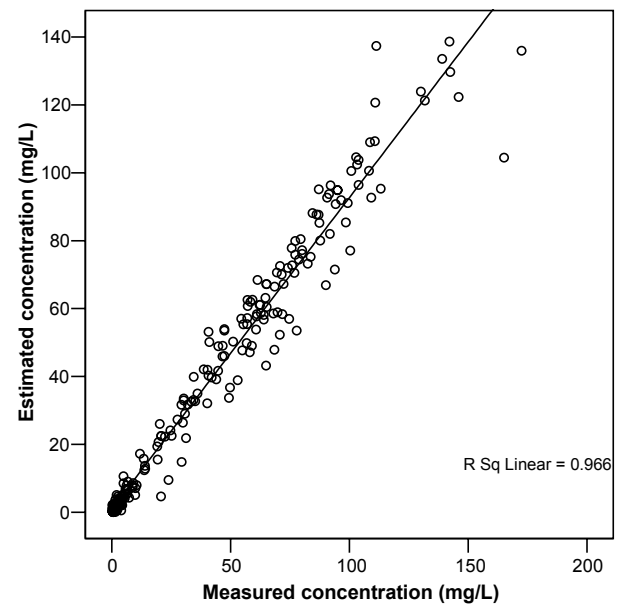

Figure 2. Correlation between actual measured concentration $(\mathrm{mg} / \mathrm{L})$ and estimated concentration $(\mathrm{mg} / \mathrm{L})$ with iterative two-stage Bayesian fitting (MWIPHARM 3.50, Mediware, The Netherlands). 


\section{Statistical Analysis}

Few statistically significant Pearson correlations were found between covariates and pharmacokinetic parameters. CL/W flucloxacillin correlated significantly with the covariates GA ( $r$ $=0.340, P=0.011)$ and PCA $(r=0.319, P=0.018)$. The correlation between CL/W flucloxacillin and GA is shown in Figure 3 . V/W flucloxacillin correlated significantly with the covariates V/W gentamicin $(r=0.397, P=0.003)$ and AP1 $(r=-0.266, P=0.049)$. Multiple regression analysis was done with CL/W flucloxacillin (normally distributed) as dependent variable and GA and PCA as possible predictors and with V/W flucloxacillin as dependent variable and V/W gentamicin and AP1 as possible predictors. GA was a significant predictor of CL/W flucloxacillin $\left(r^{2}=0.116, n=55\right)$, and V/W gentamicin was a significant predictor of V/W flucloxacillin $\left(r^{2}=0.158, n=55\right)$. The standardized studentized residuals of all models seemed to be normally distributed.

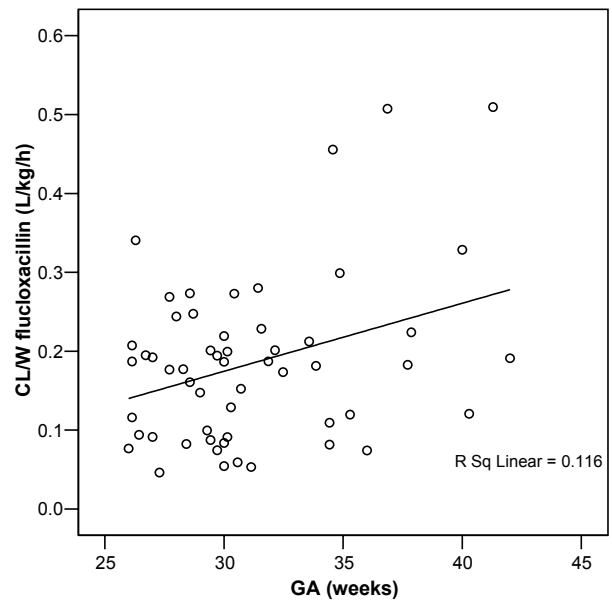

Figure 3. Correlation between total body clearance of flucloxacillin

corrected for body weight (CL/W) $\left(\mathrm{Lkg}^{-1} \mathrm{~h}^{-1}\right)$ and gestational age (GA) (weeks).

\section{Evaluation of Current and Proposed Dosage Regimen}

Flucloxacillin peak and trough concentrations after the second dose and $\mathrm{T}>\mathrm{MIC}_{0.25}$ and $\mathrm{T}>\mathrm{MIC}_{2.0}$ of each patient are shown in Table 2. With the current dosage regimen, $\mathrm{T}>\mathrm{MIC}_{0.25}$ was much higher than $40 \%$ in all neonates, except one (36\%). $\mathrm{T}>\mathrm{MIC}_{2.0}$ was lower than $40 \%$ in $17(31 \%)$ of the 55 neonates. None of the neonates had peak concentrations above 200 $\mathrm{mg} / \mathrm{L}$. Thus, the current dosage regimen resulted in ineffective plasma concentrations in several patients, especially for the treatment of $S$. aureus. $S$. aureus is a less common, but virulent pathogen isolated in late-onset infections. Therefore, the initial flucloxacillin dose should result in free plasma concentrations exceeding $2.0 \mathrm{mg} / \mathrm{L}$ during at least $40 \%$ of the time. We suggest an initial dose of $25 \mathrm{mg} / \mathrm{kg} / 4 \mathrm{~h}$. After isolation of the causative agent of infection, the initial dose should be either reduced to $10 \mathrm{mg} / \mathrm{kg} / 6 \mathrm{~h}$, when CoNS are isolated, or maintained, when $S$. aureus is isolated. 
With the suggested initial dose of $25 \mathrm{mg} / \mathrm{kg} / 4 \mathrm{~h}$, simulated peak concentrations did not exceed $200 \mathrm{mg} / \mathrm{L}: 76.4 \pm 31.1 \mathrm{mg} / \mathrm{L}$ (mean $\pm \mathrm{SD}$ ) with a range of 31.8 to $161.2 \mathrm{mg} / \mathrm{L}$ (Fig. 4 ). Simulated $\mathrm{T}>\mathrm{MIC}_{2.0}$ was at least $40 \%$ in 52 neonates with a mean of $86.3 \% \pm 19.5 \%$ (mean \pm SD) with a range of $29 \%$ to $100 \%$ (Fig. 4). With the dose of $10 \mathrm{mg} / \mathrm{kg} / 6 \mathrm{~h}$, simulated peak concentrations were all $<200 \mathrm{mg} / \mathrm{L}$ with a mean of $25.2 \pm 8.8 \mathrm{mg} / \mathrm{L}$ (range 11.8 to 48.8 $\mathrm{mg} / \mathrm{L})$. Simulated $\mathrm{T}>\mathrm{MIC}_{0.25}$ was satisfactory $(>40 \%)$ in all neonates with a mean of $94.1 \% \pm$ $12.7 \%$ (range $52 \%$ to $100 \%$ ).

Table 2. Flucloxacillin Peak and Trough Concentrations after the Second Dose and the Time the Free Concentration Exceeds the Minimum Inhibitory Concentration of $0.25\left(\mathrm{~T}>\mathrm{MIC}_{0.25}\right)$ and $2.0 \mathrm{mg} / \mathrm{L}\left(\mathrm{T}>\mathrm{MIC}_{2.0}\right)$

\begin{tabular}{|c|c|c|c|c|c|c|}
\hline $\begin{array}{l}\text { Dose } \\
\text { (mg/kg) }\end{array}$ & $\begin{array}{l}\text { Interval } \\
\text { (h) }\end{array}$ & $\mathbf{N}$ & $\begin{array}{l}\text { Trough (SD) } \\
\text { (mg/L) }\end{array}$ & $\begin{array}{l}\text { Peak (SD) } \\
(\mathrm{mg} / \mathrm{L})\end{array}$ & $\begin{array}{l}\mathrm{T}>\mathrm{MIC}_{0.25} \text { (SD) } \\
(\%)\end{array}$ & $\begin{array}{l}\mathrm{T}>\mathrm{MIC}_{2.0}(\mathrm{SD}) \\
(\%)\end{array}$ \\
\hline \multirow[t]{2}{*}{25} & 12 & 4 & $1.4(2.2)$ & $38.4(5.5)$ & $66.0(26.7)$ & $24.5(16.2)$ \\
\hline & & & $0.4(0.1 / 3.6)^{*}$ & & & \\
\hline 35 & 8 & 1 & 0.3 & 82.0 & 70 & 33 \\
\hline 35 & 12 & 2 & $0.8(0.1)$ & $70.9(19.2)$ & $76.5(2.1)$ & $34.0(5.7)$ \\
\hline \multirow[t]{2}{*}{50} & 8 & 9 & $10.8(16.9)$ & $114.4(38.8)$ & $94.9(12.6)$ & $64.1(28.6)$ \\
\hline & & & $3.8(1.5 / 14.6)^{*}$ & & & \\
\hline \multirow[t]{2}{*}{50} & 12 & 39 & $8.0(11.2)$ & $106.3(31.0)$ & $91.4(12.8)$ & $59.3(26.0)$ \\
\hline & & & $2.2(0.9 / 13.3)^{*}$ & & & \\
\hline
\end{tabular}

SD, standard deviation; *median (percentile 25/75).
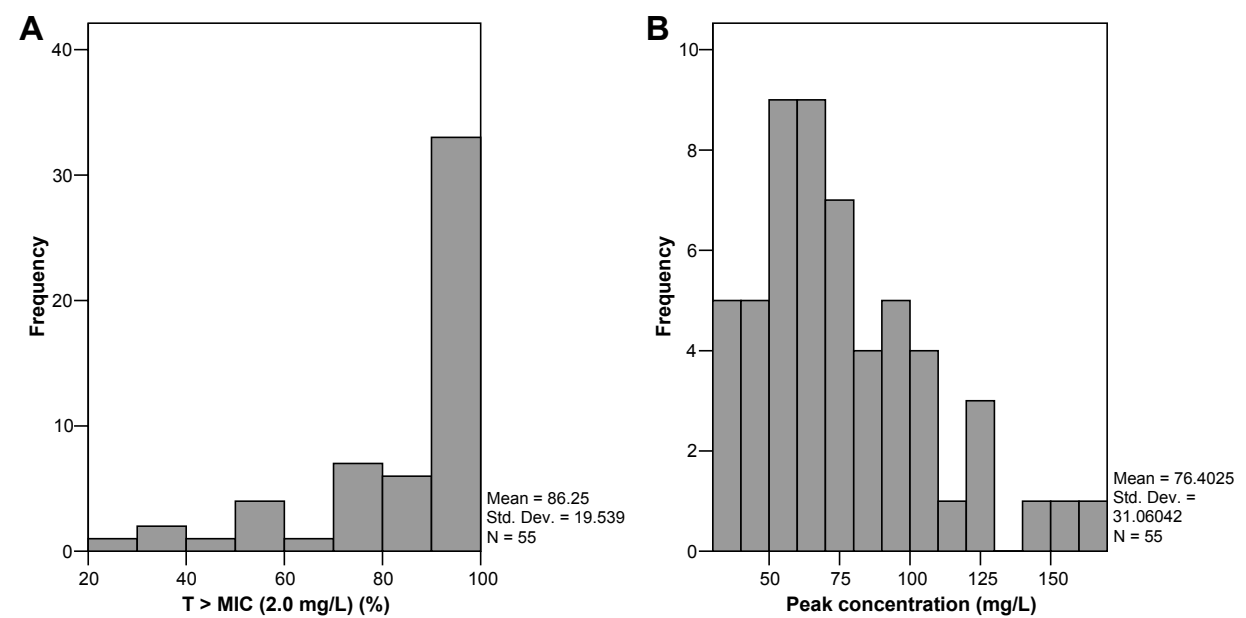

Figure 4. Histogram at the time above the minimum inhibitory concentration ( $T>M I C)$ of $2.0 \mathrm{mg} / \mathrm{L}(\%)(\mathrm{A})$ and histogram at the peak concentration $(\mathrm{mg} / \mathrm{L})(B)$ with the proposed dosage regimen $(25 \mathrm{mg} / \mathrm{kg} / 4 \mathrm{~h})$. 


\section{Discussion}

\section{Population Pharmacokinetic Parameters}

We found a high inter-individual variability in the pharmacokinetic parameters. CL/W flucloxacillin was about three times higher than CL/W gentamicin in our neonates. This suggests the presence of other elimination pathways in addition to glomerular filtration, such as tubular secretion and nonrenal clearance (metabolism), because gentamicin is completely cleared by glomerular filtration. ${ }^{12}$ However, tubular secretion is believed to be very inefficient in neonates. ${ }^{26}$ For isoxazolyl penicillins, including flucloxacillin, about $30 \%$ to $40 \%$ of their total plasma clearance in healthy adults is by a nonrenal route. ${ }^{27,28}$ The formation of inactive penicilloic acids seems to be the main route by which these penicillins are metabolized. ${ }^{29}$ In addition, as the result of other metabolic pathways, active metabolites are formed. ${ }^{30}$ Because the formation of active metabolites is small (about $10 \%$ in adults) and their antibacterial activities are of the same order of magnitude as the parent compounds, it is not to be expected that their formation will have any influence on the outcome of therapy. ${ }^{30}$

The population pharmacokinetic parameters of flucloxacillin in the present study differ from the population pharmacokinetic parameters found by Herngren et al. ${ }^{9} \mathrm{CL} / \mathrm{W}\left(0.04 \mathrm{Lkg}^{-1} \mathrm{~h}^{-1}\right)$ and V/W $(0.28 \mathrm{~L} / \mathrm{kg})$ were low and $t^{1} / 2(4.6 \mathrm{~h})$ was high compared with our results. These differences may be attributable to their relatively small study population $(n=9)$ and the use of the method of disk diffusion in nutrient agar instead of the more specific HPLC method. The population pharmacokinetic parameters found by Adrianzén Vargas et al ${ }^{10}$ were: CL/W 0.12 $\mathrm{Lkg}^{-1} \mathrm{~h}^{-1}, t^{1} / 22.6 \mathrm{~h}$, and V/W $0.45 \mathrm{~L} / \mathrm{kg}$. They studied older neonates $(\mathrm{n}=11)$, as a result of which we would expect a higher CL/W, a shorter $t^{1} 12$, and a lower V/W. However, cardiopulmonary bypass has an effect on drug pharmacokinetics and leads to a decreased CL/W, a prolonged $t \frac{1}{2}$, and an increased $\mathrm{V} / \mathrm{W} .^{10}$

\section{Predictors of Individual Pharmacokinetic Parameters}

The investigated covariates had no or very low predictive power for the pharmacokinetic parameters of flucloxacillin. The age parameters GA and PNA had low predictability for CL/W flucloxacillin in contrast with our earlier study of amoxicillin. ${ }^{31}$ Herngren et al $^{9}$ found a significant negative correlation between elimination half-life of flucloxacillin and gestational age in 9 neonates $(r=-0.661, P<0.05)$. The correlation between elimination half-life of flucloxacillin and gestational age in our population was not statistically significant $(r=-0.257, P=0.058)$. This difference may be associated with the size of the study population, 9 versus 55 neonates, and with the range of gestational age of the population, 33 to 41 versus 26 to 42 weeks.

In our previous study we found that CL/W gentamicin and $1 / \mathrm{Cr}$ were very good predictors of $\mathrm{CL} / \mathrm{W}$ amoxicillin in (pre)term neonates. ${ }^{31}$ In the present study we did not find a significant correlation between CL/W flucloxacillin and the covariates CL/W gentamicin and 1/Cr. Therefore, we think that the relative contribution of glomerular filtration to the elimination of flucloxacillin is small compared with that of gentamicin and amoxicillin. Glomerular filtration of flucloxacillin may be lowered by its high protein binding. ${ }^{32}$ 


\section{Dosage Regimen}

The efficacy of the current and proposed dosage regimen was investigated by calculating the time the free plasma concentration of flucloxacillin exceeds the MIC. The free plasma concentration was assumed as constant in all neonates. However, there are a lot of factors, such as circulating substances (albumin, bilirubin, free fatty acids), disease, albumin structure, plasma volume, and GA, that may influence protein binding and cause inter-patient variability in protein binding. ${ }^{33}$ Herngren et $\mathrm{al}^{9}$ found a significant positive correlation between protein binding (mean 86.3\%) and GA (mean 36.6 weeks, range 33 to 41 weeks). Therefore, we expect part of our neonates (mean GA 31.2 weeks, range 26 to 42 weeks) to have protein binding below $86.3 \%$ and a favourably higher T>MIC. Knowledge of the free fraction would be beneficial in estimating the required dose. However, there are ethical and practical problems in obtaining a sufficiently large sample for analysis from neonates and the assay is time-consuming and complicated.

We suggest one dose for all neonates, irrespective of their age, because of the low correlation between CL/W flucloxacillin and the covariates GA and PNA. This is in contrast with the existing dosing schemes. For initial therapy, we suggest a higher dose and a more frequent administration than is customary now to reach sufficiently high plasma concentrations. Continuous infusion could be considered as an alternative for frequent intermittent administration, because flucloxacillin is reported to be stable at room temperature for 24 hours. ${ }^{18}$ We suggest an initial dose of $25 \mathrm{mg} / \mathrm{kg} / 4 \mathrm{~h}$. This initial dose should be reduced to $10 \mathrm{mg} / \mathrm{kg} / 6 \mathrm{~h}$ when CoNS are isolated. Dose reduction lowers the costs and prevents unnecessary use of the antibiotic, which promotes bacterial overgrowth and resistance. These new dosage regimens need prospective verification, because they have been tested only by the original data from which the regimens derived.

Simulation with the new dosage regimens indicated that satisfactory plasma concentrations were reached in 52 of the 55 neonates. A large inter-individual variability of T>MIC and peak concentrations was observed with these dosage regimens. With the suggested initial dose of $25 \mathrm{mg} / \mathrm{kg} / 4 \mathrm{~h}$, simulated $\mathrm{T}>\mathrm{MIC}_{2.0}$ did not exceed $40 \%$ in three neonates $(29 \%, 35 \%$, and $35 \%$ ). With a higher initial dose, e.g. $30 \mathrm{mg} / \mathrm{kg} / 4 \mathrm{~h}$, simulated $\mathrm{T}>\mathrm{MIC}_{2.0}$ did exceed $40 \%$ in all 55 neonates, but simulated peak concentrations came very close to the toxic limit of 200 $\mathrm{mg} / \mathrm{L}$ in several patients. We think it is safer to have $\mathrm{T}>\mathrm{MIC}_{2.0}$ somewhat below the desired $40 \%$ in a few patients instead of risking toxic levels in several patients. Flucloxacillin is always administered in combination with gentamicin for the initial treatment of suspected lateonset sepsis. Moreover, the toxic limit of $200 \mathrm{mg} / \mathrm{L}$ found in adults might even be lower in neonates, because of the lower binding capacity of albumin in neonates. ${ }^{34}$

The suggested dosage regimens will result in plasma concentrations sufficiently high for the treatment of infections which are easily reached by antibiotics, such as bacteremia, urinary tract infection, and intravascular catheter-related infection. However, in patients who are suspected of infections which are not easily reached by antibiotics, such as meningitis, higher doses should be necessary. In these patients, flucloxacillin administration ought to be reconsidered, because doses higher than our proposed dosage regimens may result in plasma concentrations exceeding $200 \mathrm{mg} / \mathrm{L}$. 


\section{Conclusions}

We suggest an initial flucloxacillin dose of $25 \mathrm{mg} / \mathrm{kg} / 4 \mathrm{~h}$ for all neonates, irrespective of their GA and PNA. This dose is higher than the customary dose. After isolation of the causative agent of infection, the initial dose should be either reduced to $10 \mathrm{mg} / \mathrm{kg} / 6 \mathrm{~h}$, when oxacillin sensitive CoNS are isolated, or maintained, when $S$. aureus is isolated. Simulation with these new dosage regimens showed that satisfactory plasma concentrations were reached in 52 of the 55 neonates. However, the regimens need prospective verification. Moreover, the exact role of neonatal protein binding needs to be further investigated.

\section{References}

1. McGuire W, Clerihew L, Fowlie PW. Infection in the preterm infant. BMJ. 2004;329:1277-1280.

2. Gordon A, Jeffery HE. Antibiotic regimens for suspected late onset sepsis in newborn infants. The Cochrane Database of Systematic Reviews 2005.

3. Janknegt R. The treatment of staphylococcal infections with special reference to pharmacokinetic, pharmacodynamic and pharmacoeconomic considerations. Pharm World Sci. 1997;19:133-141.

4. Hey E, Hall C. Neonatal Formulary. 4th ed. London: Blackwell BMJ Books; 2003.

5. Adam D, Koeppe P, Heilmann HD. Pharmacokinetics of amoxicillin and flucloxacillin following the simultaneous intravenous administration of $4 \mathrm{~g}$ and $1 \mathrm{~g}$, respectively. Infection. 1983;11:150-154.

6. Thijssen HHW, Wolters J. The metabolic disposition of flucloxacillin in patients with impaired kidney function. Eur J Clin Pharmacol. 1982;22:429-434.

7. Røder BL, Frimodt-Møller N, Espersen F, et al. Dicloxacillin and flucloxacillin: pharmacokinetics, protein binding and serum bactericidal titers in healthy subjects after oral administration. Infection. 1995;23:107-112.

8. Gath J, Charles B, Sampson J, et al. Pharmacokinetics and bioavailability of flucloxacillin in elderly hospitalized patients. J Clin Pharmacol. 1995;35:31-36.

9. Herngren L, Ehrnebo M, Broberger U. Pharmacokinetics of free and total flucloxacillin in newborn infants. Eur J Clin Pharmacol. 1987;32:403-409.

10. Adrianzén Vargas MR, Danton MH, Javaid SM, et al. Pharmacokinetics of intravenous flucloxacillin and amoxicillin in neonatal and infant cardiopulmonary bypass surgery. Eur J Cardiothorac Surg. 2004;25:256260.

11. Guignard JP, Drukker A. Why do newborn infants have a high plasma creatinine? Pediatrics. 1999;103:E49.

12. Koren G, James A, Perlman M. A simple method for the estimation of glomerular filtration rate by gentamicin pharmacokinetics during routine drug monitoring in the newborn. Clin Pharmacol Ther. 1985;38:680-685.

13. Stolk LML, Degraeuwe PLJ, Nieman FHM, et al. Population pharmacokinetics and relationship between demographic and clinical variables and pharmacokinetics of gentamicin in neonates. Ther Drug Monit. 2002;24:527-531.

14. Stolk LML, Degraeuwe PLJ. Gentamicin pharmacokinetics in preterm infants of less than 30 weeks gestational age at birth: effect of postnatal age [abstract]. Br J Clin Pharmacol. 1999;48:767P.

15. Young TE, Mangum B. Neofax®: A Manual of Drugs Used in Neonatal Care. 17th ed. Raleigh, North Carolina: Acorn Publishing; 2004.

16. Dodge WF, Jelliffe RW, Zwischenberger JB, et al. Population pharmacokinetic models: effect of explicit versus assumed constant serum concentration assay error patterns upon parameter values of gentamicin in infants on and off extracorporeal membrane oxygenation. Ther Drug Monit. 1994;16:552-559.

17. Thijssen HHW. Analysis of isoxazolyl penicillins and their metabolites in body fluids by high-performance liquid chromatography. J Chromatogr B Biomed Appl. 1980;183:339-345.

18. Thalhammer F, Maier-Salamon A, Jäger W. Prüfung von stabilität und kompatibilität von flucloxacillin (Floxapen $\AA$ ) und ceftazidim (Fortum $\left.{ }^{\circledR}\right)$ in zwei infusionslösungen: relevanz für die klinische praxis. Wien Med Wochenschr. 2005;155:337-343.

19. Proost JH, Meijer DKF. MWIPHARM, an integrated software package for drug dosage regimen calculation and therapeutic drug monitoring. Comput Biol Med. 1992;22:155-163.

20. Bonate PL. A brief introduction to Monte Carlo simulation. Clin Pharmacokinet. 2001;40:15-22.

21. Mediware: software for healthcare. Available at: http://www.mediware.nl.

22. Hoog de M, Mouton JW, Anker van den JN. New dosing strategies for antibacterial agents in the neonate. Semin Fetal Neonatal Med. 2005;10:185-194. 
23. National Committee for Clinical Laboratory Standards. Performance Standards for Antimicrobial Susceptibility Testing; Twelfth Informational Standard M100-S12. Wayne, PA: NCCLS; 2002.

24. Bratlid D. Pharmacologic aspects of neonatal hyperbilirubinemia. Birth Defects. 1976;12:184-191.

25. Rolinson GN, Sutherland R. The binding of antibiotics to serum proteins. Br J Pharmacol. 1965;25:638-650.

26. Morselli PL. Clinical pharmacology of the perinatal period and early infancy. Clin Pharmacokinet. 1989;17 (Suppl. 1):13-28.

27. Dittert LW, Griffen WO, LaPiana JC, et al. Pharmacokinetic interpretation of penicillin levels in serum and urine after intravenous administration. Antimicrob Agents Chemother. 1969;9:42-48.

28. Nauta $\mathrm{EH}$, Mattie $\mathrm{H}$. Pharmacokinetics of flucloxacillin and cloxacillin in healthy subjects and patients on chronic intermittent haemodialysis. Br J Clin Pharmacol. 1975;2:111-121.

29. Cole M, Kenig MD, Hewitt VA. Metabolism of penicillins to penicilloic acid and 6-aminopenicillanic acid in man and its significance in assessing penicillin absorption. Antimicrob Agents Chemother. 1973;3:463-468.

30. Thijssen HHW, Mattie H. Active metabolites of isoxazolyl penicillins in humans. Antimicrob Agents Chemother. 1976;10:441-446.

31. Pullen J, Stolk LML, Nieman FHM, et al. Population pharmacokinetics and dosing of amoxicillin in (pre)term neonates. Ther Drug Monit. 2006;28:226-231.

32. Bowman $\mathrm{RH}$. Renal secretion of 35S-furosemide and its depression by albumin binding. Am $\mathrm{J}$ Physiol. 1975;229:93-98.

33. Notarianni LJ. Plasma protein binding of drugs in pregnancy and in neonates. Clin Pharmacokinet. 1990;18:20-36.

34. Ehrnebo M, Agurell S, Jalling B, et al. Age differences in drug binding by plasma proteins: studies on human foetuses, neonates and adults. Europ J Clin Pharmacol. 1971;3:189-193. 


\section{Chapter 6}

\section{Protein Binding of Flucloxacillin in Neonates}

Joyce Pullen, Leo M.L. Stolk, Pieter L.J. Degraeuwe, Frank H. van Tiel, Cees Neef, and Luc J.I. Zimmermann

Ther Drug Monit (in press) 


\section{Abstract}

The isoxazolyl penicillins, including flucloxacillin, have the highest levels of plasma protein binding among the semisynthetic penicillins. Since only the free fraction of the penicillin is pharmacologically active, it would be useful to measure both protein-bound and free flucloxacillin to determine its protein binding. Until now, flucloxacillin protein binding in newborn infants has been investigated in only two studies with relatively small populations. In the present study, flucloxacillin protein binding was investigated in 56 (preterm) infants aged 3 to 87 days (gestational age 25 to 41 weeks). Surplus plasma samples from routine gentamicin assays of each infant were collected and combined to obtain a sufficiently large sample for analysis. Free flucloxacillin was separated from protein-bound flucloxacillin using ultrafiltration. Reversed-phase HPLC with UV detection was used to measure free flucloxacillin concentrations in ultrafiltrate and total flucloxacillin concentrations in pooled plasma. Flucloxacillin protein binding was $74.5 \% \pm 13.1 \%$ (mean $\pm S D$ ) with a high variability among the infants (34.3\% to $89.7 \%)$. High Pearson correlations were found between protein binding and the covariates - plasma albumin concentration $(r=0.804, P<0.001, \mathrm{n}=18)$ and plasma creatinine concentration $(r=-0.601, P<0.001, \mathrm{n}=45)$. Statistically significant but less striking correlations were found between protein binding and gestational age, postconceptional age, body weight, and triglyceride concentration. Because of the high variability of protein binding among infants, it is difficult to devise a flucloxacillin dosage regimen effective for all infants. Individualized dosing, based on free flucloxacillin concentrations, might help to optimize treatment of late-onset neonatal sepsis, but practical obstacles will probably prevent analysis of free flucloxacillin concentrations in newborn infants on a routine basis. 


\section{Introduction}

Flucloxacillin is used frequently for the initial treatment of late-onset neonatal sepsis in Dutch hospitals, in spite of limited information about protein binding. ${ }^{1}$ In an earlier study, we investigated flucloxacillin population pharmacokinetics, flucloxacillin dosing, and the influence of covariates on the individual pharmacokinetic parameters in 55 (pre)term neonates. ${ }^{2}$ To evaluate the efficacy of the dosage regimen, the time the free (non-protein-bound) plasma concentration exceeded the minimum inhibitory concentration ( $T>M I C)$ was calculated. ${ }^{2} \mathrm{~A}$ dosage regimen, based on a T>MIC of at least $40 \%$, as advised in the literature ${ }^{3}$, was devised. Based on previous studies it was assumed that all neonates had a protein binding level of $86.3 \% .{ }^{4}$ However, there are many covariates that affect protein binding, including circulating substances (albumin, bilirubin, free fatty acids), disease, presence of other drugs, plasma volume, and gestational age (GA). ${ }^{5}$

The isoxazolyl penicillins, including flucloxacillin, have the highest levels of plasma protein binding among the semisynthetic penicillins. ${ }^{6}$ Plasma protein binding is the major factor determining extravascular penetration of antimicrobial agents into tissues. ${ }^{7}$ Zeitlinger et $\mathrm{al}^{8}$ showed a significant decrease in bacterial killing by penicillins after the addition of albumin, suggesting that only the free fraction of the penicillin is available for bacterial killing. Therefore, knowledge of the plasma protein binding of flucloxacillin and the covariates affecting its protein binding is essential for estimating the flucloxacillin dose required for effective treatment of late-onset neonatal sepsis.

Plasma protein binding of flucloxacillin has already been studied in healthy adults ${ }^{9-11}$, patients with pacemakers ${ }^{12}$, postpartum mothers ${ }^{13}$, and patients with impaired kidney function ${ }^{10}$. Protein binding values ranged from $91 \%$ in pacemaker patients ${ }^{12}$ to $95.7 \%$ in healthy adults ${ }^{9}$. In neonates, plasma protein binding of drugs is generally lower than in adults. ${ }^{5}$ In two studies, flucloxacillin protein binding was investigated in relatively small populations of newborn infants. Herngren et $\mathrm{al}^{4}$ found a mean protein binding value of $86.3 \%$ (range $82.7 \%$ to $89.7 \%$ ) in nine newborn infants aged 7.2 days (mean GA 36.6 weeks). In another study, plasma protein binding of flucloxacillin was determined in vitro by equilibrium dialysis in newborn infants at delivery and during their first postnatal week. ${ }^{13}$ Median protein binding values of $93.4 \%$ (range $90.5 \%$ to $95.8 \%$ ) and $88.6 \%$ (range $86.5 \%$ to $90.6 \%$ ) were reported in 22 infants immediately after delivery (mean GA 40.1 weeks) and in two infants during the first week ( $5^{\text {th }}$ to $7^{\text {th }}$ day) after delivery (mean GA 40.7 weeks), respectively. ${ }^{13}$ Free flucloxacillin was separated from protein-bound flucloxacillin using an ultrafiltration method ${ }^{9,11}$ or equilibrium dialysis $^{4,10,12,13}$. Protein binding values of flucloxacillin, as determined by equilibrium dialysis and ultrafiltration, are comparable. ${ }^{14}$ Flucloxacillin concentrations were measured with a microbiological assay ${ }^{4,9,11-13}$ or a more specific high-performance liquid chromatography (HPLC) method $^{10}$.

In this study, plasma protein binding of flucloxacillin was investigated in a large population of (preterm) infants, who were treated with flucloxacillin for (suspected) late-onset sepsis. Several covariates possibly affecting flucloxacillin protein binding were tested for significance and the implications for flucloxacillin dosing of variation in free-fraction were explored. 


\section{Materials and Methods}

\section{Patients}

The study was approved by the local Medical Ethical Committee. Plasma of fifty-six (pre)term infants was investigated. All infants had been admitted to the neonatal ward at the University Hospital of Maastricht and received flucloxacillin in combination with gentamicin for (suspected) late-onset sepsis.

\section{Sample Preparation of Non-Protein-Bound Flucloxacillin}

Free flucloxacillin was separated from protein-bound flucloxacillin in samples from 56 infants (Table 1) by ultrafiltration, using a Centrifree ${ }^{\circledR}$ micropartition device (Millipore Corporation, Bedford, MA) ${ }^{15}$ This system required a minimum plasma volume of $150 \mu \mathrm{L}$ for analysis. ${ }^{15}$ Unused portions of plasma samples from routine gentamicin assays were collected and combined for each infant to obtain a sufficiently large sample. $5.5 \pm 2.1$ plasma samples were collected per infant that had been obtained over a period of $3.4 \pm 1.3$ days (mean \pm SD). For more efficient flow rates, fibrin was first removed by centrifugation at $1780 \times g$ for 5 minutes at room temperature. Micropartition devices were then centrifuged at $4000 \mathrm{rpm}$ for 25 minutes at room temperature using a $33^{\circ}$ fixed-angle centrifuge rotor for optimum solvent flow.

\section{Assay of Free Flucloxacillin}

Flucloxacillin was provided by Synopharm (Barsbüttel, Germany). A stock solution of flucloxacillin (1000 mg/L) was freshly prepared on the day of analysis by dissolving $11 \mathrm{mg}$ sodium flucloxacillin in $10 \mathrm{~mL}$ water. This stock solution was diluted 10 fold with $0.9 \%$ saline solution to obtain the working solution $(100 \mathrm{mg} / \mathrm{L})$. Calibration standards were prepared by adding the required amount of working solution to $0.9 \%$ saline solution to obtain concentrations of 10 , $25,50,75$, and $100 \mathrm{mg} / \mathrm{L}$ of flucloxacillin. A quality control sample, containing $100 \mathrm{mg} / \mathrm{L}$ of flucloxacillin in plasma, was prepared and ultrafiltrated. The calibration standards, the ultrafiltrate of the quality control, and the ultrafiltrates of the infants, were directly injected $(25 \mu \mathrm{L})$ into a RP-HPLC with UV detection. ${ }^{2}$ Mean concentration of free flucloxacillin in the ultrafiltrates of the quality controls was $8.1 \pm 0.6 \mathrm{mg} / \mathrm{L}(\mathrm{n}=11)$ (mean $\pm \mathrm{SD})$. Thus, mean protein binding of flucloxacillin in quality control adult plasma was $91.9 \%$. Coefficient of variation was $7.8 \%$. The RP-HPLC assay was validated for linearity, precision, and accuracy. The correlation coefficients of the calibration curves $(n=6)$ were $>0.99$. To determine inter-day precision and accuracy, three concentrations of flucloxacillin $(0.5,1$, and $25 \mathrm{mg} / \mathrm{L})$ were prepared in blank neonatal ultrafiltrate and each of them was analyzed six times. Coefficients of variation were $14.0 \%, 9.3 \%$, and $3.3 \%$, respectively. Inaccuracy, measured at the three concentrations, was $<15 \%(+13.0 \%,-1.5 \%$, and $+3.2 \%$, respectively). The lowest free flucloxacillin concentration measured in the ultrafiltrates from infants was $0.6 \mathrm{mg} / \mathrm{L}$.

\section{Total Flucloxacillin Concentrations}

Analysis of total flucloxacillin concentrations in pooled plasma was performed as described previously. ${ }^{2}$ RP-HPLC with UV detection was used. The mobile phase consisted of perchlorate buffer and acetonitrile. Cloxacillin was used as internal standard and methylene chloride was used for extraction. 


\section{Protein Binding}

The binding of flucloxacillin to plasma proteins was determined using the following equation: $\left(C_{p}-C_{u}\right) / C_{p} \cdot 100 \%$, where $C_{p}$ and $C_{u}$ are the concentrations in plasma (total) and ultrafiltrate (free), respectively.

\section{Covariates Affecting Protein Binding}

Pearson correlation coefficients $(r)$ between flucloxacillin protein binding and covariates possibly affecting this protein binding were calculated with SPSS ${ }^{\circledR} 12.0$ (Chicago, IL), considering a $P$ value of $<0.05$ as being statistically significant. Covariates possibly affecting flucloxacillin protein binding were: plasma albumin concentration, unconjugated plasma bilirubin concentration, plasma concentration of free fatty acids, and plasma creatinine concentration. ${ }^{5,16}$ Unfortunately, the plasma concentration of free fatty acids was measured in only one infant. However, plasma triglyceride concentrations were measured in 38 infants. Pearson correlation coefficients were also calculated between protein binding and GA, postnatal age (PNA), postconceptional age (PCA), and body weight. Co-administered drugs with a high protein binding might also affect flucloxacillin protein binding. Therefore, complete concomitant medication of each infant was registered. One-way analysis of variance was used to test if the co-administered drugs with high protein binding had a significant influence on flucloxacillin protein binding. Because of the large number of missing values, mainly of plasma albumin concentration, regression analysis was not performed.

\section{Results}

\section{Patients}

The main characteristics of the infants are presented in Table 1. The population consisted of 30 boys (54\%) and 26 girls (46\%). In 53 infants ( 3 missing), blood cultures were taken. Twenty-six $(49 \%)$ of the 53 blood cultures were positive, most frequently with coagulase negative staphylococci (CoNS) $(77 \%)$.

Table 1. Demographic, Anthropometric, and Clinical Characteristics of 56 Infants

\begin{tabular}{lllll}
\hline & Unit & N & Mean (SD) & Range \\
GA & weeks & 55 & $31.2(4.7)$ & $25.0-41.4$ \\
PNA & days & 56 & $20.4(18.7)$ & $3-87$ \\
PCA & weeks & 55 & $34.1(4.6)$ & $27.7-42.7$ \\
Weight & $\mathrm{kg}$ & 56 & $1.63(0.83)$ & $0.67-3.90$ \\
Creatinine & $\mu \mathrm{mol} / \mathrm{L}$ & 45 & $57.3(26.8)$ & $20-139$ \\
Total bilirubin & $\mu \mathrm{mol} / \mathrm{L}$ & 33 & $95.7(50.7)$ & $3-193$ \\
Unconjugated bilirubin & $\mu \mathrm{mol} / \mathrm{L}$ & 13 & $68.1(51.7)$ & $7-163.6$ \\
Albumin & $\mathrm{g} / \mathrm{L}$ & 18 & $17.5(5.1)$ & $10.1-27.8$
\end{tabular}

GA, gestational age; PCA, postconceptional age; PNA, postnatal age; SD, standard deviation. 


\section{Protein Binding}

Free and total flucloxacillin plasma concentrations of all infants are illustrated in Figure 1. Plasma protein binding of flucloxacillin was $74.5 \% \pm 13.1 \%$ (mean \pm SD) (median $79.4 \%$ ) with a range of $34.3 \%$ to $89.7 \%$. The distribution of the free fraction of flucloxacillin among the infants is illustrated in Figure 2.

\section{Covariates Affecting Protein Binding}

Statistically significant Pearson correlation coefficients were found between flucloxacillin protein binding and plasma albumin concentration $(r=0.804, P<0.001, \mathrm{n}=18)$, plasma creatinine concentration $(r=-0.601, P<0.001, \mathrm{n}=45)$, body weight $(r=0.475, P<0.001, \mathrm{n}$ =56), PCA $(r=0.450, P=0.001, \mathrm{n}=55), \mathrm{GA}(r=0.374, P=0.005, \mathrm{n}=55)$, and plasma triglyceride concentration $(r=-0.326, P=0.046, \mathrm{n}=38)$. The relationship between flucloxacillin protein binding and plasma albumin concentration is shown in Figure 3 . The regression equation to predict flucloxacillin protein binding from plasma albumin concentration was: flucloxacillin protein binding $(\%)=23.05+2.58$ plasma albumin concentration $(\mathrm{g} / \mathrm{L})\left(r^{2}=\right.$ $0.647, n=18$ ). The standard error of the estimate (SEE), which is a measure of the accuracy of the predictions made with the regression line, was 9.92. The correlation between flucloxacillin protein binding and plasma creatinine concentration is presented in Figure 4. Fifteen infants received co-administered drugs with a protein binding $>90 \%$ (e.g. furosemide, hydrochlorothiazide/triamterene, and indometacin). We did not observe a significant difference in protein binding between these 15 infants and the other 41 infants.

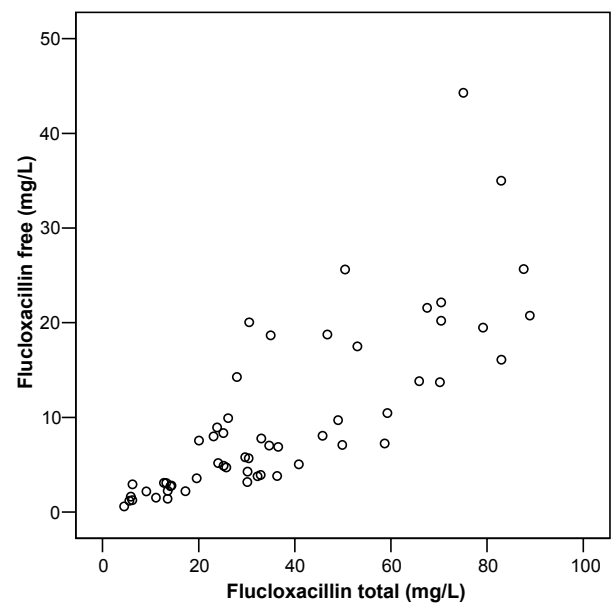

Figure 1. Free versus total flucloxacillin plasma concentrations of 56 infants. 


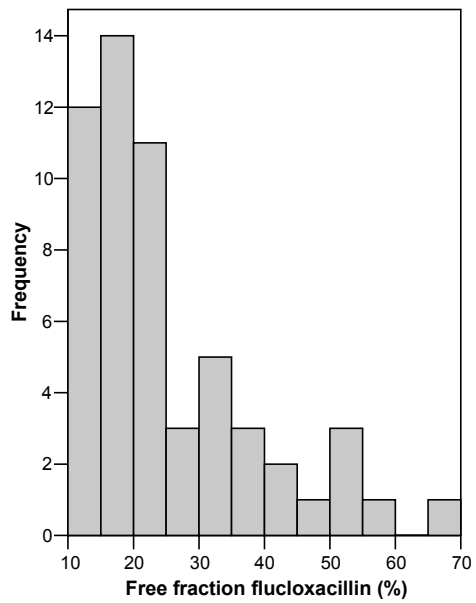

Figure 2. Distribution of free flucloxacillin among 56 infants.

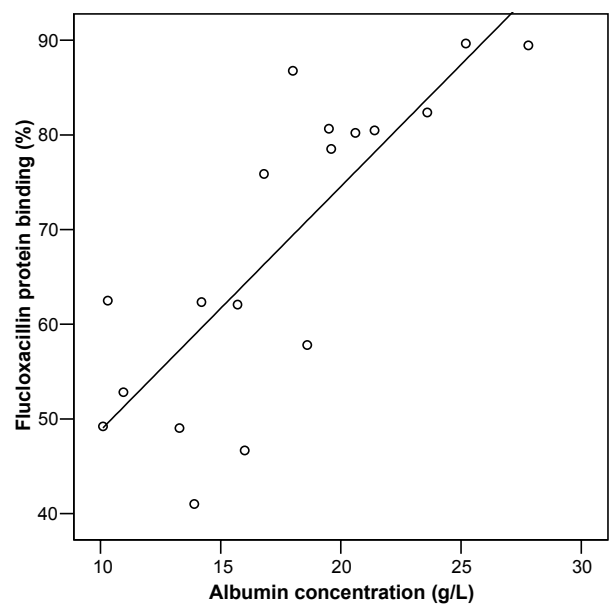

Figure 3. Correlation between flucloxacillin protein binding and plasma albumin concentration $(n=18)$. The equation of the regression line was $y=23.05+2.58 x$ and the coefficient of correlation was $0.804(P<0.001)$. 


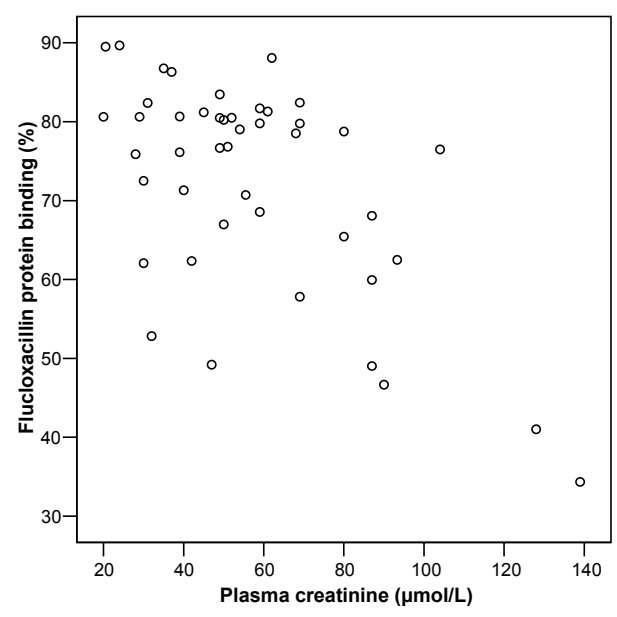

Figure 4. Correlation between flucloxacillin protein binding and plasma creatinine concentration $(n=45)$.

\section{Discussion}

In the present study, flucloxacillin has been shown to be highly bound to plasma proteins in neonates (median 79.4\%). However, even higher protein binding values were found by Herngren et al., ${ }^{413}$ The high inter-infant variability in protein binding found in the present study $(34.3 \%$ to $89.7 \%)$ and the differences between our results and the results reported by Herngren et al ${ }^{4,13}$ might be explained by difference in covariates affecting protein binding.

A highly significant relationship was found between the plasma protein binding of flucloxacillin and plasma albumin concentration $(r=0.804, P<0.001, \mathrm{n}=18)$. Herngren et $\mathrm{al}^{13}$ found a correlation coefficient of $0.612(P<0.01)$ between the molar concentration of plasma albumin and plasma binding ratio (bound flucloxacillin/unbound flucloxacillin) in 22 newborn infants. Mean plasma albumin concentration (17.5 g/L) measured in 18 of our 56 infants (mean GA 30.2 weeks, mean PNA 27.1 days) was somewhat lower than that generally seen in healthy infants of the same age. ${ }^{17}$ It should be noted that in our Neonatal Unit plasma albumin concentrations are only measured in sick infants suffering usually from oedema or liver dysfunction. Mean protein binding of these 18 infants was $68.2 \%$ and was considerably lower that the protein binding found by Herngren et $\mathrm{al}^{4,13}$, which may partly be explained by the difference in plasma albumin concentration, $17.5 \mathrm{~g} / \mathrm{L}$ versus $33 \mathrm{~g} / \mathrm{L}^{4}$ and $39.0 \mathrm{~g} / \mathrm{L}^{13}$.

We also noticed a significant relationship between flucloxacillin protein binding and plasma creatinine concentration $(r=-0.601, P<0.001, \mathrm{n}=45)$, as noted for phenytoin, theophylline, methotrexate and diazepam $(r=-0.87,-0.80,-0.79$, and -0.67 , respectively, $P<0.001)$ in chronic renal failure. ${ }^{16}$ This relationship supports earlier findings that endogenous acidic ligands, which accumulate in renal failure, act as binding inhibitors. These ligands are responsible for decreased plasma protein binding in renal failure of many acidic drugs, including the isoxazolyl penicillins. ${ }^{10,18-21}$ In addition, decreased drug binding in renal failure may be at least partly due to altered albumin composition. ${ }^{22}$ Moreover, the relationship between flucloxacillin protein binding and plasma creatinine concentration may partly be explained by 
the relationship between protein binding and GA, PCA, and body weight, since plasma creatinine concentration is inversely related to these parameters.

Two other endogenous compounds that may affect plasma protein binding of flucloxacillin in neonates are free fatty acids and unconjugated bilirubin. Unfortunately, the plasma concentration of free fatty acids was measured in only one infant. However, we found a significant relationship between flucloxacillin protein binding and plasma triglyceride concentration. Flucloxacillin protein binding decreased when the plasma concentration of triglyceride, which is split into glycerol and free fatty acids in the intestine, increased. Most neonates have high levels of unconjugated bilirubin in plasma, since bilirubin production is increased and bilirubin removal is decreased in the first weeks of life. ${ }^{5}$ Unconjugated bilirubin is capable of binding to plasma albumin. Isoxazolyl penicillins may displace bilirubin from albumin binding sites. ${ }^{4,23}$ Bilirubin itself may also displace drugs from their binding to albumin and thereby increase the free fraction of the drug. ${ }^{24}$ However, we did not find any relationship between flucloxacillin protein binding and unconjugated plasma bilirubin concentration. In contrast, a significant correlation between total (conjugated + unconjugated) bilirubin/albumin molar concentration ratio and flucloxacillin binding ratio (bound/unbound flucloxacillin) was reported by Herngren et al. ${ }^{4}$ We did not observe a significant correlation between total bilirubin/albumin ratio, which could be calculated for only 12 of our 56 infants, and flucloxacillin binding ratio. It should be noted that total bilirubin concentration varies considerably in the first few days/weeks of life. ${ }^{5}$ In most newborn infants, total plasma bilirubin concentration increases during the first week after birth and then decreases, because metabolic processes become more efficient in its removal. ${ }^{5}$ Mean total bilirubin concentration in our infants (mean PNA 16.5 days) was low compared to the concentration in the much younger infants (mean PNA 7.2 days) investigated by Herngren et $\mathrm{al}^{4}$ (95.7 versus $131 \mu \mathrm{mol} / \mathrm{L}$ ).

The plasma protein binding of flucloxacillin was also significantly correlated with GA, PCA, and body weight. Herngren et $\mathrm{al}^{4}$ also showed a significant correlation between flucloxacillin protein binding and GA. This may partly be explained by the quantitative and qualitative changes in plasma proteins during foetal and postnatal growth. ${ }^{25}$ Plasma albumin concentration and binding affinity increases with gestational and postnatal age. ${ }^{5}$ Moreover, plasma volume and, therefore, the absolute number of drug binding sites increase during gestational and postnatal growth. ${ }^{5} \mathrm{GA}$, PCA, and body weight of our population are lower than those of the populations investigated by Herngren et $\mathrm{al}^{4,13}$, which may partly explain the lower protein binding found in the present study.

In an earlier study, we investigated flucloxacillin population pharmacokinetics, flucloxacillin dosing, and the influence of covariates on the individual pharmacokinetic parameters in 55 (pre)term neonates. ${ }^{2}$ An initial flucloxacillin dose of $25 \mathrm{mg} / \mathrm{kg} / 4 \mathrm{~h}$ was suggested for all neonates. This initial dose should be either reduced to $10 \mathrm{mg} / \mathrm{kg} / 6 \mathrm{~h}$, when oxacillin sensitive CoNS are isolated, or maintained, when $S$. aureus is isolated. ${ }^{2}$ The free flucloxacillin fraction was assumed to be $13.7 \%$ in all neonates, based on the literature. ${ }^{4}$ Patient characteristics were comparable to the characteristics in this study, except for PNA (11.1 days versus 20.4 days). In the present study, the free flucloxacillin fraction was higher than $13.7 \%$ in most infants, but in nine infants it was lower than $13.7 \%$. To reach effective plasma concentrations in all infants, including those having a low free flucloxacillin fraction, the earlier suggested dosage regimens should probably be increased. However, higher doses may result in plasma concentrations exceeding the possibly toxic limit of $200 \mathrm{mg} / \mathrm{L} .{ }^{2}$ Thus, because of the high variability of protein binding among infants, caused by many covariates, it is difficult to 
devise a flucloxacillin dosage regimen effective for all infants. Individual measurement of the free flucloxacillin fraction would be beneficial in estimating the required dose, but methods for separating free and protein-bound drug are labour intensive and there are ethical and practical problems in obtaining a sufficiently large sample for analysis from newborn infants. ${ }^{5}$ Moreover, the literature ${ }^{5}$ indicates that newborns display a continuingly changing plasma composition, which might affect protein binding. Subsequently, frequent dosage adaptation is required in newborn infants. Perhaps, plasma albumin measurement could be helpful in predicting protein binding or use of alternative antibiotics could be considered.

\section{Conclusions}

Predicting flucloxacillin protein binding in newborn infants, aimed at optimal dosing of this drug, is very difficult, because many covariates affect protein binding. A high variability of flucloxacillin protein binding was demonstrated among 56 infants with (suspected) late-onset sepsis. Effective treatment with flucloxacillin should take this variability into account. Individualized dosing, based on free flucloxacillin concentrations, might help to optimize treatment of late-onset neonatal sepsis, but practical obstacles will probably prevent their analysis in newborn infants on a routine basis. We suggest further studies or efforts to develop an inexpensive and efficient test to measure free flucloxacillin concentrations in neonates.

\section{References}

1. Janknegt R. The treatment of staphylococcal infections with special reference to pharmacokinetic, pharmacodynamic and pharmacoeconomic considerations. Pharm World Sci. 1997;19:133-141.

2. Pullen J, Rozario de L, Stolk LML, et al. Population pharmacokinetics and dosing of flucloxacillin in preterm and term neonates. Ther Drug Monit. 2006;28:351-358.

3. Hoog de M, Mouton JW, Anker van den JN. New dosing strategies for antibacterial agents in the neonate. Semin Fetal Neonatal Med. 2005;10:185-194.

4. Herngren L, Ehrnebo M, Broberger U. Pharmacokinetics of free and total flucloxacillin in newborn infants. Eur J Clin Pharmacol. 1987;32:403-409.

5. Notarianni LJ. Plasma protein binding of drugs in pregnancy and in neonates. Clin Pharmacokinet. 1990;18:20-36.

6. Ullmann $U$. The binding of isoxazolyl penicillins to human serum proteins. Arzneimittelforschung. 1977;27:2136-2138.

7. Bergan T, Engeset A, Olszewski W. Does serum protein binding inhibit tissue penetration of antibiotics? Rev Infect Dis. 1987;9:713-718.

8. Zeitlinger MA, Sauermann $R$, Traunmüller $F$, et al. Impact of plasma protein binding on antimicrobial activity using time-killing curves. J Antimicrob Chemother. 2004;54:876-880.

9. Røder BL, Frimodt-Møller N, Espersen F, et al. Dicloxacillin and flucloxacillin: pharmacokinetics, protein binding and serum bactericidal titers in healthy subjects after oral administration. Infection. 1995;23:107-112.

10. Thijssen HHW, Wolters J. The metabolic disposition of flucloxacillin in patients with impaired kidney function. Eur J Clin Pharmacol. 1982;22:429-434.

11. Sutherland R, Croydon EAP, Rolinson GN. Flucloxacillin, a new isoxazolyl penicillin, compared with oxacillin, cloxacillin, and dicloxacillin. Br Med J. 1970;4:455-460.

12. Anderson $\mathrm{P}$, Bluhm G, Ehrnebo M, et al. Pharmacokinetics and distribution of flucloxacillin in pacemaker patients. Eur J Clin Pharmacol. 1985;27:713-719.

13. Herngren L, Ehrnebo M, Boréus LO. Drug distribution in whole blood of mothers and their newborn infants. Eur J Clin Pharmacol. 1982;22:351-358.

14. Craig WA, Suh B. Protein binding and the antimicrobial effects: methods for the determination of protein binding. In: Lorian V, editor. Antibiotics in Laboratory Medicine. 2nd ed. Baltimore: Williams \& Wilkins; 1986: 500-504. 
15. Millipore Corporation. Centrifree ${ }^{\circledR}$ Micropartition Devices For In Vitro Diagnostic Use and MPS Micropartition Devices Not for Use in Diagnostic Procedures. Available at: http://www.millipore.com/userguides.nsf/docs/p36146.

16. Vanholder R, Landschoot van N, Smet de R, et al. Drug protein binding in chronic renal failure: evaluation of nine drugs. Kidney Int. 1988;33:996-1004.

17. Cartlidge PHT, Rutter N. Serum albumin concentrations and oedema in the newborn. Arch Dis Child. 1986;61:657-660.

18. Depner TA, Gulyassy PF. Plasma protein binding in uremia: extraction and characterization of an inhibitor. Kidney Int. 1980;18:86-94.

19. Robertz GM, Dengler HJ. Endogenous ligand(s) decrease drug-protein binding in uremic sera: a fluorescence probe study. Klin Wochenschr. 1983;61:649-653.

20. McNamara PJ, Lalka D, Gibaldi M. Endogenous accumulation products and serum protein binding in uremia. J Lab Clin Med. 1981;98:730-740.

21. Gulyassy PF, Bottini AT, Stanfel LA, et al. Isolation and chemical identification of inhibitors of plasma ligand binding. Kidney Int. 1986;30:391-398.

22. Boobis SW. Alteration of plasma albumin in relation to decreased drug binding in uremia. Clin Pharmacol Ther. 1977;22:147-153.

23. Friedman LA, Lewis PJ. The effect of semisynthetic penicillins on the binding of bilirubin by neonatal serum. Br J Clin Pharmacol. 1980;9:61-65.

24. Bratlid D. Pharmacologic aspects of neonatal hyperbilirubinemia. Birth Defects. 1976;12:184-191.

25. Ehrnebo M, Agurell S, Jalling B, et al. Age differences in drug binding by plasma proteins: studies on human foetuses, neonates and adults. Europ J Clin Pharmacol. 1971;3:189-193. 



\section{Chapter 7}

\section{Pharmacokinetics of Intravenous Rifampicin (Rifampin) in Neonates}

Joyce Pullen, Leo M.L. Stolk, Pieter L.J. Degraeuwe, Frank H. van Tiel, Cees Neef, and Luc J.I. Zimmermann

Ther Drug Monit 2006;28(5):654-661 


\section{Abstract}

Few reports have addressed neonatal rifampicin plasma concentrations and data on neonatal rifampicin pharmacokinetics are completely lacking. Therefore, plasma concentrations of rifampicin and its main metabolite 25-O-desacetylrifampicin (DES) were measured in 123 surplus plasma samples from routine vancomycin monitoring in 21 neonates using reversedphase HPLC. Rifampicin peak and trough plasma concentrations were $4.66 \pm 1.47 \mathrm{mg} / \mathrm{L}$ and $0.21 \pm 0.20 \mathrm{mg} / \mathrm{L}$, respectively, after a dose of $8.5 \pm 2.1$ (mean $\pm \mathrm{SD}$ ) $\mathrm{mg} / \mathrm{kg}$ per day. A significant linear relationship between rifampicin dose and peak plasma concentrations was found, but inter-patient variability was high. Pharmacokinetic parameters of rifampicin were calculated according to a one-compartment open model with iterative two-stage Bayesian fitting (MWMPARM 3.60, Mediware, The Netherlands). First-order elimination constant, volume of distribution corrected for weight, total body clearance corrected for weight (CL/W), and elimination half-life were $0.16 \pm 0.06 \mathrm{~h}^{-1}, 1.84 \pm 0.59 \mathrm{~L} / \mathrm{kg}, 0.28 \pm 0.11 \mathrm{Lkg}^{-1} \mathrm{~h}^{-1}$, and $4.9 \pm$ $1.7 \mathrm{~h}$, respectively. A high Pearson correlation was found between CL/W rifampicin and the covariates plasma creatinine and CL/W gentamicin of a preceding gentamicin treatment course, $r=0.728(\mathrm{n}=17)$ and $r=0.837(\mathrm{n}=12)$, respectively. DES was detected in each plasma sample. Therefore, rifampicin seems to be eliminated by both renal and metabolic pathways in neonates. In 8 study patients, plasma concentrations of rifampicin and DES were measured again after two weeks of therapy. CL/W rifampicin was significantly higher $(67 \% \pm 50 \%)$. The authors suggest maintaining the current dose regimen of $10 \mathrm{mg} / \mathrm{kg}$ once a day. Because of the large inter-patient variability in rifampicin plasma concentrations and $\mathrm{CL} / \mathrm{W}$ increase during therapy, the authors suggest monitoring rifampicin peak and trough plasma concentrations to avoid low plasma concentrations. More research is needed to determine well-founded dosing guidelines. 


\section{Introduction}

The initial antibiotic choice in suspected late-onset neonatal infections depends on the local susceptibility patterns. In most Dutch hospitals, flucloxacillin, in combination with gentamicin, is used for this indication. ${ }^{1}$ After isolation of the causative agent of infection, antibiotic choice ought to be reconsidered based on the expected or determined susceptibility pattern of the isolate. Flucloxacillin is used for the treatment of infections caused by methicillin-susceptible staphylococci, whereas vancomycin is the drug of choice for infections caused by methicillinresistant coagulase negative staphylococci (CoNS), mainly Staphylococcus epidermidis. ${ }^{2}$ However, some neonates do not respond to treatment with vancomycin. ${ }^{2}$ The addition of rifampicin is a safe and effective option in the treatment of these persistent staphylococcal infections in neonates. ${ }^{2-5}$ However, rifampicin and vancomycin have been shown to be synergistic, indifferent, or antagonistic, depending on the rifampicin concentration. Rifampicin and vancomycin seem to be antagonistic when the concentrations of rifampicin are high.,

Rifampicin has a wide spectrum of antibacterial activity and is the most active antistaphylococcal agent known. ${ }^{4}$ Rifampicin is highly soluble in lipids and has the unique ability to penetrate phagocytic leukocytes and kill intracellular staphylococci. ${ }^{8}$ Plasma protein binding of rifampicin in adults is about $80 \% .{ }^{9}$ Rifampicin cannot be used as monotherapy because resistance may develop during therapy. ${ }^{10}$

Several studies have investigated the pharmacokinetics of IV rifampicin in children ${ }^{11,12}$ and adults. ${ }^{13-15}$ In neonates, rifampicin pharmacokinetics have not been studied yet. Only one small study investigated peak and trough plasma concentrations after IV rifampicin administration in four neonates (gestational age 30 to 40 weeks, mean 35 weeks). ${ }^{2}$ However, rifampicin pharmacokinetic parameters were not reported. Because very little is known about the pharmacokinetics of rifampicin in neonates, the current dosage regimen ${ }^{5}$ is based on pharmacokinetic data from studies in children and adults. Knowledge about neonatal rifampicin pharmacokinetics is essential for optimizing rifampicin dosing in neonates. Therefore, we have determined plasma concentrations of rifampicin in surplus plasma samples from routine vancomycin monitoring in 21 neonates, who received cotreatment with IV rifampicin and vancomycin for persistent staphylococcal bacteremia, in order to determine the pharmacokinetic parameters of rifampicin. We also investigated the influence of several demographic, anthropometric, and clinical covariates on the individual pharmacokinetic parameters of rifampicin.

\section{Materials and Methods}

\section{Patients}

The study was approved by the local Ethical Board. Twenty-one neonates, admitted to the neonatal ward at the University Hospital of Maastricht from July, 2002 through November, 2005, participated in the study. They were treated concurrently with IV rifampicin and vancomycin for persistent staphylococcal infections. To calculate the individual pharmacokinetic parameters of rifampicin, at least two surplus plasma samples from routine vancomycin assays of each neonate had to be available. Patient information concerning gestational age (GA), postnatal age (PNA), postconceptional age (PCA), birth weight (BW), body weight (W), gender, multiple pregnancy (P), 1-minute Apgar score (AP1), 5-minute Apgar score (AP5), 
plasma creatinine $(\mathrm{Cr})$, plasma urea concentration (Ur), C-reactive protein (CRP), and blood culture result $(\mathrm{BC})$ was obtained from patient records.

\section{Demographic, Anthropometric, and Clinical Characteristics}

The demographic, anthropometric, and clinical characteristics of the neonates are described in Table 1. Of the eight patients who were treated with rifampicin for more than two weeks, GA and PNA were $28.4 \pm 2.3$ weeks and $24.8 \pm 15.9$ days (at the beginning of the rifampicin therapy), respectively. Seven neonates (33\%) were immature (GA $<28$ weeks) and 12 neonates $(57 \%)$ were premature $(28 \leq \mathrm{GA}<37$ weeks). These 19 preterm neonates had a low birth weight $(<2500 \mathrm{~g})$ and 18 of them had a very low birth weight $(<1500 \mathrm{~g})$. Seventeen neonates $(81 \%)$ were male. Fourteen neonates $(67 \%)$ were products of singleton pregnancies and 7 neonates (33\%) were products of twin pregnancies. Seventeen out of the 19 blood cultures (89\%) (2 missing) were positive. In all cases, CoNS, including Staphylococcus epidermidis (41\%), were isolated.

Table 1. Demographic, Anthropometric, and Clinical Characteristics of the Neonates

\begin{tabular}{llllll}
\hline & Unit & $\mathbf{N}$ & Mean (SD) & Median (Percentile 25/75) & Range \\
GA & weeks & 21 & $29.9(4.1)$ & $28.6(26.9 / 31.5)$ & $26.0-41.3$ \\
PNA & days & 21 & $24.8(13.4)$ & $18.0(15.0 / 34.5)$ & $11-55$ \\
PCA & weeks & 21 & $33.5(5.0)$ & $31.4(30.4 / 36.2)$ & $28.3-48.0$ \\
BW & $\mathrm{kg}$ & 21 & $1.24(1.02)$ & $0.88(0.68 / 1.30)$ & $0.37-4.30$ \\
$\mathrm{~W}$ & $\mathrm{~kg}$ & 21 & $1.58(1.14)$ & $1.25(0.92 / 1.50)$ & $0.49-4.78$ \\
$\mathrm{AP1}$ & points & 21 & $6.6(2.9)$ & $8(5 / 9)$ & $0-9$ \\
$\mathrm{AP5}$ & points & 21 & $8.6(1.8)$ & $9(9 / 9)$ & $2-10$ \\
$\mathrm{Cr}$ & $\mu \mathrm{mol} / \mathrm{L}$ & 17 & $52.1(13.4)$ & $52.0(42.5 / 58.0)$ & $33.0-85.0$ \\
$\mathrm{Ur}$ & $\mathrm{mmol} / \mathrm{L}$ & 17 & $3.5(2.6)$ & $2.7(1.9 / 5.3)$ & $0.4-11.1$ \\
$\mathrm{CRP}$ & $\mathrm{mg} / \mathrm{L}$ & 20 & $74.7(45.8)$ & $62.0(38.3 / 116.8)$ & $2.9-158.0$ \\
\hline
\end{tabular}

AP1, 1-minute Apgar score; AP5, 5-minute Apgar score; BW, birth weight; Cr, plasma creatinine level; CRP, Creactive protein; GA, gestational age; PCA, postconceptional age; PNA, postnatal age; SD, standard deviation; Ur, plasma urea concentration; W, body weight.

\section{Drug Administration and Sample Collection}

Rifampicin was dosed at 5 to $10 \mathrm{mg} / \mathrm{kg}$ intravenously on a once-a-day schedule: $5 \mathrm{mg} / \mathrm{kg}$ ( $\mathrm{n}$ $=4), 7 \mathrm{mg} / \mathrm{kg}(\mathrm{n}=1), 9 \mathrm{mg} / \mathrm{kg}(\mathrm{n}=3)$, and $10 \mathrm{mg} / \mathrm{kg}(\mathrm{n}=12)$. One neonate received $5 \mathrm{mg} / \mathrm{kg}$ every 12 hours. Rifampicin was infused over 30 minutes using an electronic infusion pump. ${ }^{5}$ Neonates with a PCA of $<30,30$ to 33,34 to 37,38 to 44 , and $>44$ weeks received 20, 20, 20,15 , and $10 \mathrm{mg} / \mathrm{kg}$ vancomycin with an interval of $24,18,12,8$, and 6 hours, respectively. Vancomycin was infused over 60 minutes using an electronic infusion pump. ${ }^{5}$ Dosing times of vancomycin and rifampicin were different. Dosing times were recorded in the patient's medical record by nursing staff each time rifampicin and vancomycin were administered.

Twelve neonates were treated with a combination therapy of IV flucloxacillin and gentamicin for $4.5 \pm 2.3$ days (range 2 to 9 days) preceding rifampicin therapy. However, this combination therapy turned out to be unsuccessful in all 12 neonates and therapy with IV vancomycin was started. The other nine neonates were treated from the beginning with IV vancomycin. 
After $3.3 \pm 2.6$ days (range 0 to 8 days), IV rifampicin was added. The duration of the rifampicin course was $16.4 \pm 7.1$ days ( 4 to 29 days). After the addition of rifampicin, 14 out of the 17 positive blood cultures were sterile after $6.6 \pm 5.0$ days ( 1 to 16 days). The other three positive blood cultures also became sterile, but it was not known after how many days.

Therapeutic drug monitoring of vancomycin was performed on a routine basis. Plasma samples were drawn by heel prick just before and two hours after the end of the vancomycin infusion. Sampling times were recorded in the patient's medical record by nursing staff each time a blood sample was taken for vancomycin analysis. Surplus plasma samples from routine vancomycin assays were collected and frozen at $-70^{\circ} \mathrm{C}$ until the rifampicin assay was performed. Heparin was used as anticoagulant. We collected $5.9 \pm 3.0$ plasma samples per neonate during $3.7 \pm 1.8$ days (mean $\pm \mathrm{SD}$ ). Fourteen of the 21 neonates were treated with rifampicin for more than two weeks. Surplus plasma samples after 2 weeks of treatment were available for only 8 of these 14 neonates. In this second study period, we collected $5.9 \pm 2.6$ plasma samples per neonate during $3.4 \pm 1.6$ days.

\section{Chemicals}

Ammonium sulphate $\left(\left(\mathrm{NH}_{4}\right)_{2} \mathrm{SO}_{4}\right.$, CAS 7783-20-2), methanol $\left(\mathrm{CH}_{4} \mathrm{O}\right.$, CAS 67-56-1), and Titriplex ${ }^{\circledR}$ III $\left(\mathrm{C}_{10} \mathrm{H}_{14} \mathrm{~N}_{2} \mathrm{Na}_{2} \mathrm{O}_{8} \cdot 2 \mathrm{H}_{2} \mathrm{O}\right.$, CAS 6381-92-6) were obtained from Merck (Darmstadt, Germany). Rifampicin $\left(\mathrm{C}_{43} \mathrm{H}_{58} \mathrm{~N}_{4} \mathrm{O}_{12}\right.$, CAS 13292-46-1) was provided by Yamanouchi Pharma (Leiderdorp, The Netherlands) and its main metabolite, 25-O-desacetylrifampicin $\left(\mathrm{C}_{41} \mathrm{H}_{56} \mathrm{~N}_{4} \mathrm{O}_{11}\right)$, was a gift from Novartis Pharma (Arnhem, The Netherlands). Ultrapure water was used in all preparations. All chemicals were of HPLC grade. Human EDTA plasma for standard and control samples was provided by the Red Cross Blood Bank (Maastricht, The Netherlands).

\section{High-Performance Liquid Chromatography}

Rifampicin and 25-O-desacetylrifampicin plasma concentrations were measured with reversed-phase high-performance liquid chromatography (RP-HPLC). The RP-HPLC assay method was based on a method described by Chandi et al. ${ }^{16}$ The RP-HPLC system consisted of an automatic sample injector (model 717, Waters, USA), a pump (model 1050, Hewlett Packard, USA), a C18 symmetry column, 150 x $4.6 \mathrm{~mm}, 5 \mu \mathrm{m}$ (Waters, USA) combined with a C18 guard column, and an UV spectrophotometric detector (model 486, Waters, USA). The effluent was composed of $0.005 \mathrm{~mol} / \mathrm{L}$ disodium EDTA $\left(0.93 \mathrm{~g}\right.$ Titriplex $^{\circledR}$ III in 500 $\mathrm{mL}$ ultrapure water) and methanol (200:300). The separations were carried out at room temperature and at a flow rate of $1.0 \mathrm{~mL} / \mathrm{min}$. The detection was performed at a wavelength of $340 \mathrm{~nm}$. The assay error pattern was determined according to a method described in the literature. ${ }^{17}$ To determine the error pattern, we measured plasma samples at twelve concentration levels $(0.1,0.2,0.3,0.4,1,2,4,6,8,10,25$, and $50 \mathrm{mg} / \mathrm{L})$ on six separate days. The relationship between the measured plasma concentration and SD was fitted with a secondorder polynomial function. The error pattern of the rifampicin assay was: SD $=0.0173+$ $0.0455 \mathrm{C}+0.0002 \mathrm{C}^{2}$. The error pattern of the 25-O-desacetylrifampicin assay was: $\mathrm{SD}=$ $0.0561+0.0323 C+0.0005 C^{2}$. The lower limit of quantification (LLOQ) of rifampicin was 0.1 $\mathrm{mg} / \mathrm{L}$ and the LLOQ of $25-O-$-desacetylrifampicin was $0.4 \mathrm{mg} / \mathrm{L}$. The rifampicin and $25-O-$ desacetylrifampicin response at the LLOQ was at least 5 times the response compared to blank response and was identifiable, discrete, and reproducible with a precision of $<20 \%$ 
( $11 \%$ and $15 \%$, respectively) and accuracy of $80 \%$ to $120 \%$ (104\% and $112 \%$, respectively) according to guidelines in the literature. ${ }^{18}$

Ammonium sulphate $(10 \mu \mathrm{L}, 5 \%)$ and $80 \mu \mathrm{L}$ methanol were added to $40 \mu \mathrm{L}$ surplus plasma, and the solution was mixed for 1 minute. The solution was centrifuged at $10,500 \times g$ for 5 minutes. Following centrifugation, chromatography of the supernatant $(30 \mu \mathrm{L})$ was accomplished. Standard solutions, containing 2, 4, 6, 8, and $10 \mathrm{mg} / \mathrm{L}$ rifampicin and 25-Odesacetylrifampicin, were freshly prepared on the day of analysis. The standard plasma samples were processed in the same way as the surplus plasma samples. A calibration curve was constructed and concentrations of rifampicin and 25-O-desacetylrifampicin in surplus plasma samples were calculated. Control plasma samples, containing $5 \mathrm{mg} / \mathrm{L}$ rifampicin and $25-\mathrm{O}$-desacetylrifampicin, were prepared and stored in separate containers at $-70^{\circ} \mathrm{C}$ until analysis.

\section{Validation}

The RP-HPLC assay method was validated for linearity, precision, and accuracy. The correlation coefficient of the calibration curves was $>0.99(n=6)$. Inter-day precision and inaccuracy, measured at $2,4,6,8$, and $10 \mathrm{mg} / \mathrm{L}(\mathrm{n}=6)$, were $<10 \%$ and $<5 \%$, respectively, for both rifampicin and 25-O-desacetylrifampicin.

Rifampicin stability in plasma samples during storage at $-70^{\circ} \mathrm{C}$ was determined by analyzing the control plasma samples stored at $-70^{\circ} \mathrm{C}$ in each run during the entire measurement period of approximately 2 months. We did not observe any decrease of rifampicin concentration. This has been found earlier by Peloquin. ${ }^{19}$ We also measured rifampicin plasma concentrations after 1, 2, 3, and 4 hours at room temperature (in the dark). We observed no loss under these conditions although Peloquin ${ }^{19}$ found rifampicin plasma extracts began to decay after approximately 4 hours at room temperature (under fluorescent ceiling lights). In each run, six standard plasma samples, one control plasma sample, and five surplus plasma samples were included. The duration of each run was about two hours. We checked rifampicin stability during the run by analyzing one control plasma sample at the beginning of the run and one control plasma sample at the end of the run after approximately two hours. We did not see any difference in rifampicin concentration between the two control plasma samples.

\section{Data Analysis}

The individual pharmacokinetic parameters of rifampicin and vancomycin were calculated by maximum a posteriori Bayesian fitting (MWIPHARM 3.60, Mediware, The Netherlands). The population pharmacokinetic parameters were calculated with an iterative two-stage Bayesian fitting procedure (IT2B) (MWIPHARM 3.60). The Bayesian method uses measured drug concentrations, population-based parameters, and the expected variability associated with each measurement to determine individualized pharmacokinetic parameters of a patient. ${ }^{20}$ Analysis took place according to a one-compartment open model. The initial pharmacokinetic parameters of rifampicin, $\mathrm{K}_{\mathrm{el}} 0.10 \pm 0.05 \mathrm{~h}^{-1}$ and V/W $1.60 \pm 0.80 \mathrm{~L} / \mathrm{kg}$, were extrapolated from rifampicin pharmacokinetic data in adults. The initial pharmacokinetic parameters of vancomycin were derived from the study by de Beer et al. ${ }^{21}$ The population pharmacokinetic model was validated with Monte Carlo analysis. ${ }^{22,23}$ With the MWPHARM program, 100 sets of 21 simulated patients were generated, based on our own original 21 patients. The individual and population pharmacokinetic parameters of these 2100 simulated patients were calculated with iterative two-stage Bayesian fitting. The calculated individual pharmacokinetic parame- 
ters were compared with the 'real' (generated) individual pharmacokinetic parameters and the bias (mean error) and the root mean square error (RMSE) were determined. The smaller the bias and the RMSE, the better the performance of the model. Also, the calculated population pharmacokinetic parameters of the 2100 simulated patients were compared with the original population pharmacokinetic parameters.

We calculated peak (one hour after the beginning of the rifampicin infusion) and trough (just before the infusion) plasma concentrations of rifampicin after the second dose of each neonate in MWIPHARM 3.60, using the individual pharmacokinetic parameters.

Statistical analysis was performed using SPSS ${ }^{\circledR} 12.0$ (Chicago, IL). $P<0.05$ was considered to be statistically significant. The paired-samples $t$ test was used to investigate the differences between the individual pharmacokinetic parameters at the beginning of the rifampicin therapy and the individual pharmacokinetic parameters after two weeks of rifampicin therapy. While it is known that statistical evaluation of estimates such as pharmacokinetic parameter values is not nearly as accurate as that of direct observations, nevertheless the pairedsamples $t$ test was used. To investigate the influence of several demographic, anthropometric, and clinical covariates on the individual pharmacokinetic parameters of rifampicin, we calculated Pearson product-moment correlation coefficients. The investigated covariates were: GA, PNA, PCA, BW, W, gender, P, AP1, AP5, 1/Cr, Ur, CRP, BC, pharmacokinetic parameters of vancomycin, and pharmacokinetic parameters of gentamicin of a preceding gentamicin treatment course. Gentamicin clearance is an ideal exogenous marker for estimation of the glomerular filtration rate in neonates, since gentamicin is eliminated almost entirely by the kidney and gentamicin clearance can easily be calculated during routine therapeutic drug monitoring. ${ }^{24,25}$ One-way ANOVA was used to test if the factor variables (gender, $\mathrm{P}$, and $\mathrm{BC}$ ) had a significant effect on the individual pharmacokinetic parameters of rifampicin.

\section{Results}

\section{Plasma Concentrations}

We measured plasma concentrations of rifampicin and 25-O-desacetylrifampicin in 123 plasma samples. These plasma concentrations are plotted against the time after rifampicin administration in Figure 1. Calculated rifampicin peak and trough plasma concentrations after the second dose were $4.66 \pm 1.47 \mathrm{mg} / \mathrm{L}$ (range 2.06 to $6.87 \mathrm{mg} / \mathrm{L}$ ) and $0.21 \pm 0.20 \mathrm{mg} / \mathrm{L}$ (range 0.01 to $0.75 \mathrm{mg} / \mathrm{L}$ ), respectively, after a dose of $8.5 \pm 2.1 \mathrm{mg} / \mathrm{kg}$. A significant linear relationship between rifampicin dose and peak plasma concentrations was found $(r=0.556$, $P=0.009$ ), but inter-patient variability was high (Figure 2).

Plasma concentrations of rifampicin and 25-O-desacetylrifampicin were also measured after 2 weeks of rifampicin therapy in 8 neonates (Figure 3). Both rifampicin and 25-Odesacetylrifampicin concentrations were lower after two weeks of rifampicin therapy. 


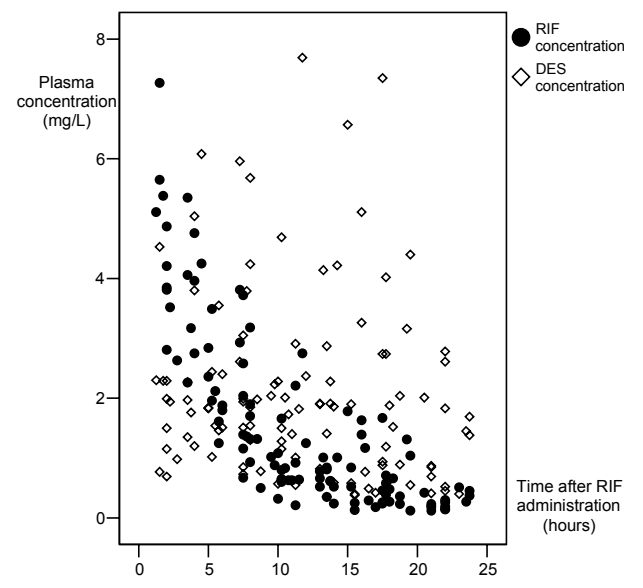

Figure 1. Plasma concentrations of rifampicin (RIF) and 25-O-desacetylrifampicin (DES) plotted against the time after rifampicin administration.

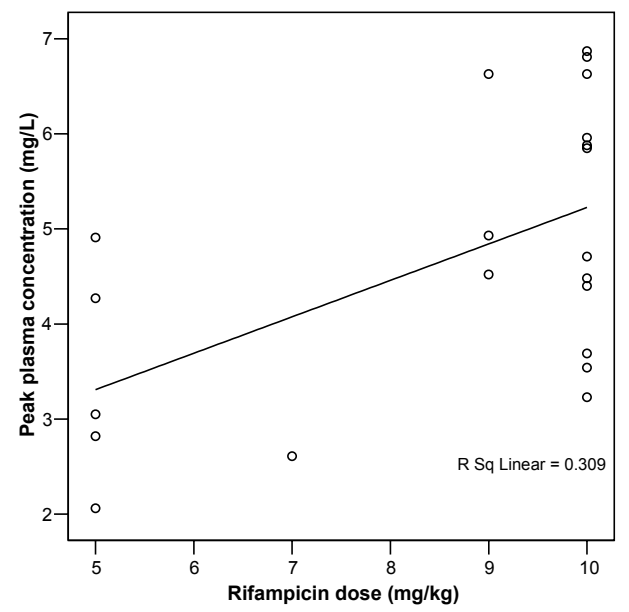

Figure 2. Rifampicin peak plasma concentrations after the second dose plotted against the rifampicin dose. 

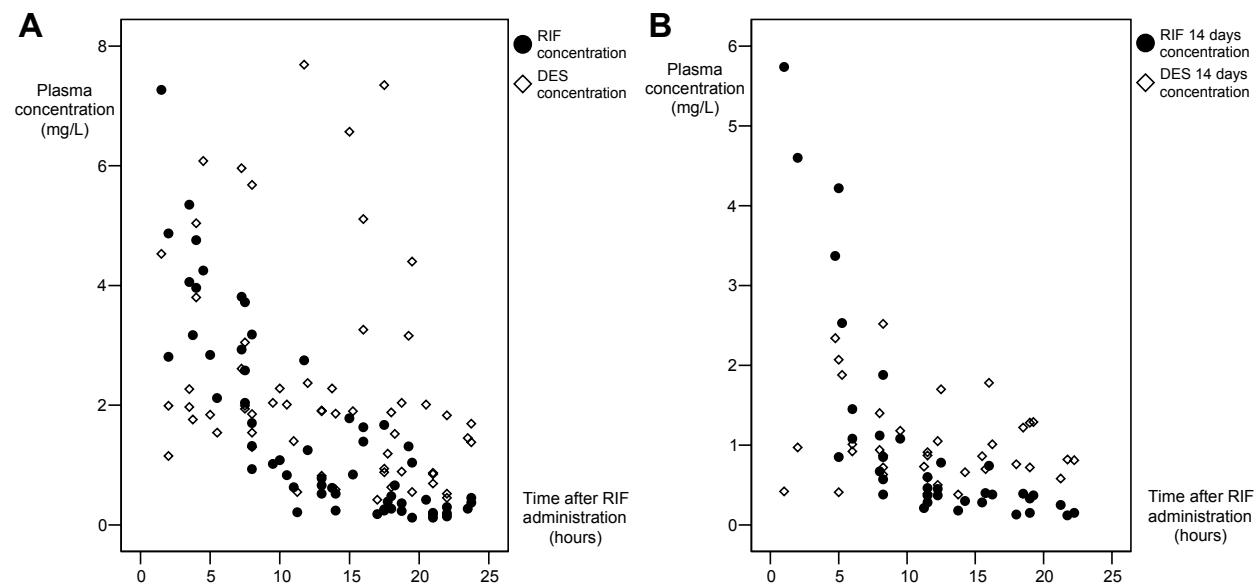

Figure 3. Plasma concentrations of rifampicin (RIF) and 25-O-desacetylrifampicin (DES) plotted against the time after rifampicin administration at the beginning of the rifampicin therapy $(A)$ and after two weeks of therapy (B) in eight study patients.

\section{Population Pharmacokinetic Parameters}

An example of a modelled concentration-time profile of a patient with iterative two-stage Bayesian fitting is shown in Figure 4. A plot of the actual measured concentrations versus the estimated concentrations with iterative two-stage Bayesian fitting is presented in Figure 5. Rifampicin first-order elimination constant $\left(\mathrm{K}_{\mathrm{el}}\right)$, volume of distribution corrected for body weight $(\mathrm{V} / \mathrm{W})$, total body clearance corrected for body weight $(\mathrm{CL} / \mathrm{W})$, and elimination half-life $\left(t^{1} / 2\right)$ were $0.16 \pm 0.06 \mathrm{~h}^{-1}, 1.84 \pm 0.59 \mathrm{~L} / \mathrm{kg}, 0.28 \pm 0.11 \mathrm{Lkg}^{-1} \mathrm{~h}^{-1}$, and $4.9 \pm 1.7 \mathrm{~h}$, respectively. The population pharmacokinetic parameters of rifampicin, estimated with Monte Carlo analysis $\left(K_{\text {el }} 0.1600 \pm 0.0562 \mathrm{~h}^{-1}\right.$ and $\left.V / W 1.7949 \pm 0.5998 \mathrm{~L} / \mathrm{kg}\right)$, were almost identical to the population pharmacokinetic parameters of our original population $\left(\mathrm{K}_{\mathrm{el}} 0.1592 \pm 0.0570 \mathrm{~h}^{-1}\right.$ and V/W $1.8425 \pm 0.5888 \mathrm{~L} / \mathrm{kg}$ ). The bias and the RMSE of the Monte Carlo analysis were low, $0.3 \%$ and $2.3 \%$, respectively, for $\mathrm{K}_{\mathrm{el}}$ rifampicin and $-1.6 \%$ and $4.3 \%$, respectively, for V/W rifampicin.

We also calculated the individual pharmacokinetic parameters of rifampicin after 2 weeks of rifampicin therapy in 8 of the 21 neonates. Mean pharmacokinetic parameters at the beginning of the rifampicin therapy, mean pharmacokinetic parameters after two weeks of rifampicin therapy, and the results of the paired-samples $t$ test of these eight neonates are presented in Table 2. The difference between CL/W rifampicin at the beginning and after 2 weeks of rifampicin therapy was statistically significant $(P=0.007 ; \mathrm{n}=8)$. CL/W rifampicin increased significantly $(67 \% \pm 50 \%)$. These results suggest that $C L / W$ rifampicin increases during the first two weeks of rifampicin therapy. 


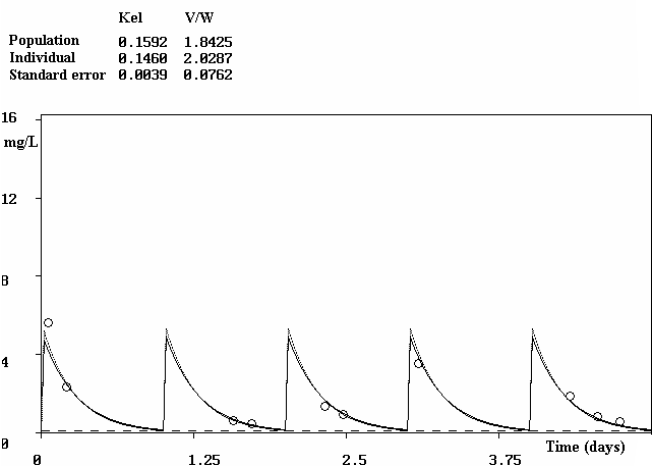

Figure 4. Example of a modelled concentration-time profile of a patient with iterative two-stage Bayesian fitting (MWIPHARM 3.60, Mediware, The Netherlands).

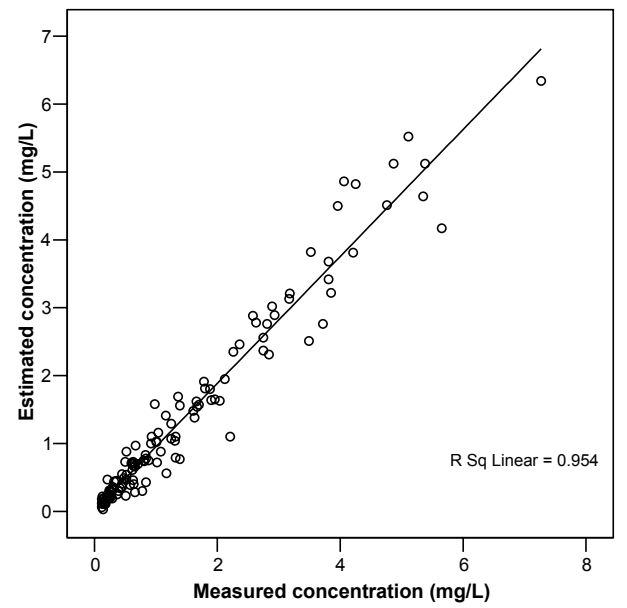

Figure 5. Correlation between rifampicin actual measured concentration and estimated concentration with iterative two-stage Bayesian fitting (MWIPHARM 3.60, Mediware, The Netherlands).

Table 2. Differences between Mean Pharmacokinetic Parameters at the Beginning and after Two Weeks of Rifampicin (RIF) Therapy $(n=8)$

\begin{tabular}{llll}
\hline $\begin{array}{l}\text { Pharmacokinetic } \\
\text { Parameter }\end{array}$ & Begin RIF Therapy & $\begin{array}{l}\text { After Two Weeks RIF } \\
\text { Therapy }\end{array}$ & Paired-Samples T Test \\
$\mathrm{K}_{\mathrm{el}}\left(\mathrm{h}^{-1}\right)$ & $0.13( \pm 0.06)$ & $0.18( \pm 0.06)$ & $-1.55(P=0.165)$ \\
$\mathrm{V} / \mathrm{W}(\mathrm{L} / \mathrm{kg})$ & $1.77( \pm 0.31)$ & $2.33( \pm 1.19)$ & $-1.30(P=0.236)$ \\
$\mathrm{CL} / \mathrm{W}\left(\mathrm{Lkg}^{-1} \mathrm{~h}^{-1}\right)$ & $0.22( \pm 0.07)$ & $0.36( \pm 0.15)$ & $-3.74(P=0.007)$ \\
$t^{1} / 2(\mathrm{~h})$ & $6.1( \pm 1.9)$ & $4.4( \pm 1.7)$ & $1.91(P=0.099)$
\end{tabular}

$\mathrm{CL}$, total body clearance; $\mathrm{K}_{\mathrm{el}}$, first-order elimination constant; $t^{1} / 2$, elimination half-life; $\mathrm{V}$, volume of distribution; $\mathrm{W}$, body weight. 


\section{Influence of Covariates on Individual Pharmacokinetic Parameters}

We found statistically significant Pearson correlations between CL/W rifampicin and the covariates CL/W gentamicin, 1/Cr, GA, PCA, CL/W vancomycin, BW, and W (Table 3). The highest correlations were found between $\mathrm{CL} / \mathrm{W}$ rifampicin and the covariates CL/W gentamicin and $1 / \mathrm{Cr}, r=0.837$ and $r=0.728$, respectively (Figure 6).

Table 3. Statistically Significant Pearson Correlations between the Individual Pharmacokinetic Parameters of Rifampicin (RIF) and the Demographic, Anthropometric, and Clinical Covariates

\begin{tabular}{|c|c|c|c|c|}
\hline & CL/W RIF & V/W RIF & $\mathrm{K}_{\mathrm{el}} \mathrm{RIF}$ & $t^{1} / 2$ RIF \\
\hline $\mathrm{CL} / \mathrm{W} / \mathrm{V} / \mathrm{W} / \mathrm{K}_{\mathrm{el}} / t^{1} / 2$ gentamicin $(\mathrm{n}=12)$ & $0.837^{\star *}$ & NS & NS & NS \\
\hline $1 / \mathrm{Cr}(\mathrm{n}=17)$ & $0.728^{* *}$ & NS & $0.506^{*}$ & $-0.580^{*}$ \\
\hline $\mathrm{GA}(\mathrm{n}=21)$ & $0.600^{* *}$ & $0.468^{*}$ & NS & NS \\
\hline $\operatorname{PCA}(n=21)$ & $0.557^{* *}$ & $0.477^{*}$ & NS & NS \\
\hline $\mathrm{CL} / \mathrm{W} / \mathrm{V} / \mathrm{W} / \mathrm{K}_{\mathrm{el}} / t^{1} / 2$ vancomycin $(\mathrm{n}=21)$ & $0.552^{* *}$ & NS & NS & $0.508^{*}$ \\
\hline$B W(n=21)$ & $0.510^{*}$ & $0.568^{* *}$ & NS & NS \\
\hline$W(n=21)$ & $0.449^{*}$ & $0.560^{* *}$ & NS & NS \\
\hline
\end{tabular}

BW, birth weight; CL, total body clearance; Cr, plasma creatinine level; GA, gestational age; $\mathrm{K}_{\mathrm{el}}$, first-order elimination constant; PCA, postconceptional age; $t \frac{1}{2}$, elimination half-life; $\mathrm{V}$, volume of distribution; $\mathrm{W}$, body weight; NS, not significant; ${ }^{*}$ correlation is significant at the 0.05 level (2-tailed); ${ }^{* *}$ correlation is significant at the 0.01 level (2-tailed).
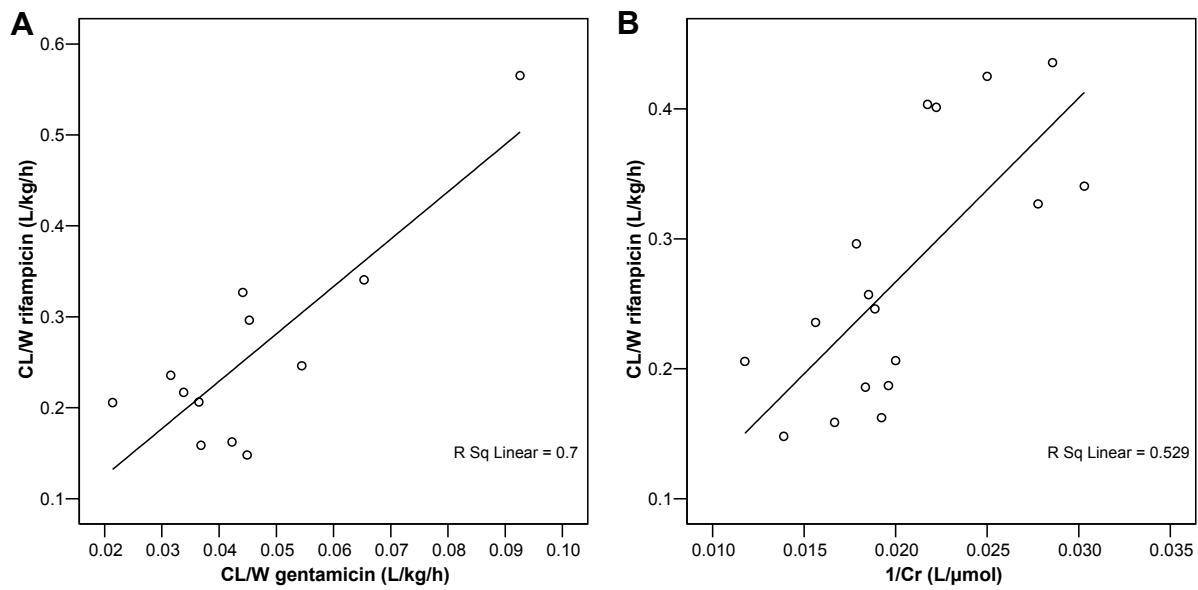

Figure 6. Correlation between total body clearance of rifampicin corrected for body weight (CL/W) and the covariates CL/W gentamicin $(n=12)(A)$ and 1/plasma creatinine $(1 / C r)(n=17)(B)$. 


\section{Discussion}

\section{Plasma Concentrations}

We calculated rifampicin peak and trough plasma concentrations after the second dose of each neonate. Rifampicin peak and trough plasma concentrations after IV rifampicin administration have been investigated earlier in neonates. Tan et $\mathrm{al}^{2}$ investigated peak and trough plasma concentrations in four neonates (GA 30 to 40 weeks, mean 35 weeks), who received $5 \mathrm{mg} / \mathrm{kg}$ rifampicin. Rifampicin peak concentration was $4.02 \pm 1.22 \mathrm{mg} / \mathrm{L}$ (range 3.13 to 5.82 $\mathrm{mg} / \mathrm{L}$ ). Five of our 21 neonates also received a rifampicin dose of $5 \mathrm{mg} / \mathrm{kg}$. Rifampicin peak concentration of these neonates was $3.42 \pm 1.15 \mathrm{mg} / \mathrm{L}$ (range 2.06 to $4.91 \mathrm{mg} / \mathrm{L}$ ). The plasma concentrations seem to be effective in the treatment of persistent staphylococcal bacteremia, since all blood cultures became sterile.

After two weeks of therapy rifampicin concentrations were lower than at the beginning of therapy. This might be explained by auto-induction of metabolism of the liver, which metabolizes rifampicin more rapidly to 25-O-desacetylrifampicin. ${ }^{4}$ However, 25-O-desacetylrifampicin concentrations were also lower after two weeks of rifampicin therapy. Probably, the elimination of 25-O-desacetylrifampicin also increases during rifampicin therapy. Mouton et $\mathrm{al}^{26}$ also found decreasing 25-O-desacetylrifampicin concentrations during therapy in adults. We did not observe any change in plasma creatinine after two weeks of rifampicin therapy. This suggests that the increase in the elimination of rifampicin and 25-O-desacetylrifampicin during rifampicin therapy is caused by an increase of non-renal clearance.

\section{Population Pharmacokinetic Parameters}

Pharmacokinetic data of rifampicin are only available of older children and adults. Koup et $\mathrm{al}^{12}$ and Nahata et $\mathrm{al}^{11}$ both investigated the pharmacokinetics of IV rifampicin in older pediatric patients. Koup et $\mathrm{al}^{12}$ studied 12 pediatric patients aged 3 months to 12.8 years (mean 4.6 years). $\mathrm{K}_{\mathrm{el}}, \mathrm{V} / \mathrm{W}, \mathrm{CL} / \mathrm{W}$, and $t^{1} / 2$ of rifampicin were $0.37 \mathrm{~h}^{-1}, 0.63 \mathrm{~L} / \mathrm{kg}, 0.16 \mathrm{Lkg}^{-1} \mathrm{~h}^{-1}$, and 1.94 $\mathrm{h}$, respectively. Nahata et $\mathrm{al}^{11}$ investigated the pharmacokinetics of IV rifampicin in 9 pediatric patients aged 1 day to 18 years (mean 5.6 years), who received a single dose of rifampicin $(20 \mathrm{mg} / \mathrm{kg}) . \mathrm{K}_{\mathrm{el}}, \mathrm{V} / \mathrm{W}, \mathrm{CL} / \mathrm{W}$, and $t^{1} / 2$ of rifampicin were $0.25 \mathrm{~h}^{-1}, 1.1 \mathrm{~L} / \mathrm{kg}, 0.29 \mathrm{Lkg}^{-1} \mathrm{~h}^{-1}$, and $2.8 \mathrm{~h}$, respectively. In the present study, V/W was higher. This difference is possibly due to a larger total body water compartment in neonates compared to infants and older children. In the present study, $t^{1} / 2$ was longer and $K_{e l}$ lower. The elimination of rifampicin seems to be less efficient in neonates compared to infants and older children.

We compared the pharmacokinetic parameters of rifampicin at the beginning of the rifampicin therapy with the pharmacokinetic parameters after two weeks of therapy. Our results suggest that $\mathrm{CL} / \mathrm{W}$ rifampicin increases during the first two weeks of rifampicin therapy. This has been found earlier by other investigators in children and adults. ${ }^{9,12,14}$ Rifampicin induces its own metabolism (auto-induction) and, as a result, clearance increases markedly during the first two weeks of treatment. ${ }^{4}$ In adults, equilibrium is reached after one to two weeks of treatment, after which no more changes occur. ${ }^{27}$ Therefore, it seems prudent to consider adaptation of the rifampicin dose after two weeks of therapy in neonates. For future research, it would be useful to develop a one-compartment open model integrated with a correction for auto-induction in MWIPHARM. 


\section{Predictors of Individual Pharmacokinetic Parameters}

We investigated the influence of several demographic, anthropometric, and clinical covariates on the individual pharmacokinetic parameters of rifampicin. The correlation between CL/W rifampicin and the covariates CL/W gentamicin and $1 / \mathrm{Cr}$ was high. About $70 \%$ of the inter-patient variance in CL/W rifampicin could be explained by CL/W gentamicin and more than $50 \%$ could be explained by $1 / \mathrm{Cr}$. CL/W gentamicin and plasma creatinine are both predictors of the glomerular filtration rate in neonates. ${ }^{24,25}$ Therefore, we conclude that glomerular filtration rate plays an important role in the elimination of rifampicin in neonates. Holdiness ${ }^{28}$ reported that $37 \%$ of the rifampicin dose $(10 \mathrm{mg} / \mathrm{kg})$ was recovered in urine in the first 12 hours in neonates compared with $2.5 \%$ of the dose in older children. In each plasma sample, 25-O-desacetylrifampicin was found. Therefore, both non-renal clearance (metabolism) and renal clearance are involved in the elimination of rifampicin in neonates.

\section{Rifampicin Dosing}

It is not possible to provide a definite dosing scheme for rifampicin in neonates at this stage. Information about effective pharmacodynamics of rifampicin, the role of protein binding, the free-fraction, and pharmacodynamic interaction with coadministered vancomycin or flucloxacillin is insufficient at this moment. For now, we suggest maintaining the current dose regimen of $10 \mathrm{mg} / \mathrm{kg}$ intravenously on a once-a-day schedule, until more information is available. The rifampicin plasma concentrations achieved with this dose seem to be effective in the treatment of persistent staphylococcal bacteremia, since all blood cultures became sterile. It may be appropriate to shorten the dosing interval from 24 to 12 hours to avoid prolonged intervals of low plasma concentrations. Tan et $\mathrm{al}^{2}$ and Shama et $\mathrm{al}^{3}$ both found prompt clearance of persistent staphylococcal infections in neonates within only five days after the addition of rifampicin to vancomycin. In both studies, the neonates received rifampicin $(5 \mathrm{mg} / \mathrm{kg}$ and $10 \mathrm{mg} / \mathrm{kg}$, respectively) twice a day. More research is needed to determine well-founded dosing guidelines.

\section{Conclusions}

We suggest maintaining the current rifampicin dose regimen of $10 \mathrm{mg} / \mathrm{kg}$ on a once-a-day schedule, until information about effective pharmacodynamics of rifampicin, the role of protein binding and the free-fraction, and pharmacodynamic interaction with co-administered vancomycin or flucloxacillin is available. Because of the large inter-patient variability in rifampicin plasma concentrations and in CL/W increase during rifampicin therapy, we suggest monitoring of peak and trough plasma concentrations to avoid low plasma concentrations. More pharmacokinetic work is required to give a solid base for neonatal rifampicin dose guidelines.

\section{References}

1. Janknegt R. The treatment of staphylococcal infections with special reference to pharmacokinetic, pharmacodynamic and pharmacoeconomic considerations. Pharm World Sci. 1997;19:133-141.

2. Tan TQ, Mason EO, Ou C-N, et al. Use of intravenous rifampin in neonates with persistent staphylococcal bacteremia. Antimicrob Agents Chemother. 1993;37:2401-2406.

3. Shama A, Patole SK, Whitehall JS. Intravenous rifampicin in neonates with persistent staphylococcal bacteraemia. Acta Paediatr. 2002;91:670-673.

4. Hey E, Hall C. Neonatal Formulary. 4 ed. London: Blackwell BMJ Books; 2003. 
5. Young TE, Mangum B. Neofax®: A Manual of Drugs Used in Neonatal Care. 17th ed. Raleigh, North Carolina: Acorn Publishing; 2004.

6. Zinner SH, Lagast H, Klastersky J. Antistaphylococcal activity of rifampin with other antibiotics. J Infect Dis. 1981;144:365-371.

7. Acar JF, Goldstein FW, Duval J. Use of rifampin for the treatment of serious staphylococcal and gramnegative bacillary infections. Rev Infect Dis. 1983;5:502S-506S.

8. Mandell GL, Vest TK. Killing of intraleukocytic Staphylococcus aureus by rifampin: in-vitro and in-vivo studies. J Infect Dis. 1972;125:486-490.

9. Acocella G. Clinical Pharmacokinetics of Rifampicin. Clin Pharmacokinet. 1978;3:108-127.

10. Wehrli W. Rifampin: mechanisms of action and resistance. Rev Infect Dis. 1983;5:407S-411S.

11. Nahata MC, Fan-Havard P, Barson WJ. Pharmacokinetics, cerebrospinal fluid concentration, and safety of intravenous rifampin in pediatric patients undergoing shunt placements. Eur J Clin Pharmacol. 1990;38:515517

12. Koup JR, Williams-Warren J, Weber A, et al. Pharmacokinetics of rifampin in children. I. Multiple dose intravenous infusion. Ther Drug Monit. 1986;8:11-16.

13. Nitti V, Virgilio R, Patricolo MR, et al. Pharmacokinetic study of intravenous rifampicin. Chemotherapy. 1977;23:1-6

14. Loos U, Musch E, Jensen JC, et al. Pharmacokinetics of oral and intravenous rifampicin during chronic administration. Klin Wochenschr. 1985;63:1205-1211.

15. Peloquin CA, Jaresko GS, Yong C-L. Population pharmacokinetic modeling of isoniazid, rifampin, and pyrazinamide. Antimicrob Agents Chemother. 1997;41:2670-2679.

16. Chandi LS, Sijs van der IH, Guchelaar HJ. Bepaling van rifampicine en desacetylrifampicine [Determination of rifampicin and desacetylrifampicin]. Ziekenhuisfarmacie. 1998;14:71-72.

17. Dodge WF, Jelliffe RW, Zwischenberger JB, et al. Population pharmacokinetic models: effect of explicit versus assumed constant serum concentration assay error patterns upon parameter values of gentamicin in infants on and off extracorporeal membrane oxygenation. Ther Drug Monit. 1994;16:552-559.

18. US Food and Drug Administration. Guidance for Industry: Bioanalytical Method Validation. Rockville: Center for Drug Evaluation and Research (CDER); 2001.

19. Peloquin CA. Rifampin stability. Ther Drug Monit. 1998;20:450-451.

20. Proost JH, Meijer DKF. MWIPHARM, an integrated software package for drug dosage regimen calculation and therapeutic drug monitoring. Comput Biol Med. 1992;22:155-163.

21. Beer de EFG, Stolk LML, Degraeuwe PLJ, et al. Pharmacokinetics of vancomycin in (pre)term neonates and influence of covariates [abstract]. Br J Clin Pharmacol. 2002;54:555.

22. Mediware: Software for healthcare. Available at: http://www.mediware.nl.

23. Bonate PL. A brief introduction to Monte Carlo simulation. Clin Pharmacokinet. 2001;40:15-22.

24. Koren G, James A, Perlman M. A simple method for the estimation of glomerular filtration rate by gentamicin pharmacokinetics during routine drug monitoring in the newborn. Clin Pharmacol Ther. 1985;38:680-685.

25. Sonntag J, Prankel B, Waltz S. Serum creatinine concentration, urinary creatinine excretion and creatinine clearance during the first 9 weeks in preterm infants with a birth weight below $1500 \mathrm{~g}$. Eur J Pediatr. 1996;155:815-819.

26. Mouton RP, Mattie $\mathrm{H}$, Swart $\mathrm{K}$, et al. Blood levels of rifampicin, desacetylrifampicin and isoniazid during combined therapy. J Antimicrob Chemother. 1979;5:447-454.

27. Acocella G. Pharmacokinetics and metabolism of rifampin in humans. Rev Infect Dis. 1983;5:428S-432S.

28. Holdiness MR. Clinical pharmacokinetics of the antituberculosis drugs. Clin Pharmacokinet. 1984;9:511-544. 


\title{
Chapter 8
}

\section{Application of Artificial Neural Network Modeling to Predict Gentamicin Clearance in Neonates: \\ Preliminary Study}

\author{
Joyce Pullen, Nick M. van Rodijnen, Eric O. Postma, Leo M.L. Stolk, Cees Neef, and \\ Luc J.I. Zimmermann
}

Submitted for Publication 


\section{Abstract}

Artificial neural networks (ANNs) are powerful tools to study complex non-linear relationships. ANNs have successfully been applied to population pharmacokinetic data analysis. In the present study, the applicability of ANN for the prediction of gentamicin clearance in neonates from covariates was compared with multiple linear regression analysis. Data of the potential predictors gestational age (GA), postnatal age (PNA), gender, multiple pregnancy, plasma creatinine concentration, and C-reactive protein were collected from 325 neonates treated with gentamicin. Gentamicin clearance was calculated with Bayesian fitting using plasma concentrations derived from routine therapeutic drug monitoring. All but five patients were randomized and divided into 10 groups (folds) of 32 patients. Each fold served once as a validation set, while the remaining 9 folds and 5 cases (293 patients) were used to establish the linear regression and neural network model. Each model was validated with the corresponding validation set and gentamicin clearances in 320 patients were predicted. Various ANNs were tested, but a single-layer perceptron with a linear transfer function appeared to be the most accurate. The ANN was created, trained, and validated with the software package Matlab ${ }^{\circledR}$ (MathWorks, Natick, MA). Both ANN and linear regression identified GA, PNA, and plasma creatinine concentration as the most important predictors of gentamicin clearance and ANN. Predictive performance measures (median (squared) prediction error) were compared using the Wilcoxon matched paired test. Linear regression predictions were significantly less biased and more precise than ANN predictions. The results suggest that ANNs may be less useful for simple linear input-output relationships. The input-output relationship (linear or non-linear) should be taken into account when selecting between ANNs and linear regression for pharmacokinetic modeling. 


\section{Introduction}

Artificial neural networks (ANNs) are powerful tools to study complex multivariate non-linear relationships and have successfully been applied to population pharmacokinetic data analysis. ${ }^{1-4}$ Ritschel et al ${ }^{1}$ used ANNs to predict human pharmacokinetic parameters from a combination of physicochemical properties and animal pharmacokinetic parameters. Chow et $\mathrm{al}^{2}$ and Brier et $\mathrm{al}^{3}$ compared the predictive performance of ANNs with that of a standard population pharmacokinetic modeling program (NONMEM) for tobramycin plasma concentrations in pediatric patients and for gentamicin plasma concentrations in adult patients, respectively. They concluded that ANNs and NONMEM provided comparable predictions of plasma drug concentrations. Yamamura ${ }^{4}$ reviewed the clinical application of ANNs to predict plasma concentrations and pharmacokinetic parameters of aminoglycosides in severely ill patients. In general, the predictive performance of ANNs was shown to be superior to that of multiple linear regression analysis. ${ }^{4}$ However, the prediction of aminoglycoside clearance using plasma creatinine concentration by linear regression analysis was much better than the ANN prediction, suggesting that aminoglycoside clearance can be evaluated without complicated non-linear calculations. ${ }^{4}$

The strength of ANNs is that they do not assume a specific model. Instead, they learn to establish the input and output relationships from the data provided to them. ${ }^{2}$ ANNs do not require assumptions about the distribution of the data and inputs that are highly correlated can be used. ${ }^{3}$ Therefore, we investigated the applicability of ANN for the prediction of gentamicin clearance in 325 neonates. Predictive performance was compared with that of multiple linear regression analysis.

\section{Materials and Methods}

\section{Patient Characteristics}

In this study, we included 325 neonates admitted to the neonatal ward at the University Hospital of Maastricht between 1996 and 2005 and receiving gentamicin treatment. Patient gentamicin clearances corrected for weight (CL/W) were derived from routine therapeutic drug monitoring data collected for pharmacokinetic studies. ${ }^{5-7}$ Gentamicin clearance was calculated according to a one-compartment model with Bayesian fitting (MWPHARM 3.60, Mediware, The Netherlands). The following potential predictors of gentamicin clearance were collected from patient records: gestational age (GA), postnatal age (PNA), gender, multiple pregnancy, plasma creatinine concentration, and C-reactive protein (CRP). There were no missing values.

All 325 patients were randomized and divided into 10 groups (folds) of 32 patients, leaving 5 patients that were used only for modeling and not for validation. Each fold served once as a validation set, while the remaining 9 folds and 5 cases (293 patients) were used to establish the linear regression model and the neural network model (10-fold cross-validation). Consequently, gentamicin clearances in 320 patients were predicted.

\section{Multiple Linear Regression Analysis}

Multiple linear regression analysis was performed using SPSS ${ }^{\circledR} 12.0$ (Chicago, IL). CL/W gentamicin was checked for normal distribution with the Kolmogorov-Smirnov test. Pearson product-moment correlation coefficients were calculated between CL/W gentamicin and GA, 
PNA, plasma creatinine concentration, and CRP. One-way analysis of variance (ANOVA) was used to test whether gender and multiple pregnancy had a significant effect on CL/W gentamicin. Multiple linear regression analysis with forward selection and backward elimination techniques was performed with CL/W gentamicin as dependent variable. The significant variables, detected with one-way ANOVA and correlation analysis, were used as possible predictors. The significant predictors of CL/W gentamicin were used to establish a directeffects model. First-order interaction effects between the significant predictors were tested for significance by forced entering within a hierarchically constructed regression model. Discrete factors were entered as dummy variables. A $P$ value of $<0.05$ was considered to be statistically significant.

\section{Artificial Neural Network}

ANNs are inspired by biological principles of learning in neural networks. An ANN consists of several artificial neurons arranged in layers, i.e. input, hidden, and output layers. All neurons in one layer are connected to all neurons within the next layer. Each connection has a realvalued weight that specifies its strength. Input data used to predict the outcome are presented to the input layer and values are propagated from each neuron to every neuron in the next layer. Eventually, a result is delivered from the output layer. Initially, all connections are assigned random weights. The propagated output is compared to the true value, the socalled target output, and the difference between the two values (mean squared error) is fed back into the ANN (backpropagation of error), gradually changing the weights as to minimize the error ${ }^{8-10} A$ high mean squared error results in higher adjustment of the ANN weights than a low mean squared error (error minimization). In this way, the ANN is learning the relationships between the input data and results (supervised training). ${ }^{8}$ Once fully trained, the ANN can be applied to future cases where the outcome is unknown.

The ANN used for the prediction of CL/W gentamicin consisted of a plain (single-layer) perceptron without any hidden layers, which provided the best results compared to multilayer ANNs that can learn more complex input-output mappings (data not shown). The structure of this ANN is presented in Figure 1. The ANN was created, trained, and validated with the software package Matlab ${ }^{\circledR}$ (MathWorks, Natick, MA). The perceptron consisted of a linear transfer function that maps the values of the weighted input. It is also possible to use a nonlinear transfer function, but the linear transfer function performed better than a non-linear transfer function (data not shown). Before ANN training, the input variables were preprocessed. This pre-processing was done by normalization of the input and target values to a range between 0 and 1 . The error minimization, as described above, was combined with Bayesian regularization that varies the number of free parameters (weights) to prevent overfitting. ${ }^{11}$ Training terminated when the number of weights and error stabilized. After successful completion of training, the input data of the 32 patients in the validation set were presented to the input layer of the trained ANN and transformed into a predicted value of CL/W gentamicin. 
INPUT

Gestational Age
Postnatal Age
Gender
Multiple Pregnancy
Plasma Creatinine
C-Reactive Protein

OUTPUT

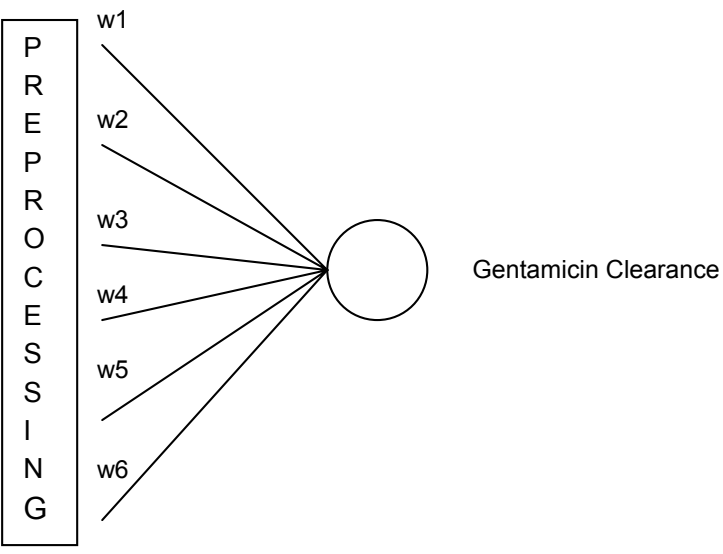

Figure 1. Artificial neural network (ANN) structure used for the prediction of gentamicin clearance in neonates. The circle represents the perceptron with linear transfer function and w1, w2, w3, w4, w5, and w6 represent the ANN input weights.

\section{Predictive Performance}

To evaluate the predictive performance of linear regression analysis and ANN, the mean prediction error (ME) (bias) and the mean squared prediction error (MSE) (precision) were used. ${ }^{12}$ The prediction error (PE) is a measure of the proximity of a predicted value to a true value (predicted value - true value). ${ }^{12}$ The ME and MSE should be presented as a mean value when (squared) PE's are normally distributed and as a median value when (squared) PE's are non-normally distributed. ${ }^{13}$ The property of distribution of (squared) PE's was determined using the Kolmogorov-Smirnov test. ${ }^{13}$ When PE's have both positive and negative signs, ME might not present the real bias of a predictive method, because positive and negative PE's can offset each other. ${ }^{13}$ Therefore, ME was divided into two parts: +ME (all positive PE's) and -ME (all negative PE's). ${ }^{13}$

Sheiner and Beal suggested evaluating the predictive performance between two predictive methods by observing whether the $95 \%$ confidence intervals for the relative performance measures ( $\triangle \mathrm{ME}$ and $\triangle \mathrm{MSE}$ ) include zero. ${ }^{12}$ However, when the number of samples is quite large and samples are non-normally distributed, it might be more convenient to use the Wilcoxon matched paired test, since the amount of calculation of the confidence intervals for a large number of non-normally distributed samples is discouraging. ${ }^{13}$ Therefore, the statistical measures of the predictive performance of linear regression analysis and ANN were compared using the Wilcoxon matched paired test. A $P$ value of $<0.05$ was considered to be statistically significant. 


\section{Results}

\section{Multiple Linear Regression Analysis}

Significant predictors of CL/W gentamicin were GA, PNA, and plasma creatinine concentration. Mean standardized beta coefficients, which represent the relative contribution of GA, PNA, and plasma creatinine concentration in the prediction of CL/W gentamicin, were 0.300 , 0.202 , and -0.496 , respectively.

\section{Artificial Neural Network}

The advantage of using a perceptron is that the learned weights represent the influence of each input variable on CL/W gentamicin. The ANN weights of GA, PNA, and plasma creatinine concentration were $0.192,0.267$, and -0.366 , respectively. The ANN weights of gender, multiple pregnancy, and CRP were $-0.009,-0.017$, and 0.072 , respectively.

\section{Predictive Performance}

The relationship between the true values of CL/W gentamicin calculated with Bayesian fitting and the predicted values of CL/W gentamicin from linear regression analysis and ANN is illustrated in Figure 2. The statistical measures of the predictive performance of linear regression analysis and ANN are summarized in Table 1. PE's and squared PE's of linear regression analysis and ANN were not normally distributed $(P<0.05$ and $P<0.001$, respectively). ANN resulted in significantly higher ME and MSE than linear regression analysis $(P<$ 0.001 and $P=0.008$, respectively).
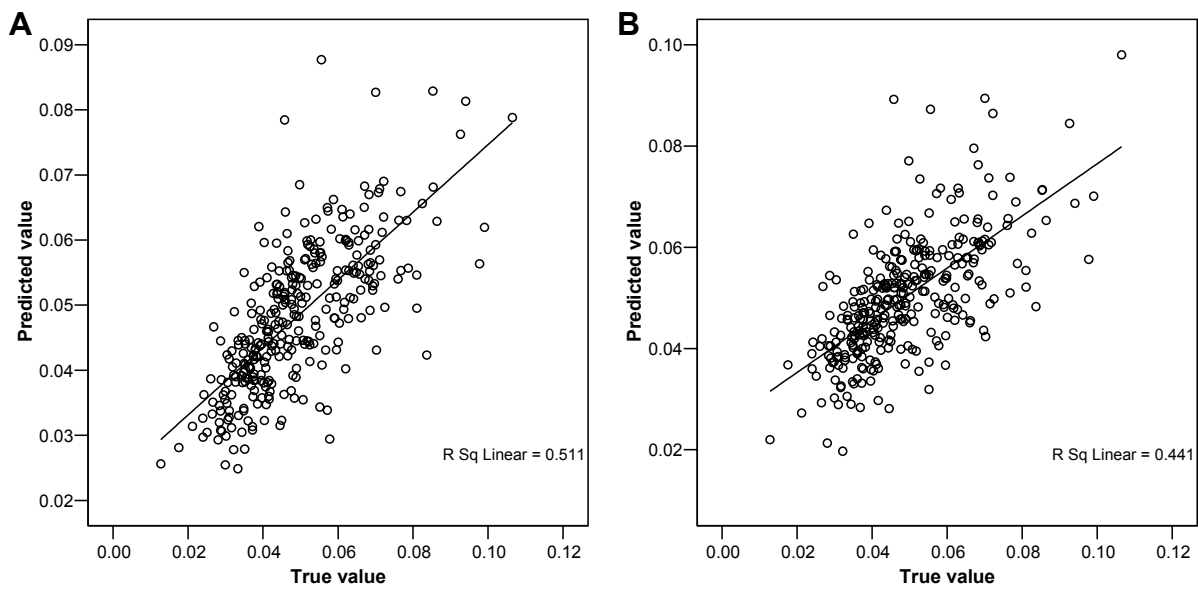

Figure 2. Plots of true values of gentamicin clearance $\left(\mathrm{Lkg}^{-1} \mathrm{~h}^{-1}\right)$ calculated with Bayesian fitting and predicted values of gentamicin clearance for multiple linear regression analysis $(A)$ and artificial neural network modeling (B). 
Table 1. Statistical Measures of Predictive Performance of Multiple Linear Regression Analysis and Artificial Neural Network (ANN) Modeling for Gentamicin Clearance $\left(\mathrm{Lkg}^{-1} \mathrm{~h}^{-1}\right)(\mathrm{n}=320$ neonates)

\begin{tabular}{lcc}
\hline & Linear Regression Analysis & ANN \\
True value calculated with Bayesian fitting & $0.0488^{*}$ & $0.0488^{*}$ \\
Predicted value & $0.0481^{*}$ & $0.0501^{*}$ \\
Median prediction error (ME) & $0.00123^{* *}$ & $0.00306^{\star *}$ \\
+ME & $0.00564(\mathrm{n}=174)^{\star *}$ & $0.00759(\mathrm{n}=194)^{\star *}$ \\
-ME & $-0.00799(\mathrm{n}=146)^{\star *}$ & $-0.00820(\mathrm{n}=126)^{\star *}$ \\
Median squared prediction error (MSE) & $0.00004^{* *}$ & $0.00006^{\star *}$ \\
\hline
\end{tabular}

*Mean; **Median.

\section{Discussion}

In the present study, gentamicin clearances in neonates were predicted by multiple linear regression analysis and ANN from patient data. Both methods indicated that GA, PNA, and plasma creatinine concentration were the most important predictors of gentamicin clearance, as expected from earlier studies. ${ }^{7,14,15}$ ANNs are often seen as a black box. ${ }^{10}$ The advantage of using a perceptron is that the ANN weights represent the influence of each predictor on gentamicin clearance. The disadvantage is that, in contrast to their multilayer counterparts, single-layer perceptrons with linear transfer function can only learn a linear mapping from input to output.

Multiple linear regression analysis showed better predictive performance than ANN for gentamicin clearance in neonates. Linear regression predictions of gentamicin clearance were significantly less biased and more precise than ANN predictions. Yamamura ${ }^{4}$ concluded from his review that the prediction of aminoglycoside clearance using plasma creatinine concentration by linear regression analysis was much better than the ANN prediction in severely ill patients. Our results support his idea that the clearance of aminoglycosides, including gentamicin, can be evaluated without complicated non-linear calculations. ${ }^{4}$ This idea may be reinforced by our finding that a perceptron with linear transfer function performed better than a perceptron with non-linear transfer function for the prediction of gentamicin clearance in our neonates. Moreover, the simplest ANN structure, a single-layer perceptron without any hidden layers, provided the best results compared to more complicate multilayer ANNs. The complexity of the transformation from input to output pattern is proportional to the number of hidden nodes. If the number of hidden nodes is too large for the transformation required, the ANN will exhibit suboptimal behaviour. ${ }^{10}$

In contrast, ANNs have successfully been used for the prediction of peak and trough plasma concentrations of aminoglycosides based on patient-related parameters, dosing regimens, time of blood drawn, and the resulting aminoglycoside plasma concentrations. ${ }^{2-4,16}$ ANNs may therefore be useful tools for population pharmacokinetic data analysis. However, our results suggest that ANNs may be less useful for simple linear input-output relationships. Therefore, the input-output relationship (linear or non-linear) should be taken into account when selecting between ANNs and multiple linear regression analysis for pharmacokinetic modeling. 


\section{Conclusions}

The relationship between gentamicin clearance and covariates, including GA, PNA, and plasma creatinine concentration, was linear. For modeling linear input-output relationships, statistical methods, such as linear regression analysis, are most suitable. Therefore, the input-output relationship (linear or non-linear) should be taken into account when selecting between ANNs and linear regression analysis for pharmacokinetic modeling. However, when the nature of the input-output relationship is not clear in advance, the predictive performance of ANNs and linear regression analysis should be compared.

\section{References}

1. Ritschel WA, Akileswaran R, Hussain AS. Application of neural networks for the prediction of human pharmacokinetic parameters. Methods Find Exp Clin Pharmacol. 1995;17:629-643.

2. Chow HH, Tolle KM, Roe DJ, et al. Application of neural networks to population pharmacokinetic data analysis. J Pharm Sci. 1997;86:840-845.

3. Brier ME, Zurada JM, Aronoff GR. Neural network predicted peak and trough gentamicin concentrations. Pharm Res. 1995;12:406-412.

4. Yamamura S. Clinical application of artificial neural network (ANN) modeling to predict pharmacokinetic parameters of severely ill patients. Adv Drug Del Rev. 2003;55:1233-1251.

5. Pullen J, Stolk LML, Nieman FHM, et al. Population pharmacokinetics and dosing of amoxicillin in (pre)term neonates. Ther Drug Monit. 2006;28:226-231.

6. Pullen J, Rozario de L, Stolk LML, et al. Population pharmacokinetics and dosing of flucloxacillin in preterm and term neonates. Ther Drug Monit. 2006;28:351-358.

7. Stolk LML, Degraeuwe PLJ, Nieman FHM, et al. Population pharmacokinetics and relationship between demographic and clinical variables and pharmacokinetics of gentamicin in neonates. Ther Drug Monit. 2002;24:527-531.

8. Mitchell TM. Machine Learning. New York: WCB/McGraw-Hill; 1997.

9. Rumelhart DE, Widrow B, Lehr MA. The basic ideas in neural networks. Commun ACM. 1994;37:87-92.

10. Jain AK, Duin RPW, Mao J. Statistical pattern recognition: a review. IEEE Trans Pattern Anal Mach Intell. 2000;22:4-37.

11. Mackay DJC. Bayesian interpolation. Neural Comp. 1992;4:415-447.

12. Sheiner LB, Beal SL. Some suggestions for measuring predictive performance. J Pharmacokinet Biopharm. 1981;9:503-512.

13. Wu G. Calculating predictive performance: a user's note. Pharmacol Res. 1995;31:393-399.

14. Koren G, James A, Perlman M. A simple method for the estimation of glomerular filtration rate by gentamicin pharmacokinetics during routine drug monitoring in the newborn. Clin Pharmacol Ther. 1985;38:680-685.

15. Rodvold KA, Gentry CA, Plank GS, et al. Prediction of gentamicin concentrations in neonates and infants using a Bayesian pharmacokinetic model. Dev Pharmacol Ther. 1993;20:211-219.

16. Corrigan BW, Mayo PR, Jamali F. Application of a neural network for gentamicin concentration prediction in a general hospital population. Ther Drug Monit. 1997;19:25-28. 


\section{Chapter 9}

General Discussion and Future Perspectives 


\section{Pharmacokinetics of Amoxicillin, Flucloxacillin, and Rifampicin}

Knowledge of the pharmacokinetic characteristics of an antibiotic is required for effective and safe antibiotic therapy. For lack of pharmacokinetic data of amoxicillin, flucloxacillin, and rifampicin in neonates, current dosage regimens are based on pharmacokinetic data obtained in relatively small numbers of neonates. Sometimes guidelines are extrapolated from data obtained in older children or even adults. The use of surplus plasma samples from routine gentamicin and vancomycin therapeutic drug monitoring made it possible to establish the pharmacokinetic parameters of amoxicillin, flucloxacillin, and rifampicin in newborn infants as described in the studies of this thesis. The pharmacokinetic results in this thesis confirm earlier described differences in drug disposition between neonates and adults. In this paragraph, the main pharmacokinetic results are discussed.

The distribution of amoxicillin, flucloxacillin, and rifampicin within the neonatal body appeared to be increased as compared to adults. This is mainly due to a relatively larger total body water compartment. In addition, the larger volume of distribution observed for all three antibiotics may partly be explained by their reduced binding to plasma proteins, as demonstrated in this thesis for flucloxacillin and to a limited extent for amoxicillin. Plasma protein binding is known to impair the antimicrobial activity of antibiotics. This is particularly relevant for highly protein-bound antibiotics, such as flucloxacillin and rifampicin, but not for low protein-bound amoxicillin. Median protein binding of flucloxacillin in neonatal plasma was nearly $80 \%$ with a high inter-patient variability, most of which could be explained by plasma albumin level. The extent and variability of rifampicin binding to plasma proteins in newborn infants should be subject to further investigation. The elimination of amoxicillin, flucloxacillin, and rifampicin from the body appeared to be reduced in the neonatal period. Glomerular filtration appeared to be an important elimination route for amoxicillin and rifampicin, but a minor route for flucloxacillin, as indicated by the correlation between antibiotic clearance and the covariates plasma creatinine level and gentamicin clearance. Plasma creatinine and gentamicin clearance both showed to be useful predictors of glomerular filtration rate (GFR). However, gentamicin clearance should be preferable to plasma creatinine for the prediction of amoxicillin clearance and/or GFR in the first two days after birth, since the correlation between amoxicillin clearance and plasma creatinine proved to be much lower than the correlation between amoxicillin clearance and gentamicin clearance during this period. Amoxicillin clearance and flucloxacillin clearance were both higher than gentamicin clearance, which suggests the presence of other elimination pathways in addition to glomerular filtration, such as tubular secretion. Metabolism may also play a role in flucloxacillin clearance and to a lesser extent in amoxicillin clearance as expected from data in adults. Amoxicillin and rifampicin clearance both correlated highly with gestational age (GA), which probably reflects the development of renal function, especially glomerular filtration. At birth, GFR is low, but the postnatal increase in glomerular perfusion pressure results in a progressive increase in GFR after birth. Amoxicillin clearance appeared to be two times higher in newborn infants aged $>9$ days compared to younger infants, mainly because of the postnatal increase in GFR, as indicated by the two times lower plasma creatinine level in the older population. In addition to glomerular filtration, metabolism of rifampicin into its main active metabolite 25-O-desacetylrifampicin seemed to be responsible for rifampicin clearance in newborn infants. Rifampicin clearance has been shown to be increased after two weeks of therapy, probably because of induction of its own metabolism. 


\section{Amoxicillin, Flucloxacillin, and Rifampicin Dosing}

Dosing of antibiotics should be based on a balance between maximal efficacy and minimal toxicity. Unfortunately, there is a lack of data on efficacy and toxicity of amoxicillin, flucloxacillin, and rifampicin in neonates. Until valuable data on efficacy are available, dosing of penicillins, including amoxicillin and flucloxacillin, should be based on the pharmacokinetic characteristics of the antibiotic in combination with the surrogate marker T>MIC, the time the free, non-protein-bound concentration remains above the minimum inhibitory concentration of the micro-organism, which should be at least $40 \%$ in neonates. Based on our acquired pharmacokinetic knowledge and the T>MIC, we conclude that currently used dosage regimens of flucloxacillin in neonates may result in ineffective therapy for Staphylococcus aureus. Despite the high variability in pharmacokinetics between neonates, predefined target concentrations seemed to be reached by increasing the dosing frequency and at the same time lowering the dose to ensure efficacy and safety of the flucloxacillin therapy. However, inter-patient variability in plasma protein binding turned out to be higher than initially thought, which makes effective and safe flucloxacillin therapy in neonates difficult. Measurement of free flucloxacillin levels is probably not a realistic option because of practical obstacles. Measuring plasma albumin levels might provide a solution, because of the high correlation between plasma albumin level and flucloxacillin protein binding. However, the predictive performance of plasma albumin for flucloxacillin protein binding still has to be investigated in a larger number of newborn infants. Also, the use of alternative antibiotics might be considered.

In contrast to flucloxacillin, currently used amoxicillin dosage regimens may result in neurotoxicity. However, it should be noted that, for lack of data on amoxicillin toxicity in neonates, the toxic limit has been selected based on few case reports in adults. As mentioned earlier, amoxicillin dosage regimens for newborn infants with (suspected) early-onset sepsis should differ from older infants. Initially, two dosage GA subgroups were recommended for amoxicillin dosing in neonates with (suspected) early-onset sepsis because of the high correlation between amoxicillin clearance and GA mentioned earlier. However, different dosage regimens could give rise to medication errors. Therefore, as an alternative regimen, we suggest an amoxicillin dose of $20 \mathrm{mg} / \mathrm{kg}$ every 8 hours for the effective and safe treatment of earlyonset neonatal infections easily reached by the antibiotic. Because of the postnatal increase in amoxicillin clearance, the amoxicillin dose should be increased to $40 \mathrm{mg} / \mathrm{kg}$ every 8 hours for the treatment of infectious diseases in older infants aged > 9 days. Increasing the dosing frequency in stead of increasing the dose could be an alternative, but might be less practical in clinical practice. Prospective validation of both dosage regimens still needs to be performed.

The acquired knowledge of the pharmacokinetic characteristics of rifampicin did not result in a definite dosage regimen. For effective and safe rifampicin dosing in newborn infants, further studies should focus on rifampicin pharmacodynamics and plasma protein binding. As expected from data in adults, plasma protein binding of rifampicin in neonates is probably high enough to have significant impact on bacterial killing. The currently used dosage regimen of rifampicin seemed to be effective in the treatment of persistent staphylococcal bacteremia, but our data suggest the necessity of dosage adjustment in case of prolonged therapy. 


\section{Future Perspectives}

As already mentioned in the general discussion, the following items should be object of further study in newborn infants:

- Prospective validation of amoxicillin dosage regimens;

- Predictive performance of plasma albumin level for flucloxacillin protein binding;

- Pharmacokinetics of rifampicin in a larger population;

- Extent and variability of rifampicin binding to plasma proteins;

- Pharmacodynamics of amoxicillin, flucloxacillin, and rifampicin using bacterial timekilling curves in the absence and presence of albumin. 
Summary

$\mathbf{s}$ 


\section{Introduction}

This thesis focuses on the pharmacokinetics and dosing of amoxicillin, flucloxacillin, and rifampicin in newborn infants. These antibiotics are used in the treatment of neonatal sepsis. Neonatal sepsis is a blood bacterial infection in neonates. Antibiotic therapy has to be started immediately in case of suspected neonatal sepsis, since neonatal sepsis is one of the most important causes of neonatal mortality. For safe and effective antibiotic therapy, knowledge of the pharmacokinetic characteristics of the antibiotic is required. Pharmacokinetics describes how drugs are absorbed, distributed, metabolized, and excreted by the body. Pharmacokinetics of drugs in neonates differ from those in adults, since physiologic processes that influence absorption, distribution, metabolism, and excretion of drugs are immature in the newborn infant. Therefore, a simple reduction of the adult dose may not be adequate to determine a safe and effective neonatal dose. The studies described in this thesis have been accomplished to establish the population pharmacokinetic parameters of amoxicillin, flucloxacillin, and rifampicin in neonates, in order to improve the safety and efficacy of these antibiotics in the neonatal period.

\section{Chapter 2}

This chapter describes the development and validation of the reversed-phase highperformance liquid chromatographic assays for the determination of amoxicillin, flucloxacillin, and rifampicin concentrations in neonatal plasma. These assays have been based on methods for adults and were made suitable for neonates by using smaller plasma volumes and smaller amounts of reagents. Because only small plasma volumes $(20-40 \mu \mathrm{L})$ are required for analysis, the assays are highly suitable for therapeutic drug monitoring and pharmacokinetic studies in (preterm) neonates. They have successfully been applied to the studies described in Chapters 3, 4, 5, 6, and 7.

\section{Chapter 3 and 4}

In Chapter 3 and 4, the population pharmacokinetic parameters of amoxicillin, established in 150 neonates with (suspected) early-onset sepsis (postnatal age $\leq 9$ days) and in 32 older infants (postnatal age $>9$ days), are presented. Amoxicillin is an aminopenicillin and is frequently used in combination with gentamicin in the treatment of early-onset neonatal sepsis and infectious diseases in older infants, for example necrotizing enterocolitis. Amoxicillin concentrations were determined in surplus plasma samples from routine gentamicin assays. These plasma concentrations were used to establish the population pharmacokinetic parameters. Mean total body clearance was $0.096 \mathrm{Lkg}^{-1} \mathrm{~h}^{-1}$, mean elimination half-life was 5.2 hours, and mean volume of distribution was $0.65 \mathrm{~L} / \mathrm{kg}$ in neonates aged $\leq 9$ days. However, in newborn infants aged $>9$ days mean total body clearance was higher $\left(0.18 \mathrm{Lkg}^{-1} \mathrm{~h}^{-1}\right)$ and mean elimination half-life was shorter (3.0 hours). Mean volume of distribution was approximately the same $(0.66 \mathrm{~L} / \mathrm{kg})$. In both studies, high correlations were found between amoxicillin clearance and gestational age, plasma creatinine concentration, and gentamicin clearance. Moreover, in newborn infants aged $>9$ days a very high correlation was found between amoxicillin clearance and postconceptional age (gestational age + postnatal age).

New dosage regimens were based on the pharmacokinetic characteristics of amoxicillin in combination with the surrogate marker $\mathrm{T}>\mathrm{MIC}$, the time the non-protein-bound (free) concentration remains above the minimum inhibitory concentration of the micro-organism. The 
T>MIC of amoxicillin should be at least $40 \%$ in neonates. The toxic limit selected was 140 $\mathrm{mg} / \mathrm{L}$, based on few case reports in adults. For neonates with (suspected) early-onset sepsis, we recommend a lower dose than currently used (20 mg/kg per 8 hours), since currently used dosage regimens might result in toxic plasma concentrations. Because of the higher amoxicillin clearance, we recommend a higher dose for older infants (40 mg/kg per 8 hours).

\section{Chapter 5 and 6}

Chapter 5 presents the population pharmacokinetic parameters of flucloxacillin, an isoxazolyl penicillin frequently used in combination with gentamicin in the treatment of late-onset neonatal sepsis. Flucloxacillin concentrations were determined in surplus plasma samples from routine gentamicin assays. Mean total body clearance was $0.18 \mathrm{Lkg}^{-1} \mathrm{~h}^{-1}$, mean elimination half-life was 2.6 hours, and mean volume of distribution was $0.54 \mathrm{~L} / \mathrm{kg}$ in 55 neonates with (suspected) late-onset sepsis.

Dosing of flucloxacillin should be based on the pharmacokinetic characteristics of flucloxacillin in combination with the T>MIC of the non-protein-bound (free) flucloxacillin concentration. Therefore, knowledge of the plasma protein binding of flucloxacillin is essential. Since flucloxacillin protein binding has been investigated in only small populations of neonates, we studied the protein binding in a large population of 56 neonates. Therefore, surplus plasma samples from routine gentamicin assays of each neonate were collected and combined to obtain a sufficiently large sample for analysis. Ultrafiltration was used to separate free flucloxacillin from protein-bound flucloxacillin. Mean flucloxacillin protein binding was $74.5 \%$ with a high variability among the neonates (34.3\%-89.7\%). For effective treatment with flucloxacillin, this variability should be taken into account. Due to this variability, a dosing schedule suitable for the whole population could not be formulated. Individualized dosing, based on free flucloxacillin concentrations, might help to optimize treatment of late-onset neonatal sepsis with flucloxacillin, but is probably not a realistic option because of practical obstacles. The high correlation between flucloxacillin protein binding and plasma albumin concentration suggests that plasma albumin measurement might be helpful to predict flucloxacillin protein binding in neonates.

\section{Chapter 7}

In Chapter 7, plasma concentrations and pharmacokinetic parameters of rifampicin after intravenous administration in 21 neonates are presented. Rifampicin is frequently used in combination with vancomycin in the treatment of persistent staphylococcal infections in neonates. Concentrations of rifampicin and its main active metabolite 25-O-desacetylrifampicin were determined in surplus plasma samples from routine vancomycin assays. Mean total body clearance was $0.28 \mathrm{Lkg}^{-1} \mathrm{~h}^{-1}$, mean elimination half-life was 4.9 hours, and mean volume of distribution was $1.84 \mathrm{~L} / \mathrm{kg}$. Rifampicin clearance was highly correlated with plasma creatinine concentration and gentamicin clearance during a preceding gentamicin treatment. Therefore, rifampicin seems to be eliminated by both renal and metabolic pathways in neonates. Plasma concentrations of rifampicin and 25-O-desacetylrifampicin were also determined after two weeks of rifampicin therapy in 8 neonates. In all neonates, rifampicin clearance was increased, probably because of induction of its own metabolism. Because of the relatively small population studied and lack of information about protein binding and pharma- 
codynamics of rifampicin, maintenance of conventional dosage policy is advised at this moment.

\section{Chapter 8}

Chapter 8 describes a preliminary study of the applicability of artificial neural networks (ANN) for the prediction of gentamicin clearance in neonates. Artificial neural networks can be used to model complex non-linear relationships between input and output data. In this study, a neural network was used to model the relationship between gentamicin clearance and several covariates, including gestational age, postnatal age, and plasma creatinine concentration, and to predict gentamicin clearance in 320 neonates. The predictive performance of the neural network was compared with that of multiple linear regression analysis. Linear regression predictions were significantly less biased and more precise than ANN predictions. Therefore, artificial neural networks seem to be less useful for simple linear relationships between input and output data.

\section{Chapter 9}

In this chapter, the pharmacokinetic results and the consequences for dosing are reviewed. Important challenges for future studies include prospective validation of the amoxicillin dosage regimens, evaluation of the predictive performance of plasma albumin for flucloxacillin protein binding, establishment of the pharmacokinetic parameters of rifampicin in a larger population of neonates, investigation of the extent and variability of rifampicin protein binding in neonates, and in particular study of the pharmacokinetic-pharmacodynamic relationships. 


\section{Samenvatting}




\section{Inleiding}

Dit proefschrift richt zich op de farmacokinetiek en dosering van amoxicilline, flucloxacilline en rifampicine bij pasgeboren. Deze antibiotica worden gebruikt bij de behandeling van neonatale sepsis. Neonatale sepsis is bloedvergiftiging (een infectie in de bloedbaan) bij neonaten. Aangezien neonatale sepsis één van de belangrijkste doodsoorzaken is bij neonaten, moet antibioticatherapie onmiddellijk gestart worden bij verdenking op neonatale sepsis. Voor een veilige en effectieve antibioticatherapie moet men kennis hebben van de farmacokinetische karakteristieken van het antibioticum. De farmacokinetiek beschrijft de wijze waarop geneesmiddelen door het lichaam worden geabsorbeerd, verdeeld, gemetaboliseerd en uitgescheiden. De farmacokinetiek van geneesmiddelen bij neonaten verschilt van die bij volwassenen vanwege de onrijpheid van de fysiologische processen die de absorptie, de distributie, het metabolisme en de uitscheiding van geneesmiddelen beïnvloeden. Een eenvoudige verlaging van de dosis voor volwassenen is daarom niet voldoende om te komen tot een veilige en effectieve dosis voor neonaten. De onderzoeken in dit proefschrift zijn uitgevoerd om de populatie farmacokinetische parameters van amoxicilline, flucloxacilline en rifampicine bij neonaten vast te stellen en zo de veiligheid en effectiviteit van deze antibiotica in de neonatale periode te vergroten.

\section{Hoofdstuk 2}

Dit hoofdstuk beschrijft de ontwikkeling en validatie van de zogenaamde reversed-phase hoge druk vloeistofchromatografische bepalingen, waarmee de concentraties van amoxicilline, flucloxacilline en rifampicine in het bloedplasma (bloedvloeistof zonder de bloedcellen) van pasgeborenen kunnen worden gemeten. Deze bepalingen zijn gebaseerd op methoden voor volwassenen en zijn geschikt gemaakt voor neonaten door gebruik te maken van kleinere hoeveelheden plasma en reageermiddelen. De bepalingen zijn zeer geschikt voor therapeutic drug monitoring (bloedspiegelbepalingen) en farmacokinetische onderzoeken bij (premature) pasgeborenen, aangezien slechts kleine hoeveelheden plasma (20-40 $\mu$ l) nodig zijn. Ze zijn met succes toegepast in de onderzoeken beschreven in Hoofdstuk 3 tot en met 7.

\section{Hoofdstuk 3 en 4}

In Hoofdstuk 3 en 4 worden de populatie farmacokinetische parameters van amoxicilline, die zijn vastgesteld bij 150 neonaten met (verdenking op) early-onset sepsis (postnatale leeftijd $\leq 9$ dagen) en bij 32 oudere pasgeborenen (postnatale leeftijd $>9$ dagen), gepresenteerd. Amoxicilline is een aminopenicilline en wordt regelmatig gebruikt in combinatie met gentamicine bij de behandeling van early-onset neonatale sepsis en infecties bij oudere pasgeborenen, bijvoorbeeld necrotiserende enterocolitis. De concentraties van amoxicilline werden bepaald in plasma dat resteerde na routine bepalingen van gentamicine. Met behulp van deze plasmaconcentraties werden de populatie farmacokinetische parameters vastgesteld. Bij neonaten $\leq 9$ dagen bedroeg de gemiddelde totale lichaamsklaring $0,096 \mathrm{Ikg}^{-1} \mathrm{~h}^{-1}$, de gemiddelde halfwaardetijd 5,2 uur en het gemiddeld verdelingsvolume 0,65 l/kg. Echter, bij pasgeborenen $>9$ dagen was de gemiddelde totale lichaamsklaring hoger $\left(0,18 \mathrm{lkg}^{-1} \mathrm{~h}^{-1}\right)$ en de gemiddelde halfwaardetijd korter (3,0 uur). Het gemiddelde verdelingsvolume was ongeveer hetzelfde $(0,66 \mathrm{l} / \mathrm{kg})$. In beide studies werd een sterke correlatie gevonden tussen de amoxicilline klaring en de zwangerschapsleeftijd, de plasmaconcentratie van creatinine en de 
gentamicine klaring. Daarnaast werd er bij pasgeborenen $>9$ dagen een heel sterke correlatie gevonden tussen de amoxicilline klaring en de postconceptionele leeftijd (zwangerschapsleeftijd + postnatale leeftijd).

Nieuwe doseerschema's werden gebaseerd op de farmacokinetische karakteristieken van amoxicillin in combinatie met de surrogaat marker T>MRC, de tijd dat de niet aan eiwit gebonden (vrije) concentratie de minimaal remmende concentratie van het micro-organisme overschrijdt. De T>MRC van amoxicilline moet bij neonaten ten minste $40 \%$ zijn. Als toxische grens werd $140 \mathrm{mg} / \mathrm{l}$ gekozen, gebaseerd op enkele case reports bij volwassenen. Voor neonaten met (verdenking op) early-onset sepsis adviseren wij een lagere dosis dan momenteel wordt gebruikt (20 mg/kg per 8 uur), aangezien de huidige doseerschema's zouden kunnen leiden tot toxische plasmaconcentraties. Voor oudere pasgeborenen adviseren wij een hogere dosis (40 mg/kg per 8 uur) in verband met de hogere amoxicilline klaring.

\section{Hoofdstuk 5 en 6}

Hoofdstuk 5 presenteert de populatie farmacokinetische parameters van flucloxacilline, een isoxazolyl penicilline, dat regelmatig gebruikt wordt in combinatie met gentamicine bij de behandeling van late-onset neonatale sepsis. De concentraties van flucloxacilline werden bepaald in plasma dat resteerde na routine bepalingen van gentamicine. De gemiddelde totale lichaamsklaring bedroeg $0,18 \mathrm{lkg}^{-1} \mathrm{~h}^{-1}$, de gemiddelde halfwaardetijd 2,6 uur en het gemiddelde verdelingsvolume $0,54 \mathrm{l} / \mathrm{kg}$ bij 55 neonaten met (verdenking op) late-onset sepsis.

De dosering van flucloxacilline moet gebaseerd worden op de farmacokinetische karakteristieken van flucloxacilline in combinatie met de $\mathrm{T}>\mathrm{MRC}$ van de niet aan eiwit gebonden (vrije) flucloxacilline concentratie. Het is daarom van essentieel belang dat men op de hoogte is van de eiwitbinding van flucloxacilline in het plasma. Aangezien de eiwitbinding van flucloxacilline alleen in kleine groepen neonaten is onderzocht, bestudeerden wij de eiwitbinding in een grote populatie van 56 neonaten. Daartoe werd van elke neonaat al het plasma dat resteerde na routine bepalingen van gentamicine verzameld en samengevoegd om zo voldoende plasma te verkrijgen voor de analyse. Met behulp van ultrafiltratie werd de vrije flucloxacilline concentratie gescheiden van de aan eiwit gebonden flucloxacilline concentratie. De gemiddelde eiwitbinding van flucloxacilline was $74,5 \%$ met een grote variabiliteit tussen de neonaten (34,3\%-89,7\%). Voor een effectieve behandeling met flucloxacilline moet men rekening houden met deze variabiliteit. Vanwege deze variabiliteit was het niet mogelijk een geschikt doseerschema te vinden voor de gehele populatie. Individuele dosering, gebaseerd op de vrije flucloxacilline concentraties, zou kunnen bijdragen aan het optimaliseren van de behandeling van late-onset neonatale sepsis met flucloxacilline, maar is waarschijnlijk geen realistische optie aangezien er praktische belemmeringen zijn. De sterke correlatie tussen de eiwitbinding van flucloxacilline en de plasmaconcentratie van albumine wijst erop dat het meten van het plasma albumine nuttig zou kunnen zijn bij het voorspellen van de eiwitbinding van flucloxacilline bij neonaten.

\section{Hoofdstuk 7}

In Hoofdstuk 7 worden de plasmaconcentraties en de farmacokinetische parameters van rifampicine na intraveneuze toediening bij 21 neonaten gepresenteerd. Rifampicine wordt bij neonaten regelmatig gebruikt in combinatie met vancomycine bij de behandeling van aanhoudende stafylokokken infecties. De concentraties van rifampicine en de belangrijkste ac- 
tieve metaboliet 25-O-desacetylrifampicine werden bepaald in plasma dat resteerde na routine bepalingen van vancomycine. De gemiddelde totale lichaamsklaring bedroeg $0,28 \mathrm{lkg}^{-1} \mathrm{~h}^{-1}$, de gemiddelde halfwaardetijd 4,9 uur en het gemiddelde verdelingsvolume 1,84 l/kg. De rifampicine klaring was sterk gecorreleerd met de plasmaconcentratie van creatinine en met de gentamicine klaring tijdens een voorafgaande gentamicine behandeling. Rifampicine schijnt bij neonaten dus zowel renaal als metabool te worden geëlimineerd. De plasmaconcentraties van rifampicine en 25-O-desacetylrifampicine werden bij 8 neonaten ook bepaald na twee weken therapie met rifampicin. Bij al deze neonaten was de rifampicine klaring toegenomen, waarschijnlijk doordat rifampicine het eigen metabolisme induceert. Op dit moment adviseren wij het huidige doseerbeleid te handhaven, aangezien wij slechts een relatief kleine populatie hebben onderzocht en omdat er tot nu toe weinig bekend is over de eiwitbinding en de farmacodynamiek van rifampicine.

\section{Hoofdstuk 8}

Hoofdstuk 8 beschrijft een inleidend onderzoek naar de toepasbaarheid van kunstmatige neurale netwerken bij de voorspelling van de gentamicine klaring bij neonaten. Kunstmatige neurale netwerken kunnen worden gebruikt om complexe, niet-lineaire verbanden tussen input en output gegevens te modelleren. In dit onderzoek werd gebruik gemaakt van een neuraal netwerk om het verband tussen de gentamicine klaring en enkele co-variabelen, waaronder de zwangerschapsleeftijd, de postnatale leeftijd en de plasmaconcentratie van creatinine, te modelleren en de gentamicine klaring bij 320 neonaten te voorspellen. De voorspelbaarheid van het neurale netwerk werd vergeleken met die van meervoudige lineaire regressie analyse. De voorspellingen van lineaire regressie hadden een kleinere systematische fout en een grotere precisie dan de voorspellingen van het neurale netwerk. Kunstmatige neurale netwerken schijnen dus minder bruikbaar te zijn voor eenvoudige lineaire verbanden tussen input en output gegevens.

\section{Hoofdstuk 9}

In dit hoofdstuk worden de farmacokinetische resultaten en de gevolgen voor de dosering bediscussieerd. Belangrijke uitdagingen voor toekomstig onderzoek zijn: prospectieve validatie van de doseerschema's van amoxicilline, evaluatie van de voorspelbaarheid van plasma albumine voor de eiwitbinding van flucloxacilline, vaststelling van de farmacokinetische parameters van rifampicine bij een grotere populatie van neonaten, onderzoek naar de grootte en variabiliteit van de eiwitbinding van rifampicine bij neonaten en in het bijzonder bestudering van de farmacokinetische-farmacodynamische relaties. 


\section{Dankwoord}

Promoveren doe je niet alleen en daarom wil ik een aantal bijzondere mensen bedanken.

Beste Leo, bedankt dat je vanaf het begin vertrouwen in me hebt gehad en me de kans hebt gegeven 'jouw' promotieonderzoek uit te voeren. Ik heb ontzettend veel van je geleerd en ik realiseer me dat ik mede dankzij jou nu een mooie carrière tegemoet ga.

Beste Luc, je hebt het altijd erg druk, maar dat is voor jou nooit een reden geweest om geen tijd voor me vrij te maken. Gelukkig maar, want je hebt een zeer waardevolle bijdrage geleverd aan dit proefschrift. Bedankt daarvoor. Je boft maar met zo'n fijne secretaresse als Tamara. Zij stond altijd voor me klaar als er promotie gerelateerde zaken geregeld moesten worden.

Beste Kees, vanaf het moment dat je de apotheek binnenkwam, was je geïnteresseerd in ons onderzoek. Ik ben er trots op dat ik je eerste promovenda ben en ik wens je heel veel succes met het begeleiden van je volgende promovendi.

Beste Pieter, ik heb je ervaren als een zeer aardige man. Samen met Leo heb je dit promotieonderzoek opgezet en het is een eer dat ik samen met jullie dit promotieonderzoek heb mogen uitvoeren.

Beste Frank, ook jij bent vanaf het begin bij mijn promotieonderzoek betrokken geweest. Ik dank je voor je altijd kritische blik op de artikelen en je waardevolle adviezen.

Beste Fred, hartelijk dank voor je hulp bij de statistiek.

Beste Nick en Eric, bedankt voor de vruchtbare maar vooral de heel gezellige samenwerking. Ik vind het leuk dat ik een kijkje heb mogen nemen in de wereld van kunstmatige intelligentie. Nick, ik wens je heel veel succes met het schrijven van je eigen proefschrift.

Beste (ex)collega's, bedankt voor de ontzettend leuke tijd die ik de afgelopen drie jaar in de apotheek heb gehad. Jacques, Karin en alle andere labmedewerkers, jullie wil ik in het bijzonder bedanken. Door jullie voelde ik me meteen thuis in de apotheek. Bedankt voor jullie hulp bij de laboratoriumwerkzaamheden. Lindsay en Marja, ik wil jullie bedanken voor de enorme hoeveelheid HPLC analyses die jullie hebben uitgevoerd tijdens jullie stage. Linds, ik ben blij dat we vriendinnetjes zijn geworden. Beste Hendrikus, bedankt dat je altijd voor me klaar stond met advies rondom het promoveren en het drukken van mijn proefschrift. Beste Hein en Afke, ik ben er trots op dat jullie mijn paranimfen willen zijn. Ik hoop, en dat meen ik, dat we elkaar nog geregeld zullen tegenkomen als we straks geen collegaatjes meer zijn.

Beste Robbert, dankzij jouw creatieve geest is de omslag van dit proefschrift precies zo geworden zoals ik het me voorstelde. Dankjewel! 
Lieve Imke, Julia, en Nicole, betere vriendinnetjes had ik me niet kunnen wensen. Bedankt voor de altijd gezellige lunches, etentjes en weekendjes, maar vooral voor jullie vriendschap. Ik kan niet wachten tot ik bij jullie promotie kan zijn. Natuurlijk wil ik ook mijn 'verre' vriendinnetjes bedanken. Lieve meiden, we zien elkaar niet veel, maar jullie vriendschap is me dierbaar.

Lieve Fleur, je bent mijn grote zus en daarnaast mijn beste vriendinnetje. We hebben altijd enorm veel aan elkaar gehad. Ik ben blij dat je zo'n lieve vriend als Ronald bent tegengekomen. Als iemand het verdient, dan ben jij het wel!

Lieve paps en mams, als ik iemand moet bedanken dan zijn jullie het wel. Jullie hebben me altijd aangemoedigd het beste van mezelf te geven. Daarom wil ik met veel liefde dit proefschrift aan jullie opdragen.

Lieve Mark, wat ben ik blij dat ik jou acht jaar geleden ben tegengekomen. Dankjewel dat ik voor jou altijd op de eerste plaats kom. Elke dag geef je me het gevoel dat ik de hele wereld aan kan. Ik hou van je. 


\section{Curriculum Vitae}

Joyce Pullen was born on March 31, 1982, in Eindhoven, The Netherlands. In 2000, she obtained her pre-university education degree at the Carolus Borromeus College in Helmond and started the study Health Sciences at the University of Maastricht. After obtaining her propedeuse in 2001, she specialized in Biological Health Science. During her graduate internship, she investigated the pharmacokinetics of amoxicillin in neonates at the department of Clinical Pharmacy and Toxicology of the University Hospital of Maastricht under supervision of dr. L.M.L. Stolk. She obtained her MSc degree in 2004. The studies described in this thesis took place from 2004 to 2006 and were supervised by prof. dr. L.J.I. Zimmermann and dr. P.L.J. Degraeuwe from the department of Paediatrics, prof. dr. C. Neef and dr. L.M.L. Stolk from the department of Clinical Pharmacy and Toxicology, and dr. F.H. van Tiel from the department of Medical Microbiology of the University Hospital of Maastricht. At this moment, Joyce is following a traineeship in Clinical Pharmacology, which she will finish in spring 2007.

Joyce Pullen werd geboren op 31 maart 1982 in Eindhoven. In 2000 behaalde zij haar diploma Gymnasium $\beta$ aan het Carolus Borromeus College te Helmond en begon zij aan de studie Gezondheidswetenschappen aan de Universiteit Maastricht. Na het behalen van haar propedeuse in 2001 koos zij voor de afstudeerrichting Biologische Gezondheidkunde. Tijdens haar afstudeerstage deed zij onderzoek naar de farmacokinetiek van amoxicilline bij neonaten bij de afdeling Klinische Farmacie en Toxicologie van het Academisch Ziekenhuis Maastricht onder begeleiding van dr. L.M.L. Stolk. Zij behaalde haar doctoraal examen in 2004. Het in dit proefschrift beschreven onderzoek vond plaats in de periode 2004-2006 en werd begeleid door prof. dr. L.J.I. Zimmermann en dr. P.L.J. Degraeuwe van de afdeling Kindergeneeskunde, prof. dr. C. Neef en dr. L.M.L. Stolk van de afdeling Klinische Farmacie en Toxicologie en dr. F.H. van Tiel van de afdeling Medische Microbiologie van het Academisch Ziekenhuis Maastricht. Momenteel volgt Joyce de opleiding tot klinisch farmacoloog, die zij in het voorjaar van 2007 zal afronden. 



\section{List of Publications}

Pullen J, Stolk LML, Nieman FHM, Degraeuwe PLJ, Tiel van FH, Zimmermann LJI. Population pharmacokinetics and dosing of amoxicillin in (pre)term neonates. Ther Drug Monit. 2006;28:226-231.

Pullen J, Rozario de L, Stolk LML, Degraeuwe PLJ, Tiel van FH, Zimmermann LJI. Population pharmacokinetics and dosing of flucloxacillin in preterm and term neonates. Ther Drug Monit. 2006;28:351-358.

Pullen J, Stolk LML, Degraeuwe PLJ, Tiel van FH, Neef C, Zimmermann LJI. Pharmacokinetics of intravenous rifampicin (rifampin) in neonates. Ther Drug Monit. 2006;28:654-661.

Pullen J, Stolk LML, Nieman FHM, Degraeuwe PLJ, Tiel van FH, Zimmermann LJI. Response to letter to the Editor 'Population pharmacokinetics and dosing of amoxicillin in (pre)term neonates'. Ther Drug Monit. 2006;28:816-817.

Pullen J, Driessen M, Stolk LML, Degraeuwe PLJ, Tiel van FH, Neef C, Zimmermann LJI. Amoxicillin pharmacokinetics in (preterm) infants aged 10-52 days: effect of postnatal age. Ther Drug Monit (in press).

Pullen J, Stolk LML, Degraeuwe PLJ, Tiel van FH, Neef C, Zimmermann LJI. Protein binding of flucloxacillin in neonates. Ther Drug Monit (in press).

Pullen J, Rodijnen van NM, Postma EO, Stolk LML, Neef C, Zimmermann LJI. Application of artificial neural network modeling to predict gentamicin clearance in neonates: preliminary study. Submitted for publication.

Pullen J, Stolk LML, Neef C, Zimmermann LJI. Microanalysis of amoxicillin, flucloxacillin, and rifampicin in neonatal plasma. Submitted for publication. 